\title{
Neogene amphibians and reptiles (Caudata, Anura, Gekkota, Lacertilia, Testudines) from south of Western Siberia, Russia and Northeastern Kazakhstan
}

\author{
Davit Vasilyan ${ }^{\text {Corresp., }}{ }^{1,2,3}$ ， Vladimir S. Zazhigin ${ }^{4}$, Madelaine Böhme ${ }^{1,5}$ \\ 1 Department of Geosciences, Eberhard-Karls-University Tübingen, Tübingen, Germany \\ 2 JURASSICA Museum, Porrentruy, Switzerland \\ 3 Department of Geosciences, University of Fribourg, Fribourg, Switzerland \\ 4 Institute of Geology, Russian Academy of Sciences, Moscow, Russia \\ 5 Senckenberg Center for Human Evolution and Palaeoecology, Tübingen, Germany \\ Corresponding Author: Davit Vasilyan \\ Email address: davit.vasilyan@jurassica.ch
}

Background. The present-day amphibian and reptile fauna of Western Siberia is the least diverse of the Palaearctic Realm, as a consequence of the unfavourable climatic conditions that predominate in this region. The origin and emergence of these herpetofaunal groups are poorly understood. Aside from the better-explored European Neogene localities yielding amphibian and reptile fossil remains, the Neogene herpetofauna of Western Asia is understudied. The few available data need critical reviews and new interpretations, taking into account the more recent records of the European herpetofauna. The comparison of this previous data with that of the European fossil record would provide data on palaeobiogeographic affiliations of the region as well as on the origin and emergence of the present-day fauna of Western Siberia. An overview of the earliest occurrences of certain amphibian lineages is still needed. In addition, studies that address such knowledge gaps can be useful for molecular biologists in their calibration of molecular clocks.

Methods and Results. In this study, we considered an critically review available data from amphibian and reptile fauna from over 40 Western Siberian, Russian and Northeastern Kazakhstan localities, ranging from the Middle Miocene to Early Pleistocene. Herein, we provided new interpretations that arose from our assessment of the previously published and new data. More than 50 amphibian and reptile taxa were identified belonging to families Hynobiidae, Cryptobranchidae, Salamandridae, Palaeobatrachidae, Bombinatoridae, Pelobatidae, Hylidae, Bufonidae, Ranidae, Gekkonidae, Lacertidae and Emydidae. Palaeobiogeographic analyses were performed for these groups and palaeoprecipitation values were estimated for 12 localities, using the bioclimatic analysis of herpetofaunal assemblages.

Conclusions. The Neogene assemblage of Western Siberia was found to be dominated by groups of European affinities, such as Palaeobatrachidae, Bombina, Hyla, Bufo bufo, and a small part of this assemblage included Eastern Palaearctic taxa (e.g. Salamandrella, Tylototriton, Bufotes viridis). For several taxa (e.g. Mioproteus, Hyla, Bombina, Rana temporaria), the Western Siberian occurrences represented their most eastern Eurasian records. The most diverse collection of fossil remains was found in the Middle Miocene. Less diversity has been registered towards the Early Pleistocene, potentially due to the progressive cooling of the climate in the Northern Hemisphere. The results of our study showed higher-amplitude changes of precipitation development in Western Siberia from the Early Miocene to the Pliocene, than previously assumed. 


\section{Neogene amphibians and reptiles (Caudata, Anura,}

2 Gekkota, Lacertilia, Testudines) from south of Western

3 Siberia, Russia and Northeastern Kazakhstan

4

5 Davit Vasilyan ${ }^{1,2,3}$, Vladimir S. Zazhigin ${ }^{4}$, and Madelaine Böhme ${ }^{1,5}$

6

$7 \quad{ }^{1}$ Department of Geosciences, Eberhard-Karls-University Tübingen, Sigwartstraße 10, 72076

8 Tübingen, Germany.

92 JURASSICA Museum, Route de Fontenais 21, 2900 Porrentruy, Switzerland,

10 davit.vasilyan@jurassica.ch.

$11{ }^{3}$ Department of Geosciences, University of Fribourg, Chemin du musée 6, 1700 Fribourg,

12 Switzerland.

$13{ }^{4}$ Institute of Geology, Russian Academy of Sciences, Pyzhevsky per. 7, 119017 Moscow, Russia,

14 zazhvol@gmail.com.

$15{ }^{5}$ Senckenberg Center for Human Evolution and Palaeoecology, Sigwartstraße 10, 72076

16 Tübingen, Germany, m.boehme@uni-tuebingen.de.

18 Corresponding author:

19 Davit Vasilyan

20 Current address: JURASSICA Museum, Route de Fontenais 21, 2900 Porrentruy, Switzerland

21 Email address: davit.vasilyan@jurassica.ch 


\section{Abstract}

24 Background. The present-day amphibian and reptile fauna of Western Siberia is the least diverse of the Palaearctic Realm, as a consequence of the unfavourable climatic conditions that predominate in this region. The origin and emergence of these herpetofaunal groups are poorly understood. Aside from the better-explored European Neogene localities yielding amphibian and reptile fossil remains, the Neogene herpetofauna of Western Asia is understudied. The few available data need critical reviews and new interpretations, taking into account the more recent records of the European herpetofauna. The comparison of this previous data with that of the European fossil record would provide data on palaeobiogeographic affiliations of the region as well as on the origin and emergence of the present-day fauna of Western Siberia. An overview of the earliest occurrences of certain amphibian lineages is still needed. In addition, studies that address such knowledge gaps can be useful for molecular biologists in their calibration of molecular clocks.

Methods and Results. In this study, we considered an critically review available data from amphibian and reptile fauna from over 40 Western Siberian, Russian and Northeastern Kazakhstan localities, ranging from the Middle Miocene to Early Pleistocene. Herein, we provided new interpretations that arose from our assessment of the previously published and new data. More than 50 amphibian and reptile taxa were identified belonging to families Hynobiidae, Cryptobranchidae, Salamandridae, Palaeobatrachidae, Bombinatoridae, Pelobatidae, Hylidae, Bufonidae, Ranidae, Gekkonidae, Lacertidae and Emydidae. Palaeobiogeographic analyses were performed for these groups and palaeoprecipitation values were estimated for 12 localities, using the bioclimatic analysis of herpetofaunal assemblages. 
45 Conclusions. The Neogene assemblage of Western Siberia was found to be dominated by groups of European affinities, such as Palaeobatrachidae, Bombina, Hyla, Bufo bufo, and a small part of this assemblage included Eastern Palaearctic taxa (e.g. Salamandrella, Tylototriton, Bufotes viridis). For several taxa (e.g. Mioproteus, Hyla, Bombina, Rana temporaria), the Western Siberian occurrences represented their most eastern Eurasian records. The most diverse collection of fossil remains was found in the Middle Miocene. Less diversity has been registered towards the Early Pleistocene, potentially due to the progressive cooling of the climate in the Northern Hemisphere. The results of our study showed higher-amplitude changes of precipitation development in Western Siberia from the Early Miocene to the Pliocene, than previously assumed.

\section{Introduction}

Western Siberia is a geographic region restricted to the territories of Russia and parts of northern Kazakhstan. It includes the region between the Ural Mountains in the west, Central Siberian Plateau in the east, and the Kazakh Plain and Altay Mountains, including the Zaisan Lake in the south (Fig. 1). Western Siberia region incorporates the drainage basin of the major Siberian rivers such as the Irtysh and Ob rivers, both flowing into the Kara Sea of the Arctic Ocean. The region is characterised by a highly continental climate, under the influence of the Westerlies (winds). The mean annual precipitation (MAP) is relatively uniform and varies from $400 \mathrm{~mm}$ in the north (415 $\mathrm{mm}$ at Omsk) to $200 \mathrm{~mm}$ in the south (255 $\mathrm{mm}$ at Pavlodar). The region has a high relative humidity in summer due to labile convective heating and frequent torrential rainfalls. The mean annual range of temperature reaches $4{ }^{\circ} \mathrm{C}$ and more $(\mathrm{Omsk}$ : cold 
67 month temperature $-\mathrm{CMT}-19^{\circ} \mathrm{C}$, warm month temperature - WMT $20^{\circ} \mathrm{C}$, mean annual

68 temperature - MAT $0.4^{\circ} \mathrm{C}$; Semipalatinsk: CMT $-16^{\circ} \mathrm{C}$, WMT $22^{\circ} \mathrm{C}$, MAT $3.1^{\circ} \mathrm{C}$; Lake Zaisan:

$69 \mathrm{CMT}$ up to $-27^{\circ} \mathrm{C}$, WMT $23^{\circ} \mathrm{C}$; after Müller \& Hennings (2000). The area is covered by diverse

70 biomes, namely the tundra ('cold steppe') and taiga (coniferous forests) biomes, which are

71 replaced by open landscapes in the north (tundra) and in the south (steppe). The region that

72 contains the studied Neogene outcrops is located in the transitional zone between the dry and

73 the more humid temperate biomes, where taiga, forest-steppe and steppe biomes are

74 distributed (Ravkin et al., 2008).

75 Due to the strong continental climate, the present-day herpetofauna in the territory of Western

76 Siberia is comparatively far less diverse, represented only by six to ten amphibian species and

77 seven reptile species (Table 1). It is assumed that the present distribution of amphibians and

78 reptiles in Western Siberia was strongly influenced by Quaternary climatic fluctuation (Ravkin,

79 Bogomolova \& Chesnokova, 2010). According to Borkin (Borkin, 1999), the present-day

80 amphibian fauna of Western Siberia belongs to the Siberian region of amphibian distribution in

81 the Palaearctic Realm. According to different authors (e.g. Kuzmin, 1995; Amphibiaweb, 2016),

82 the region is inhabited by few amphibians, namely two species of salamanders and four to eight

83 species of anurans, belonging to five genera and five families (Table 1). This is the poorest

84 regional diversity of fauna in the Palaearctic Realm, without any endemic species. Only

85 Salamandrella keyserlingii and Rana amurensis are characteristic of the territory, but they are

86 widely distributed and are also found in smaller areas in the neighbouring regions (Borkin,

87 1999). The Western Siberian reptile fauna listing includes few species: Natrix natrix, Elaphe 
88

89

90

91

92

94

95

dione, Vipera berus, Vipera renardi, Gloydius halys, Zootoca vivipara, Lacerta agilis and Eremias arguta (Ananjeva et al., 2006; Ravkin, Bogomolova \& Chesnokova, 2010).

\section{Geology and stratigraphy}

The Neogene sediments in Western Siberia have a wide distribution. Over many decades, through systematic palaeontological studies and research in the Neogene and Quaternary sediments of this area, rich fossil deposits of molluscan and small and large mammalian faunas have been discovered (e.g. Zykin, 1979; Zykin \& Zazhigin, 2008; Zykin, 2012). Based on the studies of the small fossil mammals, the Neogene stratigraphy of the area is complemented with biochronologic data. Continental sedimentation in the western part of the Siberian Plain began in the Oligocene, after regression of the Turgai Strait in the Late Eocene, and continued until the Quaternary period (e.g. Chkhikvadze, 1984, 1989; Tleuberdina et al., 1993; Malakhov, 2005). The sedimentary basin is surrounded by the Ural Mountains in the west, the Central

Kazakh Steppe and Altai-Sayan Mountains in the south, and the western margin of the Siberian Plateau in the east. The surrounding regions deliver clastic material to the basin. Some researchers include the Zaisan Basin, located to the west of the Altai-Sayan Mountains in this territory (Borisov, 1963). The Neogene sediments are represented by lacustrine, fluvial, alluvial and other continental depositions, overlying marine Eocene sediments. The thickest section (300 m) of the Neogene and early Quaternary sediments occurs in the Omsk Basin. Neogene strata outcrops are mainly found in the interfluves of the Irtysh and Ishim rivers (Gnibitenko, 2006; Zykin, 2012). All these sediments are terrestrial (fluvial and alluvial facies) and have produced rich fossil layers of vertebrate fauna (Zykin, 2012). The vertebrate-bearing Neogene 
110 sediments are found in several areas along the Irtysh River and its tributaries - Petropavlovsk-

111 Ishim (e.g. Petropavlovsk 1, Biteke 1A), Omsk (e.g. Novaya Stanitsa 1, Cherlak), Pavlodar (e.g.

112 Pavlodar, Baikadam) and the Novosibirsk areas (e.g. Kamen-na-Obi) (Fig. 1). Detailed geological

113 descriptions of the stratigraphic sections and fossil localities are summarised in Zykin (1979);

114 Zykin \& Zazhigin (2004); Gnibitenko (2006); Zykin (2012).

115 The stratigraphic subdivision is based mainly on the Russian concept of svitas. A svita has

116 lithologic, biochronologic and genetic (sedimentologic) significance and has no precise

117 equivalent in Western stratigraphic theory and terminology (Lucas et al., 2012). The

118 stratigraphy of Neogene sediments in Western Siberia is supported by magnetostratigraphic

119 investigations (e.g. Gnibitenko, 2006; Gnibidenko et al., 2011), in which the recovered polarity

120 signals are combined with biochronologic data and correlated to the geomagnetic polarity time

121 scale (GPTS) (Fejfar et al., 1997; Vangengeim, Pevzner \& Tesakov, 2005; Zykin, Zykina \&

122 Zazhigin, 2007). The biozonation is based on fast-evolving lineages of small mammals, mainly

123 jerboas (Dipodidae), hamsters (Cricetidae) and voles (Arvicolidae). Owing to these bio-

124 magnetostratigraphic data the mean temporal resolution of the late Neogene faunal record

125 from the Ob-Irtysh Interfluve is estimated to be approximately 200 kyr (Fig. 2, Table S1, Data

126 S2). The main sections of these vertebrate fossil localities are referred to certain svitas (e.g.

127 Kalkaman, Pavlodar, Irtysh Svitas), however, the stratigraphic assignment of three localities

128 Olkhovka $1 \mathrm{~A}, 1 \mathrm{~B}, 1 \mathrm{C}$ to svitas is not available (Fig. 2, Table S1). No fossils are available in the 129 initial deposits of the early Late Miocene.

\section{State-of-art in palaeoherpetological studies in Western Siberia}


132 The fossil record of amphibians and reptiles in Western Siberia, including the Zaisan Basin

133 record, remain largely unknown. There are very few works devoted to the studies of the

134 Western Siberian late Paleogene and Neogene herpetofaunal assemblages (e.g. Chkhikvadze,

135 1984, 1989; Tleuberdina et al., 1993; Malakhov, 2005). The vast majority of data on fossil

136 amphibians and reptiles are represented as short notes or are mentioned in faunal lists (e.g.

137 Bendukidze \& Chkhikvadze, 1976; Chkhikvadze, 1985; Malakhov, 2005). In this present

138 contribution we analysed the available data from specimens described below and from new

139 generated data as well.

140 The earliest report on Neogene fossil amphibians was compiled by Iskakova (1969), wherein

141 she described amphibian faunas from two Priirtyshian localities, Gusiniy Perelet and Karashigar.

142 Gusiniy Perelet is a well-renovated Late Miocene vertebrate fossil locality, situated on the

143 riverbank of the Irtysh River, within the town of Pavlodar. The sedimentary sequence in this

144 locality contains layers of different ages from the late Late Miocene until the late Early Pliocene.

145 Three localities (also 'horizons') within the town of Pavlodar (Pavlodar 1A, 1B, 3B) are grouped

146 into several svitas and can be distinguished from the Gusiniy Perelet vertebrate locality. The

147 fossil content of the Gusiniy Perelet locality comes from the lower horizon - Pavlodar 1A.

148 Iskakova (1969) described an amphibian fauna from this layer.

149 The age of the Karashigar locality is unclear. In a study by Tleuberdina et al. (1989), this locality

150 has been estimated to date back to the Late Oligocene; however, Lychev (1990) placed it in the

151 Middle Miocene, Kalkaman Svita (the list of the small mammal fauna; see Data S2). The

152 amphibian taxa described by Iskakova (1969) in the Priirtyshian localities (Bombina cf.

153 bombina, Pelobates cf. fuscus, Bufo cf. viridis, Bufo cf. bufo, Rana cf. ridibunda, Rana cf. 
154 temporaria) were identified based mainly on the vertebrae (cervical, dorsal and sacral)

155 morphology, which is not diagnostic in frogs at that taxonomic level. Chkhikvadze (1984)

156 restudied the material from the Pavlodar $1 \mathrm{~A}$ (= Gusiniy Perelet) locality and identified Bufo cf.

157 raddei, Bufo sp., Pelophylax cf. ridibundus, Eremias sp., and Coluber sp. In this study, we did not,

158 however; assess the material from the above-mentioned works in order to verify Chkhikvadze

159 (1984) taxonomic identifications. Our sample from this locality (Pavlodar 1A) (Table S1), did not

160 reveal any element listed in these earlier studies (Chkhikvadze, 1984).

161 Chkhikvadze (1984) summarised all known fossil amphibians and reptiles from the former

162 Union of Soviet Socialist Republics (USSR), including those from Western Siberia. Accurate

163 descriptions are not yet available for many of these species. The Middle Miocene Kalkaman

164 locality (Tleuberdina, 1993), presently known as Malyi Kalkaman 1 (Zykin, 2012), has provided a

165 diverse record of fossil herpetofauna. The fossil record of this locality was partially restudied

166 and amended by us, which included the collection of new material.

167 Over the last decade, fresh attempts has been made to study the herpetofauna from the

168 Western Siberian localities (Malakhov, 2003, 2004, 2005, 2009). In the resultant works,

169 undescribed material from several Neogene localities of Kazakhstan were summarised, revised,

170 and studied, thereby providing critical overviews. In spite of the advances of the recent years,

171 however, the Neogene herpetofauna from Western Asia remains largely unknown, with

172 available fossil material continuing to be insufficiently studied. The main goals of the present

173 study were, therefore, to assess the descriptions and taxonomic classifications of the new

174 amphibian and reptile fossil material collected by Vladimir Zazhigin (co-author), as well as

175 already published data so as to provide a comprehensive faunistic analysis and 
176 palaeobiogeographic and environmental interpretations. To avoid confusion around the names

177 used by different authors in the Russian literature to describe the localities, we have provided

178 all known names for these studied fossil localities.

179

180

\section{Materials \& Methods}

181 The new materials used in the present study were collected by V. Zazhigin (co-author) using the

182 screen-washing technique during his long-term excavations in different Western Siberian

183 localities from the 1960 's to 2008 . These localities outcrop along the riverbanks of the Irtysh,

184 Ishim and Ob rivers. This fossil material is stored in the Institute of Geology, Russian Academy

185 of Sciences under the collection numbers:

186 GIN 950/2001 (Baikadam), GIN 1107/1001 (Malyi Kalkaman 1), GIN 1107/2001 (Malyi Kalkaman

187 2), GIN 1106/1001 (Shet Irgyz 1) GIN 952/1001 (Petropavlovsk 1), GIN 1109/1001 (Znamenka),

188 GIN 640/5001 (Pavlodar 1A), GIN 951/1001 (Selety 1A), GIN 951/2001 (Kedey), GIN 948/2001

189 (Novaya Stanitsa 1A), GIN 1115/1001 (Borki 1A), GIN 1110/2001 (Cherlak), GIN 945/2001

190 (Beteke 1A), GIN 640/6001 (Pavlodar 1B), GIN 1130/1001 (Lezhanka 2A), GIN 1130/2001

191 (Lezhanka 2B), GIN 1111/1001 (Olkhovka 1A), GIN 1111/2001 (Olkhovka 1B), GIN 1111/3001

192 (Olkhovka 1C), GIN 1118/3001 (Peshniovo 3), GIN 1131/2001 (Isakovka 2), GIN 1131/1001

193 (Isakovka 1A), GIN 1131/3001 (Isakovka 1B), GIN 1117/1001 (Kamyshlovo), GIN 945/2001

194 (Beteke 1B), GIN 945/3001 (Beteke 1C), GIN 1112/1001 (Andreievka - Speranskoe), GIN

195 1108/2001 (Pavlodar 2B), GIN 1112/2001 (Andreievka 1), GIN 1129/2001 (Livenka), GIN

196 1129/1001 (Lezhanka 1), GIN 1108/3001 (Pavlodar 3A), GIN 950/3001 (Lebiazhie 1A), GIN 
197 950/4001 (Lebiazhie 1B), GIN 950/5001 (Podpusk 1), GIN 945/60001 (Beteke 2), GIN 946/2001

198 (Kamen-na-Obi), GIN 945/8001 (Beteke 4), GIN 664/2001 (Razdole).

199 Various groups of amphibians and reptiles are represented in the available material. A report of 200 part of this material, i.e. of the snakes and anguine lizards, has been published in a separate 201 paper (e.g. Vasilyan, Böhme \& Klembara, 2016). The present study included an assessment of 202 the materials collected from four fossil sites in Kazakhstan: Akyspe (also known as Agyspe), Aral 203 Horizon, leg. by Bendukidze in 1977; Kentyubek, Turgai Basin; Ryzhaya II (Ryzhaya Sopka), 204 Zaisan Svita, Zaisan Basin, leg. in 1970; Ayakoz (known also as Ayaguz), Zaisan Basin, leg. in 205 1970-1971; Petropavlovsk 1/21 , leg. 1972 (Table S1). In addition, the few available data from 206 the literature were included in this study (after critical revision) to amend the record of 207 herpetofaunal assemblages of some localities as well as to reassign and revise the stratigraphic 208 position of these localities using biochronologic information of small and large mammalian 209 fauna (see full list in the Datas S2, S3).

210 The photographs of the fossil material were taken using a digital microscope Leica DVM5000

211 (Tübingen) and inspected with a scanning electron microscope, FEI Inspect S (Madrid). The

212 figures and tables were produced using Adobe Photoshop and Illustrator programs. The 213 osteological nomenclature of this study followed that of Vasilyan et al. (2013) for the 214 salamander remains, that of Sanchíz (1998a) for frogs, that of Daza, Aurich \& Bauer (2011) and 215 Daza \& Bauer (2010) was used for Gekkota, and the lepidosaurian terminology of Evans (2008).

\footnotetext{
${ }^{1}$ In the town of Petropavlovsk two fossil sites (Petropavlovsk 1 (MN12) and Petropavlovsk 2 (MN14)) having different ages are known, see Zykin (2012). Since the enclosed collection label to the material indicates only 'locality Petropavlovsk, leg. 1972' any stratigraphic allocation of the fossils to one of those layers is impossible.
} 
216 Based on the herpetofaunal assemblages, the palaeoprecipitation values for the fossil localities

217 were estimated using the method of bioclimatic analysis of the ecophysiologic groups of

218 amphibian and reptile taxa (Böhme et al., 2006). For the localities considered to be 'poor' in

219 amphibian and reptile taxa, the range-through approach (Barry et al., 2002) was used, in which

220 the faunas of two or more localities with age differences less than $100 \mathrm{kyr}$ and/or belonging to

221 a single stratigraphic unit - svita, were considered as one. The taxa, that were added to the

222 herpetofaunal assemblage using the range-through approach, are indicated in grey in Table S4.

223

224 Institutional/collection abbreviations.

225 GPIT: Paläontologische Sammlung der Universität Tübingen, Tübingen, Germany; HC: collection 226 of Marcela Hodrova (Prague University), now stored in GPIT; MNCN: Museo Nacional de

227 Ciencias Naturales, Madrid, Spain; NMNHK: National Museum of Natural History, Kiev, Ukraine;

228 PIN: Palaeontological Institute, Russian Academy of Sciences, Moscow, Russia; GNM: National

229 Museum of Georgia, Tbilisi, Georgia; GIN: Geologic Institute, National Academy of Russia, 230 Moscow, Russia.

231

232 Anatomical abbreviations.

233

ao: antrum olfactorium; alo: antrum pro lobo olfactorio; dl: dental lamina; ds: dental shelf; hl: horizontal lamella; is: incisura semielliptical; ff: frontoparietal facet; fcpr: facial process of

235 maxilla; fMx5: foramina for mandibular division of the fifth cranial (trigeminal) nerve; hfr:

236 haemal foramen; hl: horizontal lamella; If: lacrimal facet; Ig: longitudinal groove; lh: lamina

237 horizontalis; Ip: lateral processes; Is: lamina supraorbitalis; mc: Meckelian canal; na: neural 
238 arch; nc: neural canal; $\mathbf{n f :}$ nasal facet; onf: orbitonasal foramina; olf: olfactory foramina; pf:

239 parasphenoid facet; pfc: palatine facet; ph: paries horizontalis; prz: prezygapophysis; psz:

240 postzygapophysis; pv: paries verticalis; pxp: premaxillary process; pyp: pterygapophysis; sac:

241 opening of superior alveolar canal; sg: symphyseal groove; sf: splenial facet; tpr: transverse

242 process.

243

244 RESULTS

245 Systematic palaeontology

246 Class Amphibia Gray, 1825

247 Order Caudata Scopoli, 1777

248 Family Hynobiidae Cope, 1859

249 Genus Salamandrella Dybowski, 1870

250 Salamandrella sp.

251

252 (Fig. 3D-3G)

253 Localities and material examined. Malyi Kalkamana 1, GIN 1107/1001-AM12, 1 right femur;

254 Selety 1A, GIN 951/1001-AM01 - -AM03, 3 trunk and GIN 951/1001-AM04, 1 caudal vertebra;

255 GIN 951/1001-AM05, 1 distal end of bone (humerus?); Novaya Stanitsa 1A, GIN 948/2001-

256 AM01 - -AM11, 11 trunk vertebrae; Lezhanka 2A, GIN 1130/1001-AM01 - -AM26, 26 trunk and

257 GIN 1130/1001-AM27 - -AM28, 2 caudal vertebrae; Cherlak, GIN 1110/2001-AM01 - -AM12, 12

258 trunk vertebrae; Lezhanka 2B, GIN 1130/2001-AM01, 1 trunk vertebra, GIN 1130/2001-AM02, 1

259 extremity bone; Olkhovka 1B, GIN 1111/2001-AM01, 1 trunk vertebra; Iskakovka 2A, GIN 
260 1131/2001-AM01, 1 trunk vertebra; Andreievka - Speransko, GIN 1112/1001-AM01, 1 trunk

261 vertebra; Lezhanka 1, GIN 1129/1001-AM01 - -AM02, 2 trunk and GIN 1129/1001-AM03, 1

262 caudal vertebrae; Beteke 1C, GIN 945/3001-AM01 - -AM02, 2 trunk vertebrae.

263 Description and comments. The vertebrae have an elongated to nearly slender form. The

264 vertebral centrum is amphicoelous. The basapophyses at the vertebral centrum are either

265 absent or are present in the form of a small protuberance at the laterodorsal corners of the

266 anterior portion of the vertebral centrum (Fig. 3G). A pair of subcentral foramina is situated at

267 the basis of the transverse processes. The neural arch is tall in lateral view (Fig. 3F) and

268 relatively broad in dorsal view (Fig. 3D). The posterior edge of the pterygapophysis is

269 bifurcated. Sometimes the neural spine is present but in general the dorsal surface of the

270 neural arch is flat. The pre- and postzygapophyses have an elongated oval shape. In anterior

271 view, the neural canal has an outline of a regular pentagon. The transverse process is

272 unicapitate (Fig. 3D, 3G). The anterior and posterior alar processes are absent. The vertebrae

273 can be assigned to the family Hynobiidae based on: (1) the small size and their amphicoelous

274 centrum with circular articular surfaces; (2) the lack of or being weakly pronounced

275 basapophyses; (3) the lack of neural spine; (4) the notch on the posterior margin of neural arch;

276 (5) the fused rib-bearers; and (6) the intervertebrally exiting spinal nerve in both trunk and

277 caudal vertebrae (e.g. Edwards, 1976; Venczel, 1999a, 1999b). Further, characteristic features

278 can be observed on the vertebrae of representatives of the genus Salamandrella, namely the

279 absence of the subcentral foramen and the concave anterior margin of the neural arch that

280 reaches the middle part of the prezygapophyseal articular facets (Venczel, 1999b; Ratnikov \&

281 Litvinchuk, 2009; Syromyatnikova, 2014) (Fig. 3D-3G). The detailed description of hynobiid 
282 material from the Western Siberian localities and comparison with recent and fossil hynobiids is

283 provided in a forthcoming paper.

284

285 Family Cryptobranchidae Fitzinger, 1826

286 Cryptobranchidae indet.

287

288 (Fig. 3A-3C)

Localities and material examined. Pavlodar $1 \mathrm{~A}$ (=Gusiniy Perelet), 1 fragmentary right dentary and 2 fragments of jaw bones, for details about the stratigraphic allocation see the section

'Cryptobranchidae', unnr. PIN specimen.

292

Description and comments. Among the fragments, a posterodorsal portion of a large right dentary, $27 \mathrm{~mm}$ in length, is present. In lingual view, the pars dentalis is composed entirely of dental lamina and the subdental lamina is present, but reduced. The pars dentalis possesses 30 pedicels of pleurodont teeth. The subdental shelf inclines slightly ventrally. The lamina horizontalis is prominent. The corpus dentalis above the Meckelian groove has a concave surface. Ventrally, this surface possesses a ridge running parallel to the lamina horzontalis. The cross section of the dentary shows a relatively low portion of cancellous bone and a dominance of compact bone. The size of the bones, the form and structure of the pars dentalis and the

302 Family Proteidae Gray, 1825

303 Genus Mioproteus Estes \& Darevsky, 1977 
Mioproteus sp.

305

306

(Fig. 3H-3S)

307

Localities and material examined. Ryzhaya II (known also Ryzhaya Sopka), GNM unnr. specimen, 2 trunk vertebrae; Malyi Kalkaman 2, GIN 1107/2001-AM01, 1 right premaxilla; Borki 1A, GIN 1115/1001-AM01, 1 trunk vertebra; Ayakoz, GNM unnr. specimen, 1 trunk vertebra; Akespe, unnr. HC specimens, 3 vertebrae; Petropavlovsk 1/2, GNM unnr. specimen, 22 vertebrae.

Description. The preserved left premaxilla is fragmentary (Fig. 3P-3Q) and the posterior process

313 is broken off. In ventral view, the bone has a rough surface. The pars dentalis of the premaxilla

314 is located on the anterior side of the bone. The crowns of pleurodont teeth are missing and only their pedicellar portions are preserved. The bone surface is slightly rough in dorsal view. The lamelliform anterolateral ridge of the posterior process is high at the middle part of the

317 bone. The amphicoelous vertebrae are flat and wide. The centrum is dumb-bell in shape and narrows to the middle region. The basapophyses, if present, are small and weakly developed.

319 Two subcentral foramina are present at the central part of the vertebral centrum. In lateral

320 view, the vertebra is low; the anterior and posterior zygapophyseal crests are pointed, forming

321 the dorsal border of the deep depressions anteriorly and posteriorly to the transverse process.

322 The middle part of the neural arch is lower than its cranial and caudal margins. The posterior

323 edge of the neural arch is forked (Fig. 3H) (not visible at Fig. 3M). The neural spine extends as

324 far as the preserved anterior margins of the neural arch, whereas posteriorly, it terminates 
325 before the posterior margin of the neural arch. The preserved right pre- and postzygapophyseal

326 articular facets are ellipsoid.

327 Comparison and comments. A direct comparison with Mioproteus specimens from previous

328 reports was not possible due to the extremely scarce description of the skull elements

329 attributed to this taxon (e.g. Estes \& Darevsky, 1977; Miklas, 2002). We therefore used the

330 material of Mioproteus sp. from the Grytsiv locality (Ukraine, earliest Late Miocene) (Fig. 3R-3S)

331 for the taxonomic identification of the fossil premaxilla from Malyi Kalkaman 2 (Fig. 3P-3Q). Our

332 comparison founds no differences in the premaxilla morphology between the Kazakhstan and

333 Ukrainian Mioproteus sp. The vertebrae from the Borki 1A and Ayakoz localities can be easily

334 assigned to the genus Mioproteus based on following characters: (1) robust vertebra with an

335 amphicoelous centrum; (2) a tall cranial margin of the neural arch; (3) the presence of the

336 basapophyses; (4) a distinct wide depression at the anterior base of the transverse process; (5)

337 intervertebrally exiting spinal nerves; and (6) a forked neural spine (Edwards, 1976; Estes \&

338 Darevsky, 1977; Ivanov, 2008).

339

340 Family Salamandridae Goldfuss, 1820

341 Subfamily Pleurodelinae Tschudi, 1838

342 Genus Chelotriton Pomel, 1853

343 Chelotriton sp.

345 (Fig. 3T-3Y) 
346 Localities and material examined. Malyi Kalkaman 1, GNM unnr. specimen, 1 trunk vertebra;

347 Ayakoz, GNM unnr. specimen, 1 trunk vertebra.

348 Description. The single fragmentary trunk vertebra of Chelotriton from the Malyi Kalkaman 1

349 locality has been scantily described (Tleuberdina et al., 1993, pp. 133-134). The centrum of the

350 vertebra is ophistocoelous and dorsally curved. Both the posterior one-third of the vertebra

351 and cotyle are broken. The condyle is dorsoventrally slightly compressed and oval in shape. The

352 middle part of the ventral surface of the centrum bears a pair of the foramina subcentrale. The

353 ventral bases of both transverse processes are pierced by a foramen (potentially the ventral

354 foramen for the spinal nerve).

355 The neural spine is tall, long, and almost equal in length to the vertebral centrum. The dorsal

356 surface of the neural spine has the form of an elongated isosceles triangle and it is covered by a

357 distinct pustular sculpture. The anterior margin of the neural spine is concave in outline. The

358 posterior half of the spine is wider than the anterior one (Fig. 3Y). In anterior view, the neural

359 arch and the neural canal have a triangular form. The roof of the neural canal is flat, on both

360 sides of the neural spine.

361 The pre- and postzygapophyses are damaged. The anterior portion of the left postzygapophysis

362 is present and it shows a horizontal surface. The anterior bases of both prezygapophyses at the

363 contact with the centrum possess small subprezygapophyseal foramina. Behind the left

364 prezygapophysis, the accessory alar process exhibits a marked step (Fig. 3Y), projects

365 posteroventrally and connects caudally with the anterior alar process. The contact point of the

366 accessory and anterior alar processes probably corresponds to the base of the parapophysis.

367 Both transverse processes are broken, but the bases are preserved. Apparently, two rounded 
368 upper and lower prominences, seen in left lateral view, correspond to the dia- and

369 parapophysis. The parapophysis is located anteriorly and dorsally to the level of the

370 diapophysis; thus, the transverse process becomes a bent projection. The arterial canal runs

371 behind the base of the transverse process. Anteriorly, its dorsal and ventral walls are built by

372 the accessory and anterior alar processes.

373 The vertebra from the Ayakoz locality (Fig. 3T-3X) is fragmentary, its neural arch and left

374 transverse process are lost, the centrum is compact, short and wide, and it possesses an

375 elliptical central foramen. The diapophysis of the preserved right transverse process is broken,

376 but it can be assumed that the dia- and parapophysis were separated from each other. The

377 accessory alar process runs from the prezygapophysis to the dorsal edge of the diapophysis.

378 The posterior and anterior alar processes run from the cotyle and condyle straight along the

379 transverse process to the parapophysis. This morphology is characteristic of the first trunk

380 vertebrae.

381 Comparison and comments. This vertebra was previously described by Tleuberdina et al.

382 (1993). Here we have assigned this specimen to the genus Chelotriton owing to the presence of

383 a triangular and well-sculptured plate on the top of the neurapophysis. This character,

384 however, is not a unique feature of Chelotriton and is also seen in other salamanders, e.g.

385 Recent species of Tylototriton and Echinotriton, and in Cynops pyrrhogaster, Lissotriton boscai

386 (unnr. GPIT specimen), Paramesotriton (MNCN 23557, 13645), as well as the fossil taxa

387 Archaeotriton (Böhme, 1998), aff. Tylototriton sp. (Baikadam locality, this paper),

388 Carpathotriton (Venczel, 2008). The vertebra from the Malyi Kalkaman 1 resembles the species

389 of Chelotriton, Paramesotriton, Tylototriton, Echinotriton, Cynops pyrrhogaster, and 
390 Carpathotriton in their mutual presence of a subprezygapophyseal foramen. The vertebra can,

391 however, be justified as Chelotriton sp. and distinguished from other salamanders by: (1) its

392 longer length (vs. Echinotriton, Cynops and Carpathotriton); (2) a longer neural spine with a

393 rugose sculptured and triangular dorsal surface (vs. aff. Tylototriton sp., Baikadam locality, this

394 paper); and (3) a well-pronounced accessory alar process (vs. Tylototriton).

395 The fragmentary vertebra from the Ayakoz locality can be assigned also to this group because

396 of the presence of massive rib-bearers and large dimensions (Ivanov, 2008). Its vertebra is

397 identical to that of vertebra of Chelotriton sp. type II described from the Mokrá-Western

398 Quarry, 2/2003 Reptile Joint (Early Miocene, Czech Republic) (Ivanov, 2008).

399 The abundant European Cenozoic record of the genus Chelotriton, however, showed that

400 vertebral morphology is insufficient for taxonomic identification as Chelotriton (Böhme, 2008).

401 This genus has an unknown higher diversity, which can be uncovered by the study of complete

402 skeletons of those species. We hence classified the vertebrae from studied localities as aff.

403 Chelotriton sp.

404

405 Genus Tylototriton Anderson, 1871 (Anderson, 1871)

406 aff. Tylototriton sp.

407

408 (Fig. 4A-4K)

409 Locality and material examined. Baikadam, GIN 950/2001-AM01, -A14--A17 5 trunk vertebrae;

410 Ayakoz, GNM unnr. specimen, 2 trunk vertebrae. 
411 Description. All preserved vertebrae are opisthocoelous. The condyle and cotyle are

412 dorsoventrally compressed. The vertebrae are slender, slightly narrow, and high. The neural

413 canal is round, but in anterior view, the ventral margin of the neural canal is flat. The same

414 occurs with the dorsal wall of the vertebral centrum. The centrum is dorsally curved in lateral

415 view (Fig. 4A, 4F, 4G). The neural spine was most probably high but does not reach the level of

416 the pustular region. The neural spine begins behind the cranial margin of the neural arch. The

417 neural arch is tilted dorsally and does not extend beyond the posterior edge of the

418 postzygapophysis. The dorsal plate of the neural spine is short, poorly developed, and covered

419 with rugosities. It has the form of an isosceles triangle. Due to the concave shape of the

420 posterior margin of the caudal border, we suggest that the neural spine was probably

421 bifurcated. The length of the neural spine, without the sculptured structure, is the same in all

422 preserved vertebrae and corresponds nearly to almost half of the entire vertebral length (Fig.

$4234 \mathrm{~A}, 4 \mathrm{~F}, 4 \mathrm{G})$.

424 The pre- and postzygapophyses are horizontal and almost at the same level (e.g. Fig. 4A). The

425 pre- and postzygapophyseal articular facets are oval in shape. Small subprezygapophyseal

426 foramina are present at the level of the connection between the anterior bases of both

427 prezygapophyses with the vertebral centrum. The posterolaterally directed transverse process

428 is horizontally flattened and displays a bicapitate articulation surface with the rip. The

429 diapophysis and parapophysis are separated, with the former being smaller than the latter. A

430 low and moderately deep notch is developed at the posterior edge of the neural arch. The

431 transverse process has an anterior (accessory alar process) and posterior laminar edges (i.e. the

432 posterior alar process and dorsal lamina). The straight, posteroventrally directed accessory alar 
433 process connects the prezygapophysis caudally with the base of the parapophysis (e.g. 4F). The 434 dorsal lamina starts from the diapophysis and extends to the postzygapophyses, whereas the 435 lamelliform posterior alar process starts at the parapophysis and terminates directly before the 436 cotyle. Subparallel to the accessory alar process, a thin anterior alar process runs along the 437 cranial half of the centrum. Behind and in front of the transverse process two 'cavities' (a 438 shallow anterior and a deep posterior) are present. These 'cavities' are connected by a canal 439 (possibly an arterial canal), that runs through the transverse process. In ventral view, the vertebral centrum does not possess a ventral keel. The centrum is flattened and nearly plane in

441 the middle portion. Its surface is rough and pierced by numerous foramina. Two large

442 subcentral foramina are located at the posterior corner between the centrum and transverse 443 process (Fig. 4C, 4L).

444 Comparison and comments. The vertebrae resemble the morphology of pleurodeline 445 salamanders Echinotriton, Tylototriton, Cynops, Chelotriton, Paramesotriton and Tylototriton 446 and Carpathotriton in characteristics such as: (1) the presence of rugosities on the neural arch; 447 (2) the connection of the prezygapophysis and parapophysis with the accessory alar process, 448 except in Carpathotriton, Cynops and cf. Tylototriton sp. from Möhren 13 (Böhme, 2010: p. 11, 449 fig. 6f), where this process connects prezygapophysis with diapophysis; (3) a moderately 450 developed posterior 'cavity' behind the transverse process; and (4) the presence of 451 subprezygapophyseal foramen (for collection references see subsection 'Comparison' of 452 Chelotriton sp. in this report). In terms of the general morphology, the vertebrae mainly 453 resemble the genus Tylototriton and differ from the compared genera in having: (1) a low, 454 elongate, narrow and lesser flattened vertebrae; (2) a weakly developed pustular structure of 
455 the neural arch (similar character as seen in Paramesotriton); (3) a low and long neural spine

456 without the sculptured structure; (4) a dorsoventrally compressed cotyle and condyle; (5) a

457 deep posterior 'cavity' behind the transverse process, and an extended dorsal lamina and

458 posterior alar process; (6) a low and shallow posterior notch of the neural arch; and (7) in

459 having an accessory alar process that reaches the parapophysis, which differs from specimens

460 of the genus Cynops wherein it reaches the diapophysis. The Siberian Tylototriton differs from

461 the European Oligocene cf. Tylototriton (see Böhme, 2010: p. 11, fig. 6f) by having: (1) a

462 ventrally deflected accessory alar process that terminates ventrally to the parapophysis; (2) a

463 shorter and lower neural spine; and (3) a shorter dorsal plate of the neural spine.

464 Taking into account the above-mentioned differences, we suggest that the described vertebrae

465 should be assigned to a new pleurodeline salamander genus that shows affinities with the

466 genus Tylototriton. However, we do not consider it reasonable to describe a new form unless

467 cranial material of this salamander is available.

468

469 Order Anura Fischer von Waldheim, 1813

470 Family Palaeobatrachidae (Cope, 1865)

471 Palaeobatrachidae sp. indet.

472

473 (Fig. 5A-5D)

474 Locality and material examined. Novaya Stanitsa 1A, GIN 948/2001-AM12, 1 sphenethmoid.

475 Description. This specimen is represented by a very robust sphenethmoid that lacks the

476 posterior region. The two anterior cavities corresponding to the antrum olfactorium are 
477 anteroposteriorly shallow. The posterior cavity, antrum pro lobo olfactorio, is deep and narrow

478 (Fig. 5A, 5B). The olfactory foramen is larger than the orbitonasal foramen (Fig. 5C). The

479 processus rostralis is elongated and projects anteriorly. Anteriorly, dorsal face of the bone, two

480 sharply marked crescentic depressions (nasal facets) correspond to the contacts with the nasal

481 bones (Fig. 5A). In dorsal view, the frontoparietal facet (contacting with the frontoparietal

482 cranial bones) shows a slightly striated surface. The lateral processes protrude laterally. The

483 lamina supraorbitalis is well developed. The most anterior part of the incisura semielliptical is

484 preserved on the specimen. The remaining part of this structure demonstrates that it

485 approaches cranially to the anterior border of the bone. The ventral face of the sphenethmoid

486 possesses a narrow and long depression corresponding to the contact area with the cultriform

487 process of the parasphenoid (the parasphenoid facet) (Fig. 5B).

488 Comparison and comments. The bone has strong similarities to that of palaeobatrachids in

489 having: (1) a long sphenethmoid with a frontoparietal fenestra corresponding to more than half

490 of the bone length; (2) the articulation area of the parasphenoid delimited by two parallel

491 ridges, in ventral view; (3) a very short septum nasi and lateral process (Vergnaud-Grazzini \&

492 Młynarski, 1969; Sanchíz \& Młynarski, 1979). The palaeobatrachid from the Novaya Stanitsa 1A

493 locality exhibits all these characters aside from the short septum nasi, which is longer in the

494 fossil bone. We presume that the frontoparietal fenestra was longer more than half of the

495 sphenethmoid length because the overall length of the frontoparietal and nasal facets has

496 similar proportions as these seen in other palaeobatrachids. Furthermore, according to Venczel,

497 Codrea \& Fărcaş (2012), the sphenethmoidal ossification forms the anterior margin of 
498 frontoparietal fontanelle in palaeobatrachid frogs (Palaeobatrachus + Albionbatrachus), which 499 can also be observed in the studied specimen.

500

501 Family Bombinatoridae Gray, 1825

502 Genus Bombina Oken, 1816

503 Bombina sp. / Bombina cf. bombina (Linnaeus, 1761)

504

505 (Fig. 6A-6F)

506 Localities and material examined. Malyi Kalkaman 2, GIN 1107/2001-AM02, 1 ilium; Selety 1A,

507 GIN 1107/2001-AM06, 1 ilium; Cherlak, GIN 1107/2001-AM06, 1 ilium.

508 Description. The bone description is based on the ilium from the Selety $1 \mathrm{~A}$ locality, since the

509 specimens from the Malyi Kalkaman 2 and Cherkal localities are greatly damaged. In lateral

510 view, the iliac shaft is almost straight and lacks the dorsal crest. The tuber superior is a weakly

511 pronounced tubercle. In dorsal view, a spiral groove is observable and continues on the medial

512 surface of the shaft. The acetabulum is round and strongly extended (Fig. 6A). The junction

513 between the iliac shaft and corpus ossi is slightly constricted and the ventral base of the corpus

514 ossi possesses a preacetabular fossa. The ventral ridge of the acetabulum is high. In lateral and

515 posterior views, the pars descendens is reduced and wide, whereas the pars ascendens is high

516 but narrow (Fig. 6A, 6B). In ventral view, the pars descendens is broad and nearly flat. In medial

517 view, the acetabular area is bordered by shallow ridges, between which there is, a triangular

518 and medially prominent interiliac tubercle (Fig. 6B, 6C). 
519 Comparison and comments. The lack of the vexillum and a poorly developed tuber superior is

520 characteristic of the genus Bombina (Böhme, 1977). The ilium differs from Bombina orientalis

521 by a poorly developed tuber superior. The ilium from the Selety $1 \mathrm{~A}$ locality is distinguishable

522 from Bombina variegata and resembles Bombina bombina in having: (1) a developed pars

523 descendens; (2) a posteroventral ridge of the pars descendens projecting ventrally rather than

524 posteriorly (Böhme, 1977); and (3) a developed preacetabular fossa (Sanchíz \& Młynarski,

525 1979). We, therefore, tentatively assign the bone to B. bombina due to the absence of well-

526 preserved material of the fire-bellied toads from the Selety 1A locality. The specific assignment

527 of the ilia from the Malyi Kalkaman 2 locality is impossible due to their fragmentary

528 preservation; therefore we describe them as Bombina sp.

529 The specimen from the Cherlak locality (Fig. 6D-6F) is greatly damaged with only a few

530 observable characters remaining that allow for its identification within Bombinatoridae. The

531 identifying characters are: (1) a large pars descendens at its anterior section, but dorsally

532 reduced; (2) a present but larger tuber superior than that of the Maly Kalkaman 2 and Selety $1 \mathrm{~A}$

533 specimens (within the family, larger tuber superior are present in the Barbatula (Folie et al.,

534 2013)); and (3) although the ventral wall of the acetabulum is not preserved, the remaining part

535 of its base allows for the assumption that it was markedly pronounced. Due to the incomplete

536 preservation, the important characters needed for taxonomic identification, e.g. interiliac

537 tubercle and junctura ilioischiadica, cannot be observed. The ilium from the Cherlak locality

538 can, therefore, be tentatively referred to the family Bombinatoridae.

539

540 Family Pelobatidae Bonaparte, 1850 
541 Genus Pelobates Wagler, 1830

542 Pelobates sp.

543

544 (Fig. 6G-6I)

545 Localities and material examined. Selety 1A, GIN 1110/2001-AM13, 1 right ilium.

546 Description. The corpus ossi and distal portion of the iliac shaft are present. The tips of the pars

547 descendes and pars ascendes are broken. The bone surface is smooth and there is no tuber

548 superior. An oblique posterolaterally-anteromedially directed spiral groove extends on the

549 dorsal surface. Laterally, the high and long pars ascendens possesses a supraacetabular fossa

550 (Fig. 6I). The junction between the iliac shaft and corpus ossi is not constricted. The

551 subacetabular groove is shallow and broad. The acetabulum has a nearly triangular form, with a

552 well-marked rim. In medial view, the corpus ilii possesses an interiliac facet with a rugose

553 surface. The interiliac facet is composed of a large lower and a small upper portions. A well-

554 developed interiliac tubercle is visible between these portions (Fig. 6G). The lower portion is

555 ventroposteriorly oblique, whereas the upper one is flat, less rugose and has a concave surface.

556 The rugose surface of the facet indicates an extensive contact between two ilia (Fig. 6G, 6H).

557 The acetabular dorsal tuber is higher than the ventral one.

558 Comparison and comments. The ilium can be assigned to the family Pelobatidae based on the

559 absence of a dorsal crest, the absence of a dorsal tubercle and the presence of an oblique spiral

560 groove on the dorsal surface (Roček et al., 2014). The bone has the same characters of the

561 genus Pelobates: (1) a high and long pars ascendes; (2) a well-developed spiral groove (Böhme,

562 2010); (3) the lack of a dorsal crest of the iliac shaft (Folie et al., 2013); and (4) a rugose surface 
563 of the interiliac facet (Rage \& Hossini, 2000). However, further identification of the ilium is

564 impossible, as it does not show relevant differences at the specific level.

565

566 Family Hylidae Rafinesque, 1815

567 Genus Hyla Laurenti, 1768

568 Hyla savignyi Audouin, 1827

569 Hyla gr. H. savignyi

570

571 (Fig. 6J-60)

572 Localities and material examined. Shet-Irgyz 1, GIN 1106/1001-AM01, 1 left ilium; Novaya

573 Stanitsa 1A, GIN 948/2001-AM20, 1 maxilla, GIN 948/2001-AM13, 1 scapula and GIN 948/2001-

574 AM14, 1 sacral vertebra; Lezhanka 2A, GIN 1130/1001-AM29 - -AM32, 4 ilia, GIN 1130/1001-

575 AM33 - -AM36, 4 scapulae and GIN 1130/1001-AM41, 1 trunk vertebra; Cherlak, GIN

576 1130/1001-AM14 - -AM15, 2 ilia; Olkhovka 1B, GIN 1111/2001-AM02, 1 fragmentary ilium;

577 Pavlodar 2B, GIN 1108/2001-AM01 - -AM03, 3 ilia.

578 Description. The ilia from all localities resemble the same morphology, i.e. the tuber superior is

579 dorsally prominent and slightly laterally. The tuber superior is located at the anterior corner of

580 the acetabulum. The preserved iliac shaft is nearly cylindrical, slightly mediolaterally

581 compressed and is devoid of crista dorsalis. The supraacetabular part of the ilium is smaller

582 than the preacetabular. The ventroposterior margin of the iliac shaft is connected with the pars

583 descendes by an expanded preacetabular zone, building a broad and thin lamina. The

584 acetabulum has a nearly triangular form. The acetabular rim is prominent at its high 
585 ventroanterior edge. The posterodorsal corner of the acetabulum ascends and builds a small

586 and prominent acetabular tuber (Fig. 6L). In medial view, the bone surface is smooth,

587 sometimes with a shallow depression in the middle part of the corpus ossi. In distal view, the

588 junctura ilioischiadica is slender, the acetabulum is high and the interiliac facet displays a well-

589 pronounced ventromedial expansion. The acetabular dorsal tuber is higher than the ventral one 590 (Fig. 6K).

591 The scapula, a triradiate element of the pectoral girdle, is comparatively long (Fig. 6M-60). The

592 bone surface is relatively smooth and is pierced by several foramina. The corpus scapulae, the

593 middle part of the bone, is slender and long. The pars suprascapularis is preserved in a

594 fragmentary state and most probably was not high. In dorsal view, the elongate pars acromialis

595 is narrow and almost equal in length (Fig. 6M). The shorter and flattened processus glenoidalis

596 is slightly broad. The processus glenoidalis and pars acromialis are separated by relatively deep

597 sinus interglenoidalis (Fig. 6N). The margo posterior, at the corner of the processus gleinoidalis

598 and corpus scapula, possesses an oval to elongated-oval angular fossa (Fig. 6N, 60). The tear-

599 shaped glenoid fossa reaches the posterior corner of the processus glenoidalis. The crista

600 supraglenoidalis is slightly pronounced.

601 Comparison and comments. The Siberian fossil tree frog differs from already described fossils

602 and some recent species of the genus Hyla. The following recent material is available for

603 comparison: Hyla savignyi, Armenia (four individuals, unnr. GPIT specimen), Hyla orientalis,

604 Armenia (two individuals, unnr. GPIT specimen) and Hyla arborea, Germany ? (one individual,

605 unnr. GPIT specimen). The Siberian forms can be distinguished from Hyla sp. (Rudabánya

606 locality in Hungary, middle Late Miocene (Roček, 2005); Bois Roche Cave in France, early Late 
607 Pleistocene (Blain \& Villa, 2006)), Hyla arborae (TD8 locality in Spain, early Middle Pleistocene 608 (Blain, 2009)), Hyla cf. arborea (Mátraszőlős 2 locality in Hungary, middle Middle Miocene 609 (Venczel, 2004)), Hyla gr. H. arborea (Capo Mannu D1 Local Fauna in Italy, Late Pliocene 610 (Delfino, Bailon \& Pitruzzella, 2011)), Hyla aff. japonica (Tologoy 38x, Baikal Lake, Russia, late 611 Late Pleistocene (Ratnikov, 1997)) and Recent Hyla japonica (Nokariya, 1983) in having: (a) a 612 fossa supragleinoidalis; (b) a slenderer and lower corpus scapula and pars suprascapularis; and 613 (c) a shorter and broader processus glenoidalis. Apart from these differences, the Siberian fossil 614 tree frogs resemble Hyla sp. from the Bois Roche Cave, France (Blain \& Villa, 2006), and $H$. 615 arborea (one individual, unnr. GPIT specimen) in possessing a low and broad processus 616 glenoidalis. The Recent $H$. savignyi is the only tree frog showing a fossa supragleinoidalis like 617 the one present in the studied remains. The Recent $H$. savignyi also possesses other similarities 618 to the fossil tree frog, namely: (1) a slender junctura ilioischiadica; (2) the same position of the 619 tuber superior; (3) comparable acetabular tubers; and (4) a similar slightly curved pars 620 ascendens. There are, however, also differences between the Recent $H$. savignyi and the fossil 621 tree frog. The fossil tree frog has: (1) a dorsally and slightly laterally prominent tuber superior; 622 (2) a deeper and larger fossa supragleinoidalis; and (3) a ventromedial expansion of the 623 interiliac facet; whereas $H$. savigyni has: (1) a dorsally and laterally significantly prominent 624 tuber superior; (2) a shallow and small angular fossa; and (3) the interiliac facet devoid of 625 ventromedial expansion. Among other fossil tree frogs, the Western Siberian Hyla sp. has the 626 lowest and broadest processus glenoidalis. Another fossil tree frog Hyla sp. reported from the 627 Russian Platform in the Kuznetsovka locality (0.5-0.65 Ma) (Ratnikov, 2002: fig. 2), displays a 628 similar morphology of the ilium as in the Siberian fossil, i.e. the orientation of the tuber 
629 superior and the form of the junctura ilioischiadica. Because of the observed differences in both

630 the Recent and fossil forms, as well as the similarities to $H$. savignyi, we assume that the fossil

631 tree frogs from Western Siberian and the Russian Platform, probably represent a new form

632 related to the group of Hyla savignyi.

633

634 Family Bufonidae Gray, 1825

635 Genus Bufo Laurenti, 1768

636

Bufo bufo (Linnaeus, 1758)

637

638 (Fig. 6P-6W)

639

Localities and material examined. Novaya Stanitsa 1A, GIN 948/2001-AM15, 1 left and GIN

640

948/2001-AM16 - -17, 2 right ilia, GIN 948/2001-AM18 - -19, 2 trunk vertebrae; Borki 1A, GIN

641

1115/1001-AM02, 1 sacral vertebra, GIN 1115/1001-AM03, 1 left ilium; Olkhovka 1B, GIN

642

1111/2001-AM04, 1 left, GIN 1111/2001-AM03, 2 right ilia and GIN 1111/2001-AM05, 1 trunk

643

vertebra; Olkhovka 1C, GIN 1111/3001-AM01, 1 left scapula, GIN 1111/3001-AM02, 1 trunk

644

vertebra and GIN 1111/3001-AM03, 1 urostyle; Lezhanka 2A, GIN 1130/1001-AM37, 1 left ilia,

645

GIN 1130/1001-AM38, 1 left scapula, GIN 1130/1001-AM39, 1 sacral and GIN 1130/1001-AM40,

646

1 trunk vertebrae; Isakovka 1B, GIN 1131/3001-AM01, 1 left ilium; Isakovka 1A: GIN 1131/1001-

647

AM01, -AM05, 2 right ilia; Peshniovo 3, GIN 1118/3001-AN01, 1 sacral vertebra; Lezhanka 1,

648

GIN 1129/1001-AM04, 1 trunk vertebra; Andreievka 1, GIN 1112/2001-AM01 1 right scapula.

649

Description and comments. The ilia are large and have a robust corpus ossi. The spiral groove is

650

broad and very shallow. The tuber superior is broad, low, covered with irregular tubercles, and 
651 it is situated above the acetabulum (Fig. 6P). The smooth and concave pars descendens is more

652 developed than the pars ascendens. The ventral edge of the pars descendens is thin and

653 lamelliform. The preacetabular fossa is absent (Fig. 6P). In posterior view, the anterolateral

654 edge of the acetabular is strongly curved. The junctura ilioischiadica shows a higher acetabular

655 ventral tuber than the dorsal tuber, and the ventral half of the corpus ossi projects

656 ventromedially (Fig. 6P).

657 The scapula is a robust bone and is longer than it is high. The material is represented by all

658 ontogenetic series. The angular fossa is absent; a shallow groove on the ventral side of the pars

659 acromialis is present and well pronounced in larger individuals. The pars acromialis and corpus

660 scapula have nearly the same height. The pars suprascapularis laterally increases in height. The

661 pars suprascapularis and corpus scapulae (anterior) have smooth surfaces. The base of the

662 lateral edge of the fossa glenoidalis is elevated but does not project laterally. The crista

663 supraglenoidalis is well developed in larger individuals. The anterior margin is concave. The

664 base of the pars acromalis is high and thin (Fig. 6R).There is a shallow and expanded depression

665 in ventral view. The anteromadial margin of the pars acromalis possesses a low tubercle. The

666 transition from the corpus scapula to the pars acromialis is nearly straight and the wall is thin

667 (Fig 6S, 6T).

668 In several localities, the large-sized frog vertebrae and urostyle (Fig. 6U-6W) are present in

669 association with diagnostic elements (ilia and scapula) (e.g. Olkhovka 1C locality) or are isolated

670 (e.g. Pehsniovo 3 locality). These individuals of the same size can be assigned to the large Bufo

671 bufo. The morphological traits described above (e.g. lack of angular fossa on the scapula and

672 preacetabular fossa on ilium, general outline, form, and size of the scapula and ilium) as well as 
673 the bone dimensions are the same as those found in the common toad Bufo bufo (Blain, Gibert

674 \& Ferràndez-Cañadell, 2010).

675

676 Genus Bufotes Rafinesque, 1815

677 Bufotes viridis Laurenti, 1768

678

679 (Fig. 6X-6Z)

680 Localities and material examined. Baikadam, GIN 950/2001-AM02 --AM04, 3 left and GIN 681 950/2001-AM05 - -AM09, 5 right ilia; Malyi Kalkaman 1, GIN 1107/1001-AM02 and -AM03, 1 682 left and 1 right scapulae; Malyi Kalkaman 2, GIN 1107/2001-AM03, 1 right scapula; Znamenka, 683 GIN 1109/1001-AM01 and -AM02, 1 left and 1 right scapulae, GIN 1109/1001-AM03 - -AM07, 5 684 left and GIN 1109/1001-AM08 - -AM11, 4 right ilia; Pavlodar 1A, GIN 640/5001-AM01 - -AM24, 685240 left and GIN 640/5001-AM25 - -AM58, 34 right ilia, GIN 640/5001-AM63 - -AM77, 15 left 686 and GIN 640/5001-AM78 - -AM88, 11 right scapulae; Cherlak, GIN 1110/2001-AM16, 1 right 687 ilium; Selety 1A, GIN 951/1001-AM08 - -AM10, 3 left and GIN 951/1001-AM11 - -AM14, 4 right 688 ilia; Isakovka 1A, GIN 1131/1001-AM02 - -AM04, 3 left ilia; Kedey, GIN 951/2001-AM01 and - 689 AM02, 1 left and 1 right ilia; Lebiazhie 1A, GIN 950/3001-AM01, 1 left scapula, GIN 950/3001690 AM01 2 left ilia; Lebiazhie 1B, GIN 950/4001-AM01, -AM02, 2 right ilia.

Description and comments. The iliac shaft is slightly lateromedially compressed and bears a 692 weakly pronounced depression along the middle section. The spiral groove between the corpus 693 ossi and iliac shaft is weakly developed. The tuber superior is low and possesses a uni- or 
694 bilabiate protuberance in its central part. The angular fossa is well pronounced. The

695 anteroventral edge of the acetabular rim is straight. The pars descendens projects sharply

696 ventrally. There is no observable 'calamita' ridge (Fig. 6X). The remains show typical features for

697 Bufotes viridis: i.e. the form and shape of the tuber superior and acetabulum (Böhme, 1977;

698 Blain, Gibert \& Ferràndez-Cañadell, 2010). Due to the absence of well-preserved material, we

699 prefer to tentatively assign the remains to the Bufotes viridis group.

700

701 Bufo sp.

702 Localities and material examined. Cherlak, GIN 1110/2001-AM17, 1 left scapula; Olkhovka 1A,

703 GIN 1111/1001-AM01, -AM02, 2 left ilia; Pavlodar 2B, GIN 1108/2001-AM04 - -AM06, 3 left ilia.

704 Description and comments. The greatly damaged ilia exhibits the typical morphology of the

705 genus Bufo, i.e. the iliac shaft without the dorsal crest and a spiral groove between the shaft

706 and corpus ilii (Böhme, 1977). There is a preacetabular fossa in the caudoventral corner of the

707 acetabulum. The tuber superior is eroded. In medial view, the pars descendens is

708 ventromedially directed.

709

710 Family Ranidae Batsch, A. J. G. K., 1796

711 Genus Pelophylax Fitzinger, 1843

712 Pelophylax sp.

713

714 (Fig. 6AA-6AD) 
715 Localities and material examined. Malyi Kalkaman 1, GIN 1107/1001-AM04, 1 left ilium, GIN

716 1107/1001-AM13, 1 left articular; Malyi Kalkaman 2, GIN 1107/2001-AM04, -AM05, 2 right ilia ,

717 and GIN 1107/2001-AM06, 1 left ilium; Petropavlovsk 1, GIN 952/1001-AM01, 1 left ilium;

718 Olkhovka 1C, GIN 1111/3001-AM04, 1 right ilium; Kamyshovo, GIN 1107/1001-AM01, 1 right

719 scapula; Lezhanka 1, GIN 1129/1001-AM05, 1 left and GIN 1129/1001-AM06, 1 right ilia, GIN

720 1129/1001-AM07, 1 left scapula; Andreevka 1, GIN 1112/2001-AM02, 1 right and GIN

721 1112/2001-AM03, 1 left ilia; Livenka, GIN 1129/2001-AM01, 1 right ilium.

722 Description and comments. The ilia have a strong, oval, nearly vertically oriented and ventrally

723 well-defined high tuber superior. The dorsal crest is high; anteriorly it is often broken. The tuber

724 superior is high and slightly more S-shaped than the crest; a well-developed supraacetabular

725 fossa is present. Posterior to the tuber, the dorsal margin of the bone is bent ventrally towards

726 the acetabulum. In posterior view, the tuber superior is curved ventromedially (Fig. 6AA). The

727 junctura ilioschiadica is damaged but based on the preserved structures we speculate that it

728 was tall (Fig. 6AB).

729 The scapula is an elongated and short bone. In ventral view, a weakly-developed crista

730 supraglenoidalis is observable. It runs subparallel to the margo posterior and reaches the

731 middle part of the pars suprascapulars (Fig. 6AC, 6AD).

732 The characters listed above, i.e. like the form and orientation of bones, tuber superior and

733 crista supraglenoidalis, allow for the attribution of the fossils to the genus of the green (water)

734 frogs Pelophylax (Böhme, 1977; Sanchíz, Schleich \& Esteban, 1993; Bailon, 1999; Blain, Bailon \&

735 Agustí, 2007). Any further identification is impossible due to the fragmentary preservation of

736 the material. 
738 Genus Rana Linnaeus, 1758 (Linnaeus, 1758)

739 Rana sp. / Rana temporaria Nilsson, 1842 (Nilsson, 1842)

740

741 (Fig. 6AE-6AH)

742 Localities and material examined. Ayakoz, unnr. HC specimens, numerous ilia, Baikadam, GIN

743 950/2001-AM10, 1 left, GIN 950/2001-AM11 - -AM13, and 3 right ilia; Malyi Kalkaman 1, GIN

744 1107/1001-AM05 - -AM09, 5 left ilia, GIN 1107/1001-AM10, 1 right ilia, GIN 1107/1001-AM01, -

745 AM11, 2 right scapula; Malyi Kalkaman 2, GIN 1107/2001-AM07, 1 right ilium, GIN 1107/2001-

746 AM08 - -AM13, 6 left ilia; Olkhovka 1C, GIN 1111/3001-AM05, 1 right ilium; Lezhanka 1, GIN

747 1129/1001-AM08, 1 left ilium; Kentyubek, unnr. HC specimens, 2 left ilia.

748 Description. The ilia have a reduced, compact, anteriorly directed and low tuber superior. The

749 lateral surface is rough. The dorsal crest is low. The pars descendens is more developed than

750 the pars ascendens (Fig.6AE). In posterior view, the junctura ilioschiadica Is low (Fig. 6AF) in

751 comparison to the ilium of Pelophylax sp. (Fig. 6AA). The tuber superior projects dorsolaterally.

752 The pars descendens projects medially (Fig. 6AE).

753 The middle portions of both scapulae are preserved without the proximal parts of the pars

754 acromialis and suprascapularis. In dorsal view, a crista supraglenoidalis is observable at the

755 processus glenoidalis, which continues until the pars suprascapularis along the longitudinal axis

756 of the bone. It is very prominent and forms a lamelliform convex ridge. The base of the

757 processus glenoidalis is high and straight (Fig. 6AG, 6AH). 
758 Comments. The ilia and scapulae morphology strongly resembles that of brown frogs genus,

759 Rana (Böhme, 1977). Due to the fragmentary preservation of the bone material, any precise

760 taxonomic identification of the frogs from nearly all localities was impossible. The comparison

761 with Recent species (e.g. Rana temporaria (unnr. GPIT specimen), Rana dalamtina (unnr. GPIT

762 specimen; Bailon, 1999), Rana graeca (unnr. GPIT specimen), Rana arvalis (unnr. GPIT

763 specimen), Rana dybowskii (MNCN 40459), Rana amurensis (unnr. GPIT specimen) etc.)

764 revealed more similarities with the European and Western Asiatic species rather than to

765 Eastern Asiatic brown frogs.

766 Only the Malyi Kalkaman 1 locality provided adequate material for specific identification. The

767 ilia and scapulae from this locality's material resembled the Recent species, Rana temporaria,

768 which has the widest distribution among the brown frogs in Eurasia. The fossil bones of brown

769 frogs from other Western Siberian localities are described here as Rana sp. Due to the poor

770 preservation of the ilia from the Kentyubek locality, it can be only identified at the family level.

771

772 Class Reptilia Laurenti, 1768

773 Order Squamata Oppel, 1811

774 Suborder Gekkota Cuvier, 1817

775 Family Gekkonidae Gray, 1825

776 Genus Alsophylax Fitzinger, 1843

777 Alsophylax sp.

778

779 (Fig. 7) 
780 Locality and material examined. Cherlak, GIN 1110/2001-RE01 - -RE10, 10 right dentaries, GIN

781 1110/2001-RE11 - -RE24, 14 left dentaries, GIN 1110/2001-RE26 - -RE38, 13 left maxillae, GIN

782 1110/2001-RE39 - -RE43, 5 right maxillae, GIN 1110/2001-RE44, 1 cervical trunk vertebra;

783 Mynsualmas-MSA 3: 1 right maxilla, unnr. GPIT specimen.

784 Description.

785 Tooth morphology. The teeth are slender, unicuspid, and not narrowly arranged. All maxillaries

786 and dentary teeth are straight, except the most anterior ones on the dentary, which are

787 anteriorly lightly oblique. The central teeth on dental lamina of both the maxilla and dentary

788 are larger than the anterior and posterior ones (Fig. 7C, 7G). The cusps of maxilla teeth are

789 rarely posteriorly oriented. The most complete dentary bone contains at least 17 (in total,

790 probably 20) teeth, counted by both teeth and their alveoles (Fig. 7B-7D).

791 Dentaries. The dentary is a slender and elongated. In the symphyseal region, the bone is slightly

792 medially curved. The pars ventralis is assumed to be enlarged, due to the bone posteriorly

793 increasing in height. The dentary is characterised by a completely closed Meckelian canal,

794 which runs along approximately two-thirds of the bone length (Fig. 7B). The symphyseal

795 articulation surface is reduced. It does not build a pronounced articulation surface. The ventral

796 surface of the symphysis bears a longitudinal, posteriorly deepening symphyseal groove, visible

797 in both the lingual and ventral views (Fig. 7B-7D). The Meckelian canal is open posteriorly at

798 about the 15th-16th tooth position. The splenial facet on the dentary, the anterior margin of

799 Meckelian opening, shows a light concave and elongated surface (Fig. 7B-7E). In lateral view,

800 the bone is smooth, and the only complete dentary possesses five foramina that are arranged

801 in a longitudinal row (Fig. 7A). The size of the foramina increases slightly in the anteroposterior 
802 direction, also changing in form from a more rounded outline to an oval appearance. The

803 position of the last mental foramen is arranged lingually in front of the posterior opening of the 804 Meckelian canal. The cavity of the Meckelian canal is divided in two, i.e. the upper and lower 805 subcanals, by a distinct horizontal lamella (Fig. 7E). The horizontal lamella runs parallel to the 806 lamina horizontalis and can be observed posteriorly behind the opening of the Meckelian canal. 807 The upper subcanal opens to the labial surface of the bone near to the mental foramina. The 808 symphyseal groove corresponds to the anterior opening of the lower subcanal. In lingual view, 809 the lamina horizontalis is situated in a low position. Its margin is rounded but not prominent. A 810 shallow and anteriorly extending dental shelf divides the lamina horizontalis from the dental

811 lamina (Fig. 7C). Posteriorly, the bone is nearly L-shaped in the transverse section. In all

812 observed specimens, the pars horizontalis is destroyed in the preserved bone. The caudal

813 portion of the paries verticalis shows bifurcation (Fig. 7E), which corresponds to the coronoid 814 insertion.

815 Maxilla. The preserved posterior part of the maxillary possesses a relatively low lacrimal facet 816 of the facial process of the maxilla (pars nasalis sensu Estes (1969)), while the latter is always 817 not preserved. The internal wall of the maxilla posteriorly bears a small distinct longitudinal 818 groove, running parallel to the lamina horizontalis (Fig. 7F-7H). The groove begins at the 819 posterior basis of the lacrimal facet and continuous until the preserved posterior tip of the 820 bone. The groove narrows at the middle section of the bone (at the position of the 3rd-4th last

821 tooth), where the lacrimal facet terminates. The lamina horizontalis is clearly visible, expands

822 laterally just under the tip of the lacrimal facet and builds a palatine facet (Fig. 7F-7H). The 823 lamina horizontalis becomes distinctly and posteriorly narrower but does not diminish fully at 
824 the posterior end of the bone. The jugal process of the maxilla is bifurcated at its distal end (Fig.

825 7H). The maxillary lappet is damaged, but its base is preserved. The internal wall surface of the

826 maxilla contains few rugosities. Here an anteroposteriorly directed, fairly well-pronounced,

827 median ridge, is observed. In labial view, several foramina occur above the dental row. Some of

828 these foramina are arranged in a longitudinal line that corresponds to the foramina for the

829 mandibular division of the fifth cranial (trigeminal) nerve. This line runs parallel to the lamina

830 horizontalis. The last foramen in the row pierces the maxilla at the base of the lacrimal facet

831 under its tip. The bases of the facial process and maxillary lappet lay a relatively large superior

832 alveolar canal (sac, Fig. 7J, 7L) for the maxillary nerve and its accompanying blood vessel. The

833 remaining foramina at the maxilla are dispersed irregularly on the bone surface. The

834 premaxillary process is present, but it is highly damaged. The anterior basis of the lacrimal facet

835 is pierced by a foramen.

836 Vertebra. A single cervical vertebra of a gecko specimen shows an elongate amphicoelous

837 centrum (Fig. 7N-7P). The cotyles are approximately circular. In anterior view, the vertebra has

838 a semi-circular outline. In lateral view, the vertebra is anteroposteriorly compressed. The neural

839 arch is concave on both sides. The transverse processes are high, extremely short, and vertically

840 aligned. The distal end of the process is round. The haemal foramina are present at the lower

841 base of the transverse processes. The prezygapophyses are small and slightly prominent. The

842 neural arch is plane and triangular in outline. It possesses a slender and low neural crest. The

843 postzygapophyses are small, nearly invisible and are situated on the ventrolateral edges of the

844 pterygapophysis. 
845 Comparison and comments. Numerous characters allow for the identification of the material as

846 a member of the family Gekkonidae. These characters are namely: (1) the amphicoelous

847 condition of the vertebra; (2) the maxillae and dentaries bearing numerous pleurodont,

848 isodont, densely packed, cylindrical, and slender monocuspid teeth; (3) the presence of a

849 medially extended dental shelf of the maxilla; and (4) the lingually closed Meckelian canal

850 (Hoffstetter \& Gasc, 1969; Daza, Alifanov \& Bauer, 2012). The gekkonid remains from the

851 Cherlak locality display a low number of teeth on the dentary (up to 20) and a rounded tooth

852 apex (making the teeth digitiform), which are diagnostic characters for the genus Alsophylax

853 (Nikitina \& Ananjeva, 2009). Within the gekkonids, a low number of teeth (up to 20) is also

854 characteristic of Mediodactylus russowi, Phelsuma laticauda, and Ph. serraticauda (Nikitina,

855 2009). The Siberian fossil geckos can be distinguished from Mediodactylus by peculiarities of

856 the maxilla (i.e. the presence of a lingual longitudinal groove and a reduced row of foramina of

857 the trigeminal nerve), the dentary with a distinct and longer horizontal lamella, plus a reduced

858 symphyseal groove. The Recent genus Phelsuma can be excluded from consideration since

859 these geckos are restricted to the islands of the southwest part of the Indian Ocean and belong

860 to another zoogeographic zone. The fossil geckos resemble the Recent species Alsophylax

861 pipiens (see in Estes (1969); tab. 2C) in the presence of the prefrontal process and their short

862 row of foramina of the trigeminal nerve, which terminates below the prefrontal process.

863 Further comparison with the Recent genus Alsophylax is, however, impossible due to the lack of

864 available comparative osteological material of the Recent Alsophylax species.

865 Fossil geckos were present in the Early Miocene of Kazakhstan, as is evident from the

866 Mynsualmas-MSA 3 locality (unnr. GPIT specimen) (Böhme \& Ilg, 2003). The re-studying of the 
867 material revealed that the posterior fragment of a right maxilla shows morphology similar to 868 Alsophylax sp. from the Cherlak locality in the presence of a lingual longitudinal groove, the 869 absence of foramina at the posterior portion of the bone and a round tooth apex. The fossil 870 material, however, differs in its larger size (Fig. 7Q). Taking this difference as well as the 871 similarities into account, we tentatively consider the Mynsualmas record as cf. Alsophylax sp. 872 This fossil probably represents a larger Alsophylax species than those registered in the Western 873 Siberia.

874

875 Suborder Lacertilia Owen, 1842 sensu Estes, Queiroz \& Gauthier, 1988

876 Family Lacertidae Fitzinger, 1826

877 Genus Lacerta Linnaeus, 1758

878

879 Remarks. The generic assignment of fossil lacertid remains is extremely difficult. This group is 880 anatomically generalised (Lacera sensu lato) and shows very few characteristic features (e.g.

881 bone and teeth morphology) for detailed taxonomic assignments (Böhme, 2010; Böhme \& 882 Vasilyan, 2014).

883

884 Lacerta s.l. sp. 1.

885

886 (Fig. 8A) 
887 Material. Baikadam, GIN 650/2001-RE07 - -RE09, 2 (3?) left dentaries, GIN 650/2001-RE10, 1 888 postsacral vertebra; Pavlodar 1A, GIN 640/5001-RE01 - -RE15, -RE41 - -RE4217 left dentaries, 889 GIN 640/5001-RE16 - -RE25, 10 right dentaries.

890 Description. The bones bear pleurodont bicuspid teeth. The most completely preserved 891 dentary possesses at least 20 teeth. The pars dentalis is tall , with its height corresponding to 892 two-thirds of the tooth length. The Meckelian groove is open ventrolingually. It starts from the 893 ventral side of the symphysis and posteriorly increases in height. The lamina horizontalis is 894 slightly curved. The anterior portion of the lamina horizontalis is high and broad, reaching its 895 maximal height in its middle section which corresponds to the tenth tooth position. Behind this 896 point, the lamina horizontalis articulates ventrally with the dorsal margin of the splenial and 897 gradually narrows posteriorly. The articulation surface is lingually exposed. The crista dentalis, 898 sensu Roček (1984), is not higher but is longer than the ventral margin of the lamina 899 horizontalis. The ventral margin of the crista dentalis, in its posterior half, bears an articulation 900 surface with the ventral margin of the coronoid. A lingually exposed articulation surface of the 901 splenial is located at the posterior portion of the ventral surface of the lamina horizontalis. Up 902 to eight small foramina are present in labial view (Fig. 8A).

903 Comments. See in Lacerta s.l. sp. 2.

904

905 Lacerta s.l. sp. 2.

906

907 (Fig. 8B) 
908 Material. Pavlodar 1A, GIN 640/5001-RE27 - -RE33, 7 left dentaries, GIN 640/5001-RE34 - -

909 RE39, 6 right dentaries; Cherlak, GIN 1110/2001-RE51, 1 right dentary.

910 Description. The dentaries possess 19 bicuspid teeth. The pars dentalis is high with its height

911 corresponding to two-thirds of the teeth length. The lamina horizontalis is curved and

912 maintains almost the same height along its entire length. The lamina horizontalis decreases

913 slightly in height only at the 9th-10th tooth positions, where the splenial articulates with the

914 lamina horizontalis. The articulation facet is lingually exposed only in its most posterior portion.

915 The crista dentalis is short but is longer than the ventral margin of the lamina horizontalis. The

916 Meckelian groove is low and ventrolingually open. Up to seven small foramina are present in

917 labial view (Fig. 8B).

918 Comments. Lacerta s.l. sp. 2 differs from Lacerta s.l. sp. 1 in having: (1) a more curved lamina

919 horizontalis that maintains nearly the same height along its length; (2) a higher and broader

920 anterior portion of the lamina horizontalis; (3) a shorter cirsta dentalis; and (4) a lower

921 Meckelian groove.

922

923 Lacerta s.I. sp. / Lacertidae indet.

924 Material. Malyi Kalkaman 2, GIN 1107/2001-RE01, 1 vertebra; Olkhovka 1A, GIN 1111/1001-

925 RE01 and-RE02, 1 anterior and 1 posterior trunk vertebrae; Cherlak, GIN 1110/2001-RE06, -

926 RE52 - -RE57, 7 trunk vertebrae, GIN 1110/2001-RE47, -RE48, 2 left maxillae, GIN 1110/2001-

927 RE49, 1 right maxilla, GIN 1110/2001-RE50, 1 left dentary; Pavlodar 1A, GIN 640/5001-RE40, 1

928 premaxilla, GIN 640/5001-RE26, numerous fragments of dentaries and maxillae, GIN 640/5001-

929 RE43, 77 vertebrae; Pavlodar 1B, GIN 640/6001-RE01, -RE02, 2 left dentaries, GIN 640/6001- 
930 RE03, -RE04, 2 right dentaries; Olkhovka 1B, GIN 1111/2001-RE01, 1 right dentary; Pavlodar 3A,

931 GIN 1108/3001-RE01, 1 right maxilla; Beteke 2, GIN 945/6001-RE01, 1 left dentary; Beteke 4,

932 GIN 945/8001-RE01, 1 left dentary.

933 Description and comments. The preserved maxillaries and dentaries possess pleurodont

934 bicuspid teeth. The Meckelian groove is lingually open. The labial surfaces of the maxillaries

935 show no ornamentation. In labial view, the foramina for mandibular division of the fifth cranial

936 (trigeminal) nerve are observable. They are situated along a longitudinal line, parallel to the

937 ventral margin of the bone. The opening of the superior alveolar canal is large. In lingual view, a

938 shallow but broad groove is present at the anterior portion of the frontal process. The large

939 foramen of the fifth cranial (trigeminal) nerve opens at the ventral surface of the lamina

940 horizontalis. A single premaxilla from Pavlodar 1A, GIN 640/5001-RE40 has a tapering nasal

941 process with a row of seven pleurodont and monocuspid teeth.

942 The bone material is extremely fragmentary, and any comparison between different localities

943 was impossible. The fossil remains (maxillae and premaxilla) from Pavlodar 1A do not show any

944 taxonomical differences, so we were not able to group them neither to Lacerta s.l. sp. 1 nor

945 Lacerta s.l. sp. 2. Besides the jaw material, vertebrae from the trunk region are available in the

946 Maly Kalkaman 2, Olkhovka 1A and Cherlak localities. It was not possible to identify all of

947 remains below the family level.

948

949 Genus Eremias Fitzinger, 1843

950 Eremias sp.

951 
952 (Fig. 8C-8D)

953 Material. Pavlodar 2B, GIN 1108/2001-RE01, -RE02, 1 frontal and 1 trunk vertebra.

954 Description. The preserved frontal has a sandglass shape and the most anterior and posterior

955 portions are broken. The bone is slightly curved in lateral view. The posterior portion of the

956 dorsal surface is rough. The crista cranii are round and slightly elevated at the narrowest

957 portion of the bone. Anteriorly, these crista cranii increase in height and build the lateral walls

958 of the cranial vault. The anteroventral surface of the bone has two drop-shaped grooves. The

959 posteroventral surface is plain and slightly lower than the anterocentral surface. The prefrontal

960 facets are developed but do not show any lateral extension. The bone margin that connects

961 both facets is concave. In dorsal view, the nasal facets that are situated at the anterolateral

962 corners, are narrow, deep, and elongated (Fig. 8A, 8D).

963 In lateral view, a single preserved trunk vertebra has a rectangular shape. The neural arch is

964 moderately convex. A narrow and deep groove is present at the transition of the neural arch

965 and prezygapophysis. The neural spine is reduced and posteriorly builds a rounded process,

966 projecting over the posterior margin of the arch. The centrum is compressed anteroposteriorly

967 and possesses two shallow subcentral grooves, with a subcentral foramina in each one. The

968 condyle is small, round and is situated in the middle part of the posterior margin of the

969 centrum.

970 Comments. Among the Eurasian lacertids, fused dorsally sculptured frontals are known in

971 Acanthodactylus, Eremias, Ophisops (Evans, 2008). Our own observations of Recent species of

972 these genera (Eremias strauchi, Eremias pleskei, Eremias arguta, Eremias multicellata, Ophisops

973 elegans, Acanthodactylus erythrurus) allowed for the assignment of the frontals to the genus 
974 Eremias and to separate them from: (1) Ophisops by a robust frontal, more pronounced

975 grooves at the anteroventral bone surface and a lack of the lateral extension of the prefrontal 976 facet; and (2) Acanthodactylus by a flat posteroventral surface of the bone and a less curved

977 outline in lateral view. The preserved single vertebra strongly resembles the morphology that is

978 found in Eremias (Rage, 1976).

979

980 Order Testudines Linnaeus, 1758

981 Suborder Cryptodira Cope, 1868

982 Family Emydidae (Rafinesque, 1815)

983 Genus Eymdoidea Gray, $1870^{2}$

984 Emydoidea sp.

985

986 (Fig. 8E-8G)

987 Material. Novaya Stanitsa 1A, GIN 948/2001-RE01, 1 posteriorly incomplete right hypoplastron, 988 GIN 948/2001-RE02, 1 left femur.

989 Description and comments. The caudal part of the left hypoplastron, which has a width of 54.3

$990 \mathrm{~mm}$, is preserved (Fig. 8E) and probably belongs to a middle-sized individual with a total length

991 of the carapace, approximately $300 \mathrm{~mm}$. In ventral view, the femoral/abdominal sulcus is nearly 992 straight and curves anteriorly only near the lateral edge of the bone, terminating at the base of

993 the inguinal buttress. The bone is comparatively thin, medially from the bridge ( $4 \mathrm{~mm})$ to

\footnotetext{
${ }^{2}$ We follow taxonomy suggested by Fritz, Schmidt \& Ernst, 2011 recognizing Emydoidea as a distinct genus from Emys.
} 
994 behind the bridge $(7.2 \mathrm{~mm})$. The lateral edge of the bone projects slightly posterolaterally. The

995 outline of the femoral/abdominal sulcus and the profile of the lateral edge are similar to those

996 of the emydid genus Emydoidea (both fossil and Recent specimens) ((Chkhikvadze, 1983), figs.

99726 and 27, p. 138; (Holman, 1995)).

998 An almost complete left femur is available from the same locality where the hypoplastron

999 fragment was found. The bone is slender and bent (Fig. 8F-8G), and is $50.6 \mathrm{~mm}$ in length. This

1000 bone could have belonged to an individual of about $300 \mathrm{~mm}$ of the carapace length. The femur

1001 lacks its proximal portion (i.e. femoral head, major and minor trochanters). In ventral view, the

1002 fossa is delimited by the trochanters and is observable below the femoral head. The dimension

1003 of the bone is characteristic of aquatic testudinoids. Taking this latter character into account, as

1004 well as the comparable reconstructed total body-sizes of both elements (hypoplastron and

1005 femur) (ca. $300 \mathrm{~mm}$ ), we consider the remains to belong to the genus Emydoidea.

1006

1007 Testudines indet.

1008 Material. Malyi Kalkaman2, GIN 1107/2001-RE02, shell fragment; Shet-Irgyz 1, GIN 1106/1001-

1009 RE01, 1 neuralia; Petropavlovsk 1, GIN 952/1001-RE01, several fragments of carapax; Borki 1B,

1010 GIN 1115/2001-RE01, 1 fragment of carapax.

1011 Comments. The preserved remains were not sufficently informative for any other taxonomic 1012 interpretation.

1013

1014 DISCUSSION

1015 Neogene evolution of amphibian and reptile assemblages in Western Siberia 
1016 In general, and in contrast with the well-studied European fossil record, very is known about

1017 the Neogene herpetofauna from Asia. This record bias is owing to: (1) the less explored and less

1018 extensively studied Neogene deposits on the Asian continent; and (2) the entirely lack of study

1019 on Recent amphibians and reptiles, in spite of the intense investigations around small mammals

1020 by many scholars. The Western Siberian localities provide an exceptional opportunity to fill

1021 these gaps in information and to explore both the unknown diversity of the Asian

1022 herpetofaunal assemblages and the palaeobiogeographic affinities of the Western Siberian

1023 Neogene herpetofauna with the European faunas. Unfortunately, the yielded fossil material

1024 from this study and from previous investigations has thus far not been rich in amphibian and

1025 reptile remains. On average, only four taxa are available from each studied locality. Our

1026 faunistic, palaeogeographic and palaeoclimatic interpretations are, hence, very tentative and

1027 should be taken within this context. The unbiased comparison and analysis of our data are also

1028 hindered by the scarce record of the Asian Neogene fossil fauna. For the comparison with the

1029 European record, we used already published data on amphibian and reptile groups (families,

1030 genus, species, etc.) which have been summarised in the fosFARbase database (Böhme \& Ilg,

1031 2003). These data are given in the Table S5. In the 'Europe' record, we consider all known fossil

1032 records from Western, Central, and Eastern Europe as well as from Anatolia (Fig. 9). By

1033 analysing the Neogene amphibian and reptile records from Europe and Asia, we were able to

1034 provide useful data that are applicable for fossil calibration of molecular clocks in the

1035 phylogenetic trees.

1036

1037 Hynobiidae 
1038 The Asiatic salamanders (Salamandrella sp.) have the most abundant and frequent record

1039 among the studied Western Siberian localities. These organisms appeared in these areas in the

1040 middle Late Miocene (in the Selety $1 \mathrm{~A}$ locality) and are present until the early Early Pleistocene.

1041 Although the herpetofaunal assemblages of the older localities are rich and represented by

1042 numerous taxa, they do not contain any hynobiid remains, demonstrating that there is no

1043 sampling bias in their record and that such specimen are not present in earlier localities.

1044 Recently, the oldest record of the genus, Salamandrella sp. has been described from the late (?)

1045 Early Miocene of Eastern Siberia (Lake Baikal) (Syromyatnikova, 2014), and a new species of

1046 Salamandrella is indicated to be present in the Late Miocene locality Ertemte 2, China (Vasilyan

1047 et al., 2013). Furthermore, the fossil Asiatic salamander, Ranodon cf. sibiricus was recovered

1048 from the Early Pleistocene of Southern Kazakhstan (Averianov \& Tjutkova, 1995), and a

1049 Salamandrella sp. was reported from a few Middle Pleistocene age localities in European Russia

1050 (Ratnikov, 2010).

1051 In Central Europe, hynobiids (genus Parahynobius) appeared at the earliest Late Miocene and is

1052 present in the record until the Middle Pleistocene (Venczel, 1999a, 1999b; Venczel \& Hír, 2013).

1053 According to our unpublished data, the hynobiids are also present in three Ukrainian localities -

1054 Grytsiv (11.1 Ma) (Kirscher et al., 2016), earliest Late Miocene; Cherevichnoe lower level,

1055 middle Late Miocene; and Kotlovina lower level, late Pliocene. The Ukrainian occurrences

1056 coincide with both the Central European and Western Siberian records of hynobiids, which at

1057 that time most probably characterised by favourable conditions for hynobiid distribution.

1058 Considering their oldest records, the origin of Hynobiidae was most probably in Eastern Asia in 
1059 the early Miocene. We will present a detailed study on the Cenozoic record of fossil Hynobiidae

1060 including the Western Siberian material in a forthcoming paper.

1061

\section{Cryptobranchidae}

1063 The cryptobranchid remains are known from two localities in the town of Pavlodar and from

1064 three localities in the Zaisan Basin. The stratigraphic positions of the Pavlodar localities are not

1065 clear. The only record of giant salamander that we were able to study is stored at the

1066 Palaeontological Institute of Moscow, Russia. The collection label provides the following

1067 information: 'collected by Gaiduchenko, in 1970, from the Gusiniy Perelet locality, at the

1068 contact of the Aral clays with overlying sands, about 200-300 m south far from the 'Gusiniy

1069 Perelet' [=Pavlodar $1 \mathrm{~A}]$ locality'. The only explanation of the stratigraphic allocation of the

1070 giant salamander remains is that they originated from the basal horizon of the Pavlodar Svita,

1071 overlaying the 'Aral clays' (or= limnic clays of the Kalkaman Svita). Gaiduchenko (1984) and

1072 Gaiduchenko \& Chkhikvadze (1985) mention a giant salamander (Cryptobranchidae indet.) from

1073 a locality named Detskaya Zheleznaja Doroga (engl. Children Railway) (Fig. 2, Table S1, Data S3),

1074 a sand pit located $10 \mathrm{~km}$ south-east from the 'Gusiniy Perelet' [=Pavlodar 1A] locality. The age

1075 of this fossiliferous horizon may fall near the Miocene-Pliocene boundary, an assumption that is

1076 mostly based on geology, age and accompanying fauna (see Data S2). This record from the

1077 Detskaya Zheleznaja Doroga presents the most northern $\left(52.3^{\circ} \mathrm{N}\right)$ occurrence of the giant

1078 salamanders in the Northern Hemisphere known so far. Unfortunately, this material was not

1079 available for our study. 
1080 Giant salamander remains have also been reported from three Burdigalian localities - Tri

1081 Bogatyrya, Vympel, Poltinik of the Zaisan Basin (Fig. 1, Table S1) (Chkhikvadze, 1984; Böhme,

1082 Vasilyan \& Winklhofer, 2012). The remains were assigned to the species Andrias karelcapeki by

1083 Chkhikvadze (1984). The taxonomic validity of the species still requires revision, which is

1084 necessary for any further interpretations.

1085

\section{Proteidae}

1087 The oldest record of the genus is described as being from the Late Oligocene and was found in

1088 the Aral Formation in the Akespe locality, on the north coast of the Aral Sea, Kazakhstan (cf.

1089 Mioproteus,) (Malakhov, 2003; Bendukidze, Bruijn \& Van den Hoek Ostende, Lars W., 2009).

1090 Here we add to the record a new, more recent Miocene (Aquitanian) Asian occurrence from the

1091 Ayakoz locality, Kazakhstan (Fig. 3D, Table S1). In the Middle Miocene, representatives of this

1092 genus occur in several localities in southern Russia and northern Kazakhstan (Table S1).

1093 According to our assessment, proteids survived until latest Miocene/earliest Pliocene (locality

1094 Petropavlovsk 1/2). The oldest stratigraphic record of Mioproteus (Mioproteus caucasicus) in

1095 Europe is described from the mid Aquitanian (early Early Miocene about 20.5-22 Ma) at two

1096 localities Ulm-Uniklinik and UIm Westtangente of the North Alpine Foreland Basin (Heizmann et

1097 al., 1989). The fossil proteids are known in Europe until the Pleistocene Epoch (Böhme \& I/g,

1098 2003).Due to the lack of complete fossil skeletons and unclear taxonomic assignments of the

1099 fossil records, Malakhov (2003) preferred to refer all known specimens of Mioproteus to the

1100 'Mioproteus caucasicus complex', including Mioproteus from Ashut, Kazakhstan,

1101 Mioproteuscaucasicus from type locality, as well as from the Late Miocene of Czech Republic, 
1102 Mioproteus wezei from the Pliocene of Poland and from the Early Pleistocene of Moldavia

1103 (Malakhov, 2003). Later, Roček (2005) considered M. wezei as a junior synonym of $M$.

1104 caucasicus, although as already mentioned by Malakhov (2003), an adequate amount of

1105 material including cranial and postcranial elements is necessary to solve the taxonomic

1106 problems of the genus. Malakhov (2003) also suggested an Asiatic origin for the 'Mioproteus

1107 caucasicus complex' and their later distribution into Europe. In summary, the oldest Late

1108 Oligocene record of Mioproteus (Mioproteus sp.) from Akespe, Kazakhstan and other localities

1109 of younger ages suggest: (1) a probable Asian origin of the genus; (2) the genus was

1110 continuously present in Central Asia/Western Siberia until the early Pliocene; and (3)

1111 Mioproteus migrated into Europe in the Early Miocene.

1112

\section{Salamandridae}

1114 As has already been established, Chelotriton is a basket taxon (Böhme, 2008) that needs further

1115 taxonomic study. It is one of the fossil amphibians that has an abundant and wide distribution

1116 in the late Paleogene and Neogene localities of Europe. In Asia, the genus was previously

1117 known only from the late Middle Miocene locality Malyi Kalkaman 1 (Tleuberdina, 1993). Our

1118 study showed that this genus was present at least since the Aquitanian age (the Aykoz locality

1119 in Kazakhstan, Early Miocene) (Table S1), making their Asiatic record older than previously

1120 assumed.

1121 Two localities (Ayakoz and Baikadam) from Western Siberia revealed aff. Tylototriton. The

1122 vertebrae showed significant similarities with the Recent East Asiatic genus Tylototriton. In

1123 Böhme \& Ilg (2003) and Böhme (2010), the genus Tylototriton (cf. Tylototriton sp. and 
1124 Tylototriton sp. nov.) has been reported from several Early Oligocene localities in southern

1125 Germany. Two Siberian records represent the first fossil occurrence of the genus in Asia, which

1126 appeared more recently in the fossil record than in the European occurrence. These Western

1127 Siberian specimens and the European specimens can be clearly separated from each other by

1128 the morphology of the trunk vertebrae. The Siberian salamanders probably represent new

1129 forms, strongly related to the East Asian terrestrial salamander, Tylototriton. The sympatric

1130 occurrence of two fossil terrestrial salamander genera Chelotriton and Tylototriton was

1131 documented for the first time from the Aquitanian age locality Ayakoz.

1132

\section{Palaeobatrachidae}

1134 The palaeobratrachids are considered a European family, with probable occurrence in North

1135 America at the terminal Cretaceous (Wuttke et al., 2012). Records of the palaeobratrachids are

1136 known from the Paleogene Western and Central Europe. It should be taken into account,

1137 however, that records from the Paleogene of Turkey, as well as from the Paleogene and Early to

1138 Middle Miocene of Eastern Europe, are very scarcely known. In the Miocene, palaeobatrachids

1139 appear to have expanded their distribution to Eastern Europe and also reached Anatolia, where

1140 they existed from the latest Oligocene and remained during the entire Early Miocene. During

1141 the Middle Miocene, palaeobatrachids were present in Europe, from Germany to Ukraine

1142 (Wuttke et al., 2012). The palaeobatrachid record in Europe is characterised by a four-million-

1143 year-long (ca. 5.6-9.78 Ma) gap in the Late Miocene (Fig. 9). During this gap, no palaeobatrachid

1144 is known from Western to Eastern Europe even in localities rich in diverse herpteofaunal

1145 assemblages (e.g. Staniantsi, Bulgaria; Morskaya 2, Russia, Böhme \& Ilg, 2003) and where 
1146 characterised by favourable environmental conditions for their distribution. After this gap,

1147 palaeobatrachids occur near the Mio-Pliocene transition in studied localities from Italy (Ciabot

1148 Cagna), (Cavallo et al., 1993) and Hungary (Osztramos 1C) (Venczel, 2001)). They seems to have

1149 disappeared from Western (Tegelen locality in Holland, Villa et al., 2016) and Central Europe

1150 (Betfia IX/B locality in Romania, Venczel, 2000) after the Early Pleistocene and remained

1151 exclusively in Eastern Europe until the middle Pleistocene (Poland - European Russia) (Wuttke

1152 et al., 2012). The palaeobatrachids appear to have never reached the east of the Ural

1153 Mountains. Their most eastern distribution is recorded in the Late Pleistocene locality of

1154 Apastovo, in Russia, which is about $600 \mathrm{~km}$ west from the Ural Mountains (Wuttke et al., 2012).

1155 The Western Siberian record does not only represent the first and only out-of-Europe

1156 occurrence of the family, but, surprisingly, falls within the Late Miocene palaeobatrachid gap of

1157 the European record. It is possible that palaeobatrachids occupied Western Eurasia again at the 1158 Mio-Pliocene boundary, from the east.

1159

\section{Bombinatoridae}

1161 The primitive family of aquatic toads Bombinatoridae includes two recent genera: Bombina and

1162 Barbourula. The family is known since the Maastrichtian, Late Cretaceous in Romania, genus

1163 Hatzegobatrachus (Venczel et al., 2016) and the Early Eocene in India, genus Eobarbourula

1164 (Folie et al., 2013). The Recent distribution of Bombina is confined to continental Europe and

1165 East Asia, representing the western and eastern genetic clades of the genus respectively. In

1166 Europe, two species Bombina bombina and Bombina variegata are known. B. bombina has the

1167 widest distribution and is found in Central to Eastern Europe, whereas B. variegata occurs in 
1168 Central Europe and in the south-eastern and western parts of Eastern Europe (Pabijan et al.,

1169 2013). The fossil record of the fire-bellied toad Bombina is patchy and limited to the Neogene

1170 of continental Europe. According to Sanchíz \& Schleich (1986), the oldest fossil occurrences of

1171 the genus (Bombina sp.) are known from two localities in Germany: Weißenburg 6 (early

1172 Aquitanian) and Stubersheim 3 (early Burdigalian) (Sanchiz \& Schleich, 1986; Böhme \& Ilg,

1173 2003). The personal observations of one of the co-authors of this study (MB) did not confirm

1174 the Weißenburg 6 record of Bombina. Therefore, in the present study, we consider

1175 Stubersheim 3 to be the earliest occurrence of the genus.

1176 Bombinatorids later appeared in Central Europe in the mid Middle Miocene (Bombina sp.,

1177 Opole 2, Poland) (Młynarski et al., 1982). Later, fire-bellied toads are present in three localities,

1178 representing the middle Tortonian age, including also the first fossil occurrences of the Recent

1179 European species - Bombina sp. from Rudabánya in Hungary (9.9-10.30 Ma) (Roček, 2005), B.

1180 cf. bombina from Kohfidisch in Austria (8.55-8.95 Ma) (Tempfer, 2005), and B. cf. variegata

1181 from Suchomasty in Czech Republic (8.8-9.2 Ma) (Hodrová, 1987). During the Pliocene,

1182 bombinatorids are represented mainly by the species $B$. bombina in six localities within Central

1183 Europe (Böhme \& /lg, 2003). The Pleistocene record is the richest in bombinatorid specimens

1184 with record from over 15 localities ranging from Central to Eastern Europe, and in which both

1185 Recent European species, B. variegata and B. bombina, are documented (Böhme \& Ilg, 2003)

1186 (Fig. 9, Table S5).

1187 In Western Siberia, bombinatorids are known from three localities: Malyi Kalkaman 2, Selety

1188 1A, and Cherlak. The oldest known record dated back to the late Serravalian (Middle Miocene).

1189 The oldest Messinian Selety 1A locality provided the fossil form of the Recent B. bombina (B. cf. 
1190 bombina) (Fig. 9). The last record of the genus dates back to the early Messinian (Late

1191 Miocene). It is interesting to note that the Western Siberian record of the genus does not

1192 coincide with their European occurrences, i.e. they are present during those periods when

1193 Bombina is absent in Europe. According to our analysis, it is clear that the ancestor of the ' $B$.

1194 bombina - B. variegata' clade was present in Europe from, at least, the later part of the Early

1195 Miocene. Later in the Middle Miocene they expanded into Western Asia, reaching the east from

1196 the Ural Mountains. The Western Siberian fossil Bombina can be clearly osteologically

1197 separated from Bombina orientalis, a member of the East Asian clade of the genus. Taking their

1198 recent distribution as well as the fossil record into account, a split of the European and Asian

1199 Bombina clades seems most probable in Asia during the Paleogene.

1200

1201 Pelobatidae

1202 The family of European spadefoot toads Pelobatidae includes only one extant genus with four

1203 species distributed in north-western Africa, Europe, in small areas that are east of the Ural

1204 Mountains in Russia and in the north of Kazakhstan (Kuzmin, 1995). The family has Laurasian

1205 affinities and records are known from the Late Cretaceous in North America. The presence of

1206 pelobatids in Europe dates back to the Early Eocene, as indicated by the fossil genus

1207 Eopelobates (Middle Eocene - late Pliocene), as well as by the fossil forms of the Recent genus

1208 Pelobates (Middle Oligocene - Recent) (Roček et al., 2014). The Asian record of Pelobatidae is

1209 very limited and includes forms from the Eo-Oligocene of Kazakhstan (Chkhikvadze, 1985) and

1210 Eocene of India (Folie et al., 2013). Recently, Roček et al. (2014) excluded the genus Uldzinia

1211 (Oligocene, Mongolia) (Gubin, 1995) from the family Pelobatidae. The Kazakhstan fossil record 
1212 of the family (Chkhikvadze, 1985, 1998) includes numerous remains of Pelobatidae indet. from:

1213 (1) the localities of the Zaisan Basin from the Upper Aksyr Svita ${ }^{3}$, early Priabonian; rare finds in

1214 the Kusto Svita and basal horizon of Buran Svita ${ }^{4}$, late Priabonian and earliest Rupelian;

1215 abundant occurrences in the Buran Svita ${ }^{5}$, early Rupelian and (2) large-sized spadefoot toads

1216 from the Kyzyl-Kak locality of the Turgay Basin, Central Kazakhstan, Late Oligocene

1217 (Chkhikvadze, 1998). Revision of this rich pelobatid record from the Zaisan Basin was not

1218 possible due to the lack of descriptions and illustrations of the material as well as the difficulty

1219 in accessing the specimens. Nevertheless, taking the Paleogene fossil records into account, we

1220 inferred that the spadefoot toads may have dispersed from Europe to Western Asia during the

1221 Late Eocene to Early Oligocene. It cannot be ascertained if the Pelobates sp. from the Selety $1 \mathrm{~A}$

1222 (early Messinian, Miocene) is a European or Asian migrant.

1223

1224 Hylidae

1225 The family of tree frogs, Hylidae, has a wide distribution in Eurasia and is represented by the

1226 monophyletic genus Hyla. The most recent phylogenetic study of the genus Hyla by Li et al.

1227 (2015) recognised two closely related clades in Eurasia, namely the West Palaearctic arborea-

1228 group and East Palaearctic chinensis-group, as well as a small East Palaearctic japonica-group

1229 that is related to the North American clade of Hyla. The revision of the Western Eurasian Hyla

\footnotetext{
${ }^{3}$ localities: Zertsalo [Sunduk Section], lager Biryukova [Kiin-Kerish Section], lower faunistic level of Plesh [KustoKyzylkain Section], probably also Tabtym [Sarykamysh Section]

${ }^{4}$ localities: main level of Plesh, Tuzkabak, Cherepakhovoe Pole [Tayzhuzgen Section], Raskop [Aksyr Section], Tyubiteika, sopki 'Rybnaya' and Kontrolnaya [Juvan-Kara Section]

${ }^{5}$ localities: Maylibay, Tologay [Tayzhuzgen Section], Podorozhnik [Jaman-Kara Section]
} 
1230 phylogeny, based on molecular genetic studies, revealed a high diversity in the area containing

1231 about eight (?nine) (Li et al., 2015) or ten (Gvoždík et al., 2010) species. Among them are two

1232 clades: (1) H. savignyi in the east (Levant and the area of Turkey, Iran, Armenia, Georgia) and (2)

1233 H. arborea (Western, Central Europe and Balkan) + H. orientalis (South-eastern Europe,

1234 Georgia, Armenia, Iran), which have wide distributions in the east and west respectively (Stöck

1235 et al., 2008a; Gvoždík et al., 2010).

1236 The oldest European record of the genus is known from the Oberdorf O4 locality, late Early

1237 Miocene, Austria (Sanchíz, 1998b). After an interruption/gap of approximately three million

1238 years, records of the genus continued in the late Langhian with the first fossil appearance of the

1239 Recent species H. arborea (H. cf. arborea, Mátraszőlős 2, Hungary) (Venczel, 2004). The record

1240 is almost consistent in the entire Neogene and Quaternary periods of Europe (Fig. 9). There is

1241 quite an abundant record of the genus with the oldest and first occurrences of $H$. savignyi $(H$.

1242 cf. savignyi) derived from five localities in Western Siberia, dating back to the late Late Miocene

1243 and early Early Pliocene. Apart from the distribution in Siberia, H. savignyi also may occur in

1244 southern Russia, in the Middle Pleistocene (Ratnikov, 2002)(see 'Comparison and Discussion' in

1245 Hyla gr. H. savignyi), representing the youngest fossil record of the species.

1246 Based on the fossil record of the tree frogs, we concluded that two large Western Eurasian

1247 clades split in Europe during the Middle Miocene. Our data indicated older ages for the first

1248 fossil occurrences of these clades than has been previously estimated from molecular data in

1249 two recent studies (Gvoždík et al., 2010; Li et al., 2015). Gvoždík et al. (2010)6 suggested that

\footnotetext{
${ }^{6}$ The divergence dates of split events were estimated by a relaxed molecular clock approach, based on the mitochondrial data set, where the calibration with fossil record is missing.
} 
1250 the split of $H$. orientalis/arborea and $H$. savignyi occurred 11.1 Ma (early Late Miocene, early

1251 Tortonian), which is approximately three million years younger than the first fossil occurrence

1252 of $H$. cf. arborea (Table S5). Whereas, without calibrating the molecular clock using the oldest

1253 European fossil Hyla (Hyla sp., Oberdorf O4 locality in Austria), Li et al. (2015) estimated this

1254 split to have occurred at 12-20 Ma, during a time interval in which the oldest fossil tree frogs

1255 related to the Recent $H$. arborea occurred. In both of the cases, the interpretation of the

1256 molecular phylogeny of the group can be improved by calibrating the phylogenetic tree with

1257 the fossil record introduced in this study.

1258 Considering our data and the results presented by Li et al. (2015), we suggest the following

1259 distribution pattern for the West Palaearctic H. arborea-group: (1) the group entered Eurasia

1260 from the east via Beringia from North America, during the Paleogene; and (2) the ancestors of

1261 the group reached Europe during the early Miocene via the Tugai Strait between Europe and

1262 Asia (the Turgai Strait) and diversified, apparently, in Western Siberian. The Late Miocene and

1263 Early Pliocene records represent the most eastern expansion of the European genera, when the

1264 climatic conditions were still favourable for their distribution; it is conceivable for us that the $H$.

1265 savignyi may have potentially so far not found fossil occurrences in the Miocene of Eastern

1266 Europe and/or from the Caucasus in the south.

1267

1268 Bufonidae

1269 Two groups of toads were found in the studied localities in Western Siberian; namely the

1270 common (Bufo bufo) and the green toads (Bufotes cf. viridis) (Fig. 7F-7K, Table S1). The toads of 
1271 both groups are, with their occurrences are the most abundant among frogs remains found at

1272 the fossil localities.

1273 Common toads. Bufo bufo is the Recent species with the widest distribution (i.e. Central,

1274 Southern, Eastern Europe and Western and Eastern Asia) of all members of the common toads

1275 Bufo bufo species group. This group includes three other species with limited distribution,

1276 namely: Bufo spinosus (northern Africa, Western Europe), Bufo eichwaldi (south coast of the

1277 Caspian Sea), and Bufo verrucosissimus (east of the Black Sea) (Arntzen et al., 2013). These

1278 species are known also as the western group of the genus. Their nearby Eastern Asian relatives

1279 - the eastern group, include the Bufo gargarizans species group. The Western Siberian fossil

1280 record of the Bufo bufo species group is restricted to the late Late Miocene to the early Early

1281 Pliocene, which in comparison to the European record, is very poorly represented. The oldest

1282 toad remains that are assigned to the Bufo bufo species group are from the Middle Miocene of

1283 Slovakia: B. bufo from the Devinská Nová Ves - Zapfe's fissure locality, 13.7-14 Ma (Hodrova,

1284 1980; Böhme, 2003) and B. cf. bufo from the Devinská Nová Ves - Bonanza locality, 13.5-13.7

1285 Ma (Hodrová, 1988). Then, since 9.2 Ma during the Late Miocene (Suchomasty locality in the

1286 Czech Republic) (Hodrová, 1987), B. bufo representatives are present in Central Europe and

1287 extend their distribution across Europe. At ca. 4.7 Ma, remains of the common toad, exhibiting

1288 characters of the Recent B. spinosus, appeared in Spain, in the Celadas 6 locality (Böhme \& $/ / g$,

1289 2003). The oldest fossil remains referred to $B$. verrucosissimus were recovered from the Late

1290 Pliocene (3.0-3.8 Ma) in the Apastovo locality in Russia (Ratnikov, 2001). The Western Siberian

1291 record suggests at least a late Miocene dispersal of $B$. bufo to the east, reaching the present

1292 distribution area of the species. Considering the genomic data of Recuero et al. (2012), these 
1293 'migrants' should represent the common ancestor of the B. bufo + B. verrucosissimus clade,

1294 expanding to the east into Asia and to the south into Eastern Europe. This bufonids most

1295 probably remained, permanently, in these areas, until present times. The lack of their

1296 representation in the fossil record in the Late Pliocene and Quaternary sites can be explained

1297 by sampling bias. Although B. bufo and B. verrucosissimus do not occur sympatrically nowadays,

1298 specimens of both these species have been found together in two Middle Pleistocene localities

1299 (Koziy Ovrag and Yablonovets from Russia; see more in Table S5).

1300 Two recent molecular studies (Garcia-Porta et al., 2012; Recuero et al., 2012; pp. 71-86)

1301 suggested models of palaeobiogeographic history and timing of major cladogenetic events in

1302 the B. bufo species group; e.g. the origin in South-western Asia and subsequent migration into

1303 Europe via Anatolia. These studies, however, did not consider the entire fossil record, including

1304 the oldest record of the groups from the Middle Miocene of Slovakia (Hodrova, 1980) nor those

1305 of the species group in both their calibration of the molecular clock and palaeogeographic

1306 considerations. The updating and improvement of the distribution models are, therefore,

1307 necessary. Moreover, further finds of the fossil forms of south-eastern species B. eichwaldi will

1308 help to reveal the place of origin and distribution routes of the ancestors of the group. Although

1309 only the molecular clock, and not the entire fossil record of the group has been used for the

1310 calibration, results from mtDNA sequencing seem to provide reliable data on diversification

1311 rates within the $B$. bufo species group, which can be confirmed by first appearances of the

1312 fossils related to each Recent species.

1313 Green toads. The range of the widely distributed Bufotes viridis species group (or Bufotes viridis

1314 sensu lato) extends across Central Europe to Central Asia, as well as the entire northern Africa 
1315 and Mediterranean area, including numerous islands. The species complex is highly diverse and

1316 includes over ten recognised species, e.g. Bufotes balearicus (southern Mediterranean and

1317 Apennine Peninsula, Corsica, Sardinia, Balearic Islands), Bufotes boulengeri (northern Africa),

1318 Bufotes siculus (Sicily), B. viridis (Central and Eastern Europe), Bufotes variabilis (Balkans,

1319 Anatolia, Caucasus) etc., found in a diverse range of environments (Stöck et al., 2006; Stöck et

1320 al., 2008b). Among them, however, no valuable osteological characters has been established for

1321 taxonomic identification (Blain, Gibert \& Ferràndez-Cañadell, 2010). Hence, no precise specific

1322 assignment of any fossil material is possible. Blain, Gibert \& Ferràndez-Cañadell (2010) recently

1323 showedthat the green toads were also present in the Iberian Peninsula in the Early Pleistocene,

1324 1.1-1.3 Ma, and suggested that they became extinct due to climatic changes and/or

1325 competition.

1326 In the studied Western Siberian localities, fossil remains that are related to $B$. viridis are the

1327 most frequently occurring element in the Western Siberian herpetofauna. This species is almost

1328 permanently present from the Middle Miocene to Early Pleistocene. Specimens are found in

1329 the late Middle Miocene localities, and although there are gaps in the record, remains are

1330 present in the late Late Miocene to Early Pleistocene localities (Table S1). In the youngest

1331 localities (Olkhovka 1A, Lebiazhie 1A, Lebiazhie 1B), they are found as a sole taxon. Further

1332 fossils assigned to the family Bufonidae (Bufonidae indet.) were already reported from the

1333 Kentyubek locality in the Turgay Basin, from the Middle Miocene (Bendukidze \& Chkhikvadze,

1334 1976), and from two localities in the Zaisan Basin: the Zmei Gorynych locality in Akzhar Svita,

1335 from the Early Miocene (Chkhikvadze, 1985) and from the early Rupelian age fossil sites (see

1336 section 'Pelobatidae') of the Buran Svita (Chkhikvadze, 1998). Malakhov (2005) described the 
1337 stratigraphically oldest green toad fossil, $B$. aff. viridis, from the early Early Miocene (20.4-22.5

1338 Ma, Aquitanian) locality of Ayakoz in North-eastern Kazakhstan (Fig. 1, Table S1). B. aff. viridis

1339 from the Ayakoz locality is older than the $B$. aff. viridis from the Early Miocene Keseköy locality

1340 (18-20 Ma) in north-western Turkey (Claessens, Leon P. A. M., 1997). All the occurrences of the

1341 oldest European fossils of green toads are from the Early Miocene: Vieux-Collonges locality in

1342 France (14-17 Ma), (Bailon \& Hossini, 1990); Petersbuch 2 and 7 (17.5-18 Ma) localities in

1343 Germany (Böhme \& Ilg, 2003); and probably the Córcoles locality (17-18 Ma) in Spain (Sanchíz,

1344 1998a). Once the green toads entered Europe, they became a regular element of the European

1345 Neogene and Quaternary herpetofaunal assemblages (Fig. 9). Besides B. aff. viridis, the

1346 European record of green toads includes another species, Bufotes priscus, from four localities of

1347 the latest Early Miocene to the earliest Late Miocene age (see Table S5). Taking into account

1348 the B. viridis Neogene records and the bufonid records from the Eurasian Paleogene, we

1349 suggest that the group arrived in the Old World in the Paleocene (Rage, 2003), entered Central

1350 Asia in the Early Oligocene and diversified there. Although we were not able to study the

1351 Paleogene bufonid record from Kazakhstan, taking into consideration the palaeogeography of

1352 common and green frogs, the assignment of the Early Oligocene Kazakhstan record to the green

1353 toad seems most probable. Apparently, the Early Oligocene forms were ancestral to the $B$.

1354 viridis lineage, which evolved in Central Asia in the Early Miocene. This assumption is also

1355 supported by molecular data suggesting that: (1) the green toad clade underwent

1356 diversification in Asia during the Oligocene/early Miocene; and (2) a high genomic and specific

1357 diversity is found within the Central Asian green toads (Stöck et al., 2006). Present in the

1358 Central Asian fossil record from the Early Miocene; they consequently dispersed via Anatolia in 
1359 the early Burdigalian into Europe during the middle Burdigalian. Apparently, the European

1360 Neogene record should not necessarily represent one 'lineage' or one dispersal event of the $B$.

1361 viridis group from Asia. Several migration events most probably took place during the Miocene.

1362 The descendants of these events were replaced later by the ancestors of the Recent species $B$.

1363 viridis, B. variabilis, etc. as indicated by the genetic data at the Mio-Pliocene transition (Stöck et

1364 al., 2006). Prospective further studies could include: (1) the verification of dispersal events in

1365 the European fossil record, with help of an abundant and species-rich fossil material from

1366 stratigraphically well-dated localities; (2) the exploration the Miocene record of Anatolian and

1367 South-eastern Europe, as well as the Paleogene record of Asia; and (3) a challenging project of

1368 establishing the osteological characters that are important for the systematic identification of

1369 the members of the $B$. viridis species group.

1370

1371 Ranidae

1372 The family of true frogs, Ranidae, are present in the Western Siberian record by both green

1373 (Pelophylax sp.) and brown (Rana sp.) frogs. The green frogs appear more frequently in the

1374 record than the brown frogs. Both frog genera are common amphibians in the Recent

1375 herpetofauna of the area. Besides this record, further true frog finds (e.g. Ranidae indet.) are

1376 reported from the early Rupelian age fossil sites (see the list of the locality section

1377 'Pelobatidae') of the Buran Svita, Zaisan Basin. We were not able to revise their taxonomic

1378 validity due to lack of figured fossils and the inaccessibility of the material.

1379 Green frogs. The genus Rana includes 21 Recent species of aquatic frogs having a wide

1380 distribution ranging from northern Africa, Europe to Eastern Asia. Two genetically distinct 
1381 clades, i.e. Western Palaearctic and the Far East, are recognised within the green frogs genus

1382 Pelophylax (Lymberakis et al., 2007). The oldest green frog record from the Western Siberian

1383 (Pelophylax sp.) is dated back to the late Middle Miocene, coinciding stratigraphically with the

1384 Eastern Siberian record of the group (Middle Miocene, ca. 13 Ma, Tagay Section, Baikal Lake,

1385 Russia) (Daxner-Höck et al., 2013). Records of this group are present in the studied localities

1386 until the late Early Pliocene with long (during the Late Miocene) and short (during the Early

1387 Pliocene) gaps in the fossil record. Due to the fragmentary preservation of the studied bones as

1388 well as the lack of other informative elements of the skeleton (e.g. frontoparietals), any

1389 assignment to the Recent green frog species was impossible. Considering the present

1390 distribution of the two green frog clades, an affiliation of the Western Siberian fossil record to

1391 the Western Palaearctic clade is most probable.

1392 Despite the being only a few green frog records described in this study, these records still

1393 significantly expand the previously scarce and poorly known fossil history of the genus.

1394 Moreover, both of the Middle Miocene records from Western and Eastern Siberia represent the

1395 oldest records of the green frogs in the Asian continent. Although an Asiatic origin of the green

1396 frogs has been already assumed by several authors e.g. Sanchíz, Schleich \& Esteban (1993),

1397 Lymberakis et al. (2007), the earliest frog remains have been assigned to the Pelophylax

1398 ridibundus species group, which occurred in Europe in the early Oligocene (Möhren 13 locality,

1399 Germany) (Sanchíz, Schleich \& Esteban, 1993). Its affiliation to a living species is impossible. In

1400 Europe, the fossil record of Pelophylax is continuous and is maintained through the Oligocene

1401 and entire Neogene (Table S5). Nevertheless, a well-documented Paleogene record of the

1402 group is not available from Asia and, therefore, any interpretations would not be confident. The 
1403 only possible scenario, taking into account both the fossil record and genomic data, is that the

1404 Western Palaearctic green frogs split from their Far East sister clade during the Eocene; they

1405 diversified in the territory of Europe and/or Western Asia during the Oligocene; they dispersed

1406 back to the East in the middle Miocene; and eventually reached the territory of the Western

1407 Siberia.

1408 Brown frogs. The genus Rana (subgenus Rana sensu Veith, Kosuch \& Vences, (2003) is

1409 comprised of more than 15 species that are distributed throughout Eurasia. Similar to green

1410 frogs, there are two known lineages from the brown frog species, namely: the Western and the

1411 Eastern Palaearctic lineages (Veith, Kosuch \& Vences, 2003). Based on the osteological

1412 characters, the studied Western Siberian brown frog remains show a relation to the Western

1413 Asiatic lineage of the genus Rana, more precisely to the Rana temporaria species group (sensu

1414 Veith, Kosuch \& Vences, 2003). Among the late Paleogene and Early Miocene fossil frogs

1415 (Böhme \& Ilg, 2003), in which the generic identification is unclear (Rana vel Pelophylax), only

1416 the frog remains from the Early Miocene in Dietrichsberg, Germany (Böhme, 2001) have

1417 definitely been assigned to the brown frog $R$. cf. temporaria, representing the oldest known

1418 record of the group so far. As already suggested by Böhme (2001), brown frogs migrated from

1419 their possible centre of origin in Western or Central Asia to Europe during the second half of

1420 the Early Miocene. This hypothesis is confirmed by the brown frog fossils from the Ayakoz

1421 locality in Kazakhstan, which dates back to the Aquitanian age and are stratigraphically older

1422 than the Dietrichsberg fossil frogs. The present-day biogeography and diversity of brown frogs,

1423 the presence of a distinct Eastern Palaearctic lineage in Eastern Asia as well as the Asian

1424 distribution of many European species provide further support for an Asiatic origin. Most likely, 
1425 the dispersal route of the brown frogs was similar to that of the green toad (Bufotes cf. viridis)

1426 whereby dispersal into Europe occured via Anatolia, during the Early Miocene.

1427 It is interesting to note that the earliest brown frog from the studied Western Siberian localities

1428 (Malyi Kalkaman 2) shows osteological similarities with the Recent species R. temporaria,

1429 representing herewith the oldest fossil record of the species in the east.

1430 Previous molecular studies (Veith, Kosuch \& Vences, 2003; Lymberakis et al., 2007), on both

1431 green and brown frogs, aimed to reconstruct their phylogenetic relationships, suggest models

1432 of biogeographic history as well as suggest when the splits between different genera, clades,

1433 species, etc. occurred. Such studies have provided contradictory results also for this group, e.g.

1434 the split of Rana and Pelophylax was at 9.32 Ma (Veith, Kosuch \& Vences, 2003), whereas

1435 Lymberakis et al. (2007) estimated the split of the Western Palaearctic and Far East lineages of

1436 Pelophylax to have occurred significantly earlier, i.e. 15 Ma before. Here neither geologic

1437 events nor the fossil records have been used consistently for the calibration of the molecular

1438 clock. Thus, the recalibrating of the timing for the splits with the new fossil finds provides a

1439 more reliable basis for phylogenetic reconstructions.

1440 For the better understanding of relationships between these groups, as well as to reveal more

1441 around the origin and palaeobiogeographic history of them, it would be interesting to review

1442 the specimens of the Paleocene frogs (Ranidae indet.) from the early Rupelian fossil sites (see

1443 section 'Pelobatidae') of the Buran Svita in the Zaisan Basin (Chkhikvadze, 1998). The

1444 incorporation of such a review, however, was not possible in the present study, due to the lack

1445 of figures of the fossils and the inaccessibility of the material. 


\section{Gekkonidae}

1448 The family Gekkonidae is represented in the Western Siberian fossil record by the straight-

1449 fingered or even-fingered geckos, genus Alsophylax. They occur only in the Cherlak locality,

1450 dated back to the terminal Miocene, ca. 5.9 Ma. Alsophylax sp. is the most abundant element in

1451 the herpetofaunal assemblage of the Cherlak locality, with approximately $70 \%$ of the

1452 identifiable bone material belonging to this taxon. The genus Alsophylax is mainly distributed in

1453 Central Asia, partly occurring also in Mongolia and China. These geckos prefer habitats in arid

1454 and warm landscapes (Ananjeva et al., 2006). The appearance of these dry and warm adapted

1455 geckos in Western Siberia, which is four degrees north of their present occurrence, suggests a

1456 shift of the arid environment from the south to the north at the end of the Late Miocene (see

1457 below). It is interesting to note that out of the seven gecko genera, e.g. Eublephareus,

1458 Mediadactylus, Terratoscincus (Ananjeva et al., 2006) inhabiting Central Asia, only Alsophylax,

1459 which has the most northern distribution, occurs in the fossil record. Apparently, this genus is

1460 ecologically more adaptable in comparison to other genera, not only in the present, but

1461 probably also in the past.

1462

1463 Lacertidae

1464 Lacertid remains are the most frequent fossil bones among those of lizards occurring in

1465 Western Siberian localities. They are very rare in the Middle Miocene faunas, but occur more

1466 frequently in the Late Miocene, Pliocene, and Pleistocene localities. In the middle Late Miocene

1467 locality Pavlodar 1A (ca. 7.25 Ma), two taxa (Lacerta s.I. sp. 1 and sp. 2) occur sympatrically.

1468 Eremias sp. appears in the Western Siberian record in the Pliocene. This genus is widely 
1469 distributed in the Central Asian steppes, inhabiting dry and warm habitats (Ananjeva et al., 1470 2006).

1471

\section{Emydidae}

1473 Emydoidea sp. is the only turtle identified from the studied fossil sites. The present-day

1474 distribution of the monotypic genus Emydoidea is restricted to the water bodies of the north-

1475 eastern territory of the USA. In Eurasia, fossil forms of this aquatic genus appear in the fossil

1476 record in Central Kazakhstan since the Middle Miocene (Emydoidea tasbaka, the Kentyubek

1477 locality in the Turgay Basin) (Chkhikvadze, 1989). Fossil forms have also been reported in

1478 Eastern Europe from the Late Miocene (Emydoidea tarashchuki, Krivoy Rog locality in Ukraine

1479 and Pantishara (8.7-9.2 Ma) in Georgia) (Chkhikvadze, 1980);(Chkhikvadze, 2003). The Siberian

1480 record indicates their occurrence in Asia also during the Late Miocene, which, interestingly, is

1481 located much further north than their Middle Miocene record from Kazakhstan. According to

1482 Chkhikvadze (2003), representatives may have also been present in Eastern Europe during the

1483 Pliocene. We avoid interpreting palaeobiogeography, stratigraphic distribution, etc. of this

1484 genus, since the available published material (e.g. Chkhikvadze, 1983, 1989), together with

1485 other extinct testudinoid taxa from Kazakhstan and Eastern Europe, is insufficiently described

1486 and poorly illustrated, requiring thorough revision. Nevertheless, we used the available

1487 published data on both freshwater turtles and terrestrial tortoises to attempt to interpret the

1488 record at the family level (Table 2). The turtle records from three well-explored regions in the

1489 studying area, i.e. Zaisan Basin, Turgay Basins and Western Siberia, are summarised in the Table

14902 . Throughout the entire Early Miocene in the Zaisan Basin, the turtle fauna is dominated by 
1491 aquatic forms, i.e. out of eight taxa only two are tortoises (Protestudo spp.). The aquatic forms

1492 remained dominant in the Zaisan Basin during the Middle Miocene, the terrestrial family

1493 Testudinidae completely replaced the aquatic turtles (Emydidae, Triochynidae) in the end of the

1494 Middle Miocene and became the only family present in the younger deposits of the Late

1495 Miocene. Similar to the Zaisan Basin, the aquatic forms represent the Middle Miocene turtle

1496 fauna in two adjacent regions, the Turgay Basin in the west and Western Siberia in the north.

1497 Subsequently, in the beginning of the early Late Miocene, a testudinid appears in Western

1498 Siberia and is replaced by an emydid towards the end of the late Late Miocene and a chelydrid

1499 at the Mio-Pliocene transition. The absence of tortoises since the end of the Late Miocene in

1500 Western Siberia and the Plio-Pleistocene in the Zaisan Basin can be explained by a less

1501 favourable, probably colder (MAT $<15^{\circ} \mathrm{C}$, cold month temperature $\mathrm{CMT}<8^{\circ} \mathrm{C}$ ) climate. Since the

1502 late Late Miocene, the emydid and chelydrid aquatic turtles are the only chelonids in Western

1503 Siberia. The presence of these chelonids not only indicate a humid environment with standing

1504 water-bodies but most probably also a cooler climate (for emydids: MAT> $8^{\circ} \mathrm{C}, \mathrm{CM}>-1.4^{\circ} \mathrm{C}$ ),

1505 since, in general, aquatic turtles can tolerate much colder conditions than tortoises, in that an

1506 aquatic environment acts as thermal buffer, consequently enabling aquatic turtles to populate

1507 higher poleward latitudes.

1508

1509 Palaeobiogeographic considerations

1510 By comparing the spatial and temporal patterns between European and Asian fossil records,

1511 including the first and last fossil occurrences, combined with an analysis of the available 
1512 genomic data of the recent relatives of the fossil groups present in the studied material, certain

1513 palaeogeographic distribution patterns can be revealed along with new interpretations.

1514 Our analysis suggests a Western Asiatic origin for Hynobiidae, Proteidae, aff. Tylototriton,

1515 Bufotes viridis species group and brown frogs, Rana. The green toads and brown frogs

1516 dispersed coincidentally in the earliest Miocene wherein, and at least for the Bufotes viridis

1517 group, Anatolia was involved. Anatolia also played an important role in the distribution of the

1518 Bufo bufo species group; however, any age estimation of the event is not available. A

1519 salamander, showing affinities to the clade of the Recent East Asian genera Tylototriton +

1520 Echinotriton, is present in Western Siberia, most probably representing the forms similar to that

1521 of the early Oligocene (aff. Tylototriton) in Europe, a sister group of the recent clade. In order to

1522 resolve the affiliations of these fossils, further Paleogene material from both the Asia and

1523 European continents are necessary.

1524 An eastward dispersal from Europe into Western Asia can be observed over a period ranging

1525 from the Middle to Late Miocene, based on the current data available from both European and

1526 Asiatic records, for at least seven amphibian groups (family Palaeobatrachidae, genera

1527 Chelotriton, Pelobates, Bombina (i.e. Bombina (cf.) bombina), Hyla (i.e. Hyla cf. savignyi),

1528 Pelophylax ?, Bufo bufo species group). Besides the amphibians, some Western Siberian

1529 reptiles, such as the glass lizards and snakes from the Middle Miocene, show European

1530 affinities, resembling the Central European faunas (Vasilyan, Böhme \& Klembara, 2016).

1531 The amphibian genera Bombina, Hyla, Bufo, Rana, and Pelophylax resemble a comparable

1532 palaeobiogeographic pattern: the molecular genetic data showed the presence of two clearly

1533 separable western and eastern clades (species groups) in each of these genera. In all cases, it 
1534 was possible to morphologically attribute the Western Siberian fossil amphibians to the

1535 western clades or species of the clades. It is interesting to note that even though the first fossil

1536 occurrences of these genera have different stratigraphic ages, they are found exclusively in

1537 Europe (see Fig. 9, Table S5). To explain this common pattern, we hypothesise that the western

1538 and eastern clades had already split in the Paleogene, most probably in the western or central

1539 parts of Asia, and subsequently dispersed into Europe.

1540 The Western Siberian fossil Mioproteus, Chelotriton, Bombina, Paleobatidae, Hyla, Bufo bufo

1541 and Rana temporaria represent the most eastern records of those groups found in the Eurasian

1542 fossil record. In comparison to their present-day geography, the Western Eurasian species of

1543 the genera Bombina and Hyla, respectively, show wider distribution ranges during the Middle

1544 to Late Miocene, and Late Miocene to Early Pliocene. The palaeogeographic affinity of the

1545 earliest Messinian pelobatid (locality Selety $1 \mathrm{~A}$ ) is still unclear. Considering the geographic

1546 location of the fossil site, its relation to the Recent genus Pelobates seems most possible.

1547 In Chkhikvadze (1985), two lizards Varanus sp. and Agamidae indet. have been reported from

1548 three Miocene localities of the Zaisan Basin. Although the taxonomic assignment of the remains

1549 could not be verified in this study, we adopt the identifications for biogeographic and

1550 palaeoenvironmental interpretations. These lizards are currently widely distributed in Central

1551 Asia. Varanus, being a thermophilous reptile species, is restricted to the southern part of the

1552 region. Its presence in the early Late Miocene of the Zaisan Basin aids in characterisation of the

1553 climate of the Sarybulak Svita, in the beginning of the late Miocene, i.e. a probable mean

1554 annual temperature of not less than $14.8^{\circ} \mathrm{C}$ (Böhme, 2003). 
1555 In summary, Western Siberia (Central Asia) can be hypothesised as a centre of evolution and

1556 dispersal for several temperate Neogene herpetofaunal taxa, e.g. the genera Salamandrella and

1557 Mioproteus, the green toad Bufotes viridis species group and brown frog Rana. The Neogene

1558 herpetofauna of Western Siberia and the adjacent areas has significant similarities with the

1559 European amphibian and reptile assemblages. The Western Palaearctic herpetofauna gradually

1560 entered the Siberian territory from Europe, between the Middle Miocene to Early Pliocene,

1561 strongly shaping the herpetofauna of Western Siberia and partially retaining the faunal

1562 elements of an Asiatic origin (e.g. Hynobiidae, Proteidae, and Alsophylax). The faunal diversity

1563 of the fossil record collapses significantly after the Early Pliocene. Only a few amphibians and

1564 reptiles, e.g. Salamandrella, Bufotes, Lacerta, and Vipera are present in the Pliocene fossil

1565 record, being able to survive in the increasingly less favourable environments to form the main

1566 part of the present-day Western Siberian herpetofauna.

1567 The palaeobiogeographic analysis of the recent amphibian faunas of Western Asia (Savage;

1568 Garcia-Porta et al., 2012) hypothesised a progressive aridification of Central Asia linked with

1569 the global cooling trends during the Miocene, forcing amphibians to shift their distribution to

1570 the south.

1571

1572 Palaeoclimatic implications

1573 The Neogene climate evolution of Western Siberia has been previously reconstructed based on

1574 palynofloras, showing a progressive change in environmental conditions, i.e. in the climate and

1575 vegetation, during the Miocene (Arkhipov et al., 2005). Between the Early to Late Miocene, a

1576 warm and humid climate was replaced by a warm temperate climate in the Middle Miocene 
1577 and a boreal-warm temperate climate in the Late Miocene. Towards the end of the Miocene, a

1578 drastic climatic shift took place resulting in semiarid and arid conditions. The Pliocene climate is

1579 predominated by frequent changes between semiarid forest-steppe/steppe and arid desert

1580 environments, however, from the Late Pliocene the environment changes into subarctic

1581 (Arkhipov et al., 2005; fig. 46, p. 76).

1582 At a lower temporal resolution, the testudinoid fossil records from the Zaisan Basin, the Turgay

1583 Basin, and Western Siberia confirm a general trend towards aridity in the Neogene (Data S4).

1584 Based on the environmental requirement (aquatic or terrestrial) of the testudinoids from the

1585 Zaisan Basin, we infer that the climate changed from humid to dry. We further infer that the

1586 Early and Middle Miocene was mostly humid (dominance of aquatic families), whereas the

1587 presence of exclusively terrestrial forms (tortoises) from the latest Middle Miocene to Late

1588 Miocene indicates dry and open habitats in the Zaisan Basin. Unfortunately, it is impossible to

1589 make any quantification of the palaeoprecipitation values based on these limited taxa and well-

1590 documented herpetofaunal assemblages are necessary from these deposits for further

1591 environmental reconstructions.

1592 To establish a better palaeoclimatic understanding, we estimated palaeoprecipitation values for

159312 data points (Table S4). These localities provided six and more amphibian and reptile taxa,

1594 applicable for the bioclimatic analysis (Böhme et al., 2006). Even so, our data do not be enable

1595 accurate reconstruction of the climate development over the Middle Miocene to earliest

1596 Pleistocene in Western Siberia. The climate development can, therefore, only be reconstructed

1597 and discussed for several short intervals. Nevertheless, our estimations rather show a dynamic

1598 climate development in the Neogene of Western Siberia, with larger precipitation amplitudes, 
1599 ranging from $158 \mathrm{~mm}$ to over $1500 \mathrm{~mm}$ per year (Table S1, Fig. 10), than previously estimated

1600 using palynological data (Arkhipov et al., 2005). Apart from the fluctuating humidity factor, in

1601 general, the MAP was significantly above the present day values (reaching $550 \%$ of the present-

1602 day values) (Fig. 10). Only two localities are characterised by drier climates, the late Serravallian

1603 (ca. $12.1 \mathrm{Ma}$ ) and the late Messinian (5.9 Ma), exhibiting either present-day or below present-

1604 day levels.

1605

1606 Reliability of precipitation estimates

1607 The accuracy of precipitation estimates, based on bioclimatic analysis of herpetofauna,

1608 depends primarily on the taxon counts and the assumption of low (stochastic) taphonomic bias

1609 (Böhme et al., 2006). In Western Siberia, some of the documented localities were rich in aquatic

1610 herpetofauna, e.g. composed by freshwater turtles, giant salamanders, proteids, etc. , but small

1611 terrestrial forms (e.g. lizards and anguids) were absent, indicating a possible non-stochastic

1612 taphonomic bias (i.e. exclusion of elements of certain habitats). These localities will result in a

1613 bias in humidity estimates toward the wet end. Examples of such localities include Kentyubek

1614 and Novaya Stanitsa 1A, where the numeric results well exceed the MAP of $1600 \mathrm{~mm}$, the

1615 upper limit to which the eco-physiologic index - humidity relation is calibrated (see details in

1616 Böhme et al., 2006). In these cases, we restrict our estimates to a limit of $1500 \mathrm{~mm}$.

\section{Aquitanian}

1618 For the Aquitanian age Ayakoz locality, we estimated a MAP value of $945 \mathrm{~mm}$, representing

1619 more than three times higher rainfall in comparison to the recent times. Using the palynologic

1620 data, Arkhipov et al. (2005) estimated a humid climate with MAP $800 \mathrm{~mm}$ for the Abrosimov 
1621 Svita (Aquitanian age) in Western Siberia. Besides this study and based on the data of fossil

1622 macroflora, Bruch \& Zhilin (2007) estimated similar values of precipitation (935 to $1232 \mathrm{~mm}$ )

1623 for about 30 Aquitanian age localities, distributed from Western to Eastern Kazakhstan. Our

1624 reconstruction, therefore, appears to fit well within the historical precipitation estimates of the

1625 region.

1626 Akzhar Svita

1627 Towards the end of the late Early Miocene (Burdigalian), an elevated humidity in Western

1628 Siberia can be suggested based on the presence of the giant salamander in three localities of

1629 the Zaisan Basin (Tri Bogatyrya, Vympel, and Poltinik). As already suggested, their occurrence

1630 indicates a high rainfall for those time periods (MAP $>900 \mathrm{~mm}$ ), as well as an increased basinal

1631 relief enabling the distribution and reproduction of this group in the lowland settings (Böhme,

1632 Vasilyan \& Winklhofer, 2012). This period of the Akzhar Svita also corresponds to the folding

1633 and uplift of the Altai Mountains (Zykin, 2012; p. 394), from which the establishment of the

1634 higher basinal relief was possible.

\section{Late Serravallian}

1636 In contrast to the already known climate development suggested by Arkhipov et al. (2005), our

1637 data suggest that there were strong humidity fluctuations during the late Middle Miocene (late

1638 Serravallian), with MAP values ranging between 282, 884 and $1108 \mathrm{~mm}$ (Fig. 10). The only 1639 botanical data of this time (Bescheul macroflora) point to a warm-temperate and humid (MAP

$1640 \sim 700 \mathrm{~mm}$ ) climate (Arkhipov et al., 2005), which best compares to our Malyi Kalkaman 2 results

1641 (MAP $884 \mathrm{~mm}$ ).

1642 Novastanitsa Svita 
1643 Although the herpetofaunal assemblage for the early Messinian locality Novaya Stanitsa $1 \mathrm{~A}$ is

1644 incomplete, a very high MAP value of at least $1500 \mathrm{~mm}$ can be estimated. The value indicates a

1645 significantly higher humidity than of Tortonian-Messinian boundary and late Messinian (see

1646 below). Our data are contrary to the palynologic results, which gave lower estimates (400-450

1647 mm; Arkhipov et al. 2005).

1648 Rytov Svita

1649 The Cherlak locality (5.9 Ma, Rytov Suite) is characterised by a rather dry climate (MAP 255

$1650 \mathrm{~mm}$ ), with a similar humidity level to that of the present-day (Fig. 10). Our data for a warm and

1651 dry climate are confirmed by the presence of: (1) gekkonid Alsophylax; (2) mollusc fauna

1652 containing thermophilous species; (3) the small mammal fauna, represented mainly by pikas,

1653 hamsters and jerboas, characteristic for open and dry habitats (Zykin, 2012); and (4) ostriches

1654 (Struthiolithus sp.) and camels (Paracamelus sp.) in this svita (Shpanskiy, 2008). Arkhipov et al.

1655 (2005) summarised the available palynological and vegetation data of the svita and reported

1656 the presence of a poor (due to the oxidation) spectra containing xerophyte plants (Asteraceae,

1657 Chenopodiacea), characterising desert and steppe environments. Interestingly, his results

1658 proposed a northward shift of dry steppe and desert environments by $4^{\circ}$ (to the latitude of

$\left.165956^{\circ}\right)$, which concurs with our data, as is indicated by the presence of the steppe-dwelling

1660 gekkonid Alsophylax sp. (see the section 'Gekkonidae').

1661 Miocene-Pliocene transition (Detskaya Zhelznaja Daroga)

1662 Even though the precise taxonomic identification of the Western Siberian and Zaisan

1663 cryptobranchids, is unclear at the generic or species level, their occurrence indicates a high

1664 rainfall > 900 mm MAP (Böhme, Vasilyan \& Winklhofer, 2012) during the Burdigalian age in the 
1665 Zaisan Basin and the Miocene-Pliocene transition in Western Siberia. Besides the presence of

1666 Cryptobranchidae indet. from the locality Detskaya Zheleznaja Doroga, the co-occurrence of the

1667 aquatic chelonids Chelydropsis kuznetsovi and probable Sakya sp. (Gaiduchenko, 1984;

1668 Gaiduchenko \& Chkhikvadze, 1985) confirms the presence of a high degree of precipitation at

1669 the Miocene-Pliocene boundary in Western Siberia.

1670 Earliest Pliocene (Olkhovka 1A-1C)

1671 Our earliest Pliocene humidity data are estimated based on the fauna from the localities

1672 Olkhovka $1 \mathrm{~A}, 1 \mathrm{~B}$ and $1 \mathrm{C}$, for which no correlation data is available for regional svitas (see

1673 'Geology and Stratigraphy section'). Nevertheless, the results still indicate significant

1674 precipitation (MAP $575 \mathrm{~mm}$ ), well above the present-day values for this region. These findings

1675 correspond well with the similar aged Speranovskaya palynoflora (Volkova, 1984), which

1676 indicates the presence of warm forests and forest-steppes with MAP estimates between 500-

$1677550 \mathrm{~mm}$ (Arkhipov et al., 2005).

1678

1679 Conclusions

1680 In summary, over 50 salamander, frog, lizard, snake and turtle taxa have been assigned to

1681 specimens from more than 40 Western Siberian localities that range in age from the Middle

1682 Miocene to the Pleistocene (Table S1). The late Middle Miocene localities have the most diverse

1683 faunas including all the main groups of the herpetofauna. According to our analysis, the fossil

1684 fauna contains taxa showing an Asian (Eastern Palaearctic) origin, such as Hynobiidae,

1685 Proteidae, Bufotes viridis species group and Rana, Varanus, and Agamidae. The main part of the

1686 herpetofaunal assemblage, including Palaeobatrachidae, Paleobatidae, the genera Chelotriton, 
1687 Bombina (i.e. Bombina (cf.) bombina), Hyla (i.e. Hyla (cf.) savignyi), Pelophylax ?, Bufo bufo,

1688 Ophisaurus sp. (Vasilyan, Böhme \& Klembara, 2016), has European (Western Palaearctic)

1689 affinities. The Western Siberian records of Mioproteus, Chelotriton, Bombina, Paleobatidae,

1690 Hyla, Bufo bufo, and Rana temporaria represent the most eastern occurrences of these groups

1691 in Eurasia. The earliest Miocene dispersal of the green toad, Bufotes viridis species group into

1692 Europe from Asia via Anatolia, can be inferred. We suggest the same distribution pattern for

1693 brown frogs, Rana, too. In this scope, it will be important to perform future detailed studies on

1694 the Neogene record of the amphibian and reptile faunas in Anatolia and analyse them in a

1695 palaeobiogeographic context.

1696 According to our study, the precipitation development in Western Siberia shows high-

1697 amplitude changes during the studied intervals. Aside from the certain time periods, i.e. late

1698 Seravalian and late Messinian, the palaeorainfall in Western Siberia was estimated to be

1699 significantly higher than the present-day values. The best results on precipitation estimates that

1700 we were able to reconstruct, with reliable age constrain, were for the period from 6.6 to $\sim 4.5$

1701 Ma. These results indicate a humid climate during the early Messinian; a dry climate during the

1702 late Messinian; a very humid climate during the Miocene-Pliocene transition and a humid

1703 climate during the earliest Pliocene (Data S4, Fig. 10). The decreasing tendency of the

1704 herpetofaunal diversity towards the end of the Neogene and Quaternary could be attributed to

1705 the progressive global cooling and forced ice-sheet development in the Northern Hemisphere.

1706

1707 Acknowledgements 
1708 We sincerely thank B. Sanchiz (Madrid), Z. Roček (Prague), J. Prieto (Munich), M. Rabi

1709 (Tübingen) M. Delfino (Turin), and V. Ratnikov (Voronezh) for their constructive discussions and

1710 comments. We are grateful to V. Chkhikvadze (Tbilisi) for providing material from the localities:

1711 Pavlodar 1A, Ayakoz, Petropavlovsk 1/2, Malyi Kalkaman 1; to Dr. L. Maul (Weimar) for

1712 providing details of the ages of the Quaternary localities where palaeobatrachid frogs occur; to

1713 A. Fatz (Tübingen) for making figure and table images; to I. Stepanyan (Yerevan) for literature

1714 help; and A. Ilg (Düsseldorf) for providing support with the database 'fosFARbase'. Finally, we

1715 would like to express our gratitude to G. Piñeiro (Montevideo) for editorial comments and

1716 guiding, and both reviewers M. Venczel (Oradea) and Sh. Meiri (Tel Aviv) for their criticism and

1717 constructive reviews.

1718

\section{REFERENCES}

1720

1721

1722

1723

1724

1725

1726

1727

1728

1729

1730

1731

1732

1733

1734

1735

1736

Amphibiaweb. 2016. <http://amphibiaweb.org>: Information on amphibian biology and conservation (accessed 1 July 2016).

Ananjeva NB, Orlov NL, Khalikov RG, Darevsky I, Ryaboc SA, Barabanov AV. 2006. The Reptiles of Northern Eurasia: Taxonomic Diversity, Distribution, Conservation Status. Sofia: Pensoft.

Anderson J. 1871. Description of a new genus of newts from western Yunan. Proceedings of the Zoological Society of London 1871:423-425.

Arkhipov SA, Volkova VS, Zolnikov ID, Zykina VS, Krukover AA, Kul'kova LA. 2005. West Siberia. Geological Society of America Special Papers 382:67-88.

Arntzen JW, Recuero E, Canestrelli D, Martínez-Solano I. 2013. How complex is the Bufo bufo species group? Molecular Phylogenetics and Evolution 69 (3):1203-1208.

Audouin JV. 1827. Explication sommaire des planches de Reptiles (supplément) ... offrant un exposé des caracteres naturelles des genres, avec la distinction des especes: Description de l'Égypte, ou Recueil des Observations et des Recherches qui ont été faites en Égypte pendant l'Expedition de l'Armée Française, publie par les Ordres de sa Majesté l'Empereur Napoléon le Grand. Histoire Naturelle 1 (4):161-184.

Averianov A0, Tjutkova L. 1995. Ranodon cf. sibiricus (Amphibia, Caudata) from the Upper Pliocene of Southern Kazakhstan: The first fossil record of the family Hynobiidae.

1737 Paläontologische Zeitschrift 69 (1):257-264. 
1738 Bailon S. 1999. Différenciation ostéologique des Anoures (Amphibia, Anura) de France. Antibes:

1739

1740

1741

1742

1743

1744

1745

1746

1747

1748

1749

1750

1751

1752

1753

1754

1755

1756

1757

1758

1759

1760

1761

1762

1763

1764

1765

1766

1767

1768

1769

1770

1771

1772

1773

1774

1775

1776

1777

1778

1779 Centre de Recherches Archéologiques du CNRS.

Bailon S, Hossini S. 1990. Les plus anciens Bufonidae (Amphibia, Anura) d'Europe: les espèces du Miocène français. Annales de Paléontologie 76:121-132.

Barry JC, Morgan ME, Flynn LJ, Pilbeam D, Behrensmeyer AK, Raza SM, Khan IA, Badgley C, Hicks J, Kelley J. 2002. Faunal and environmental change in the late Miocene Siwaliks of northern Pakistan. Paleobiology 28 (sp3):1-71.

Batsch, A. J. G. K. 1796. Umriß der gesammten Naturgeschichte: ein Auszug aus den frühern Handbüchern des Verfassers für seine Vorfesungen. Jena, Leipzig: Christian Ernst Gabler.

Bendukidze OG, Bruijn H de, Van den Hoek Ostende, Lars W. 2009. A revision of Late Oligocene associations of small mammals from the Aral Formation (Kazakhstan) in the National Museum of Georgia, Tbilissi. Palaeodiversity 2:343-377.

Bendukidze OG, Chkhikvadze VM. 1976. Preliminary results of study on fossil amphibians, reptiles and birds from Turgay and Ustyurt. Bulletin of the Moscow Society of Naturalists, Geological Series 51 (5):156.

Blain H-A. 2009. Contribution de la paléoherpétofaune (Amphibia \& Squamata) à la connaissance de l'évolution du climat et du paysage du Pliocène supèrieur au Pléistocène moyen d'Espagne. Treballs del Museu de Geologia de Barcelona 16:39-170.

Blain H-A, Bailon S, Agustí J. 2007. Anurans and squamate reptiles from the latest early Pleistocene of Almenara-Casablanca-3 (Castellón, East of Spain). Systematic, climatic and environmental considerations. Geodiversitas 29 (2):269-295.

Blain H-A, Gibert L, Ferràndez-Cañadell C. 2010. First report of a green toad (Bufo viridis sensu lato) in the Early Pleistocene of Spain: Palaeobiogeographical and palaeoecological implications. Comptes Rendus Palevol 9 (8):487-497.

Blain H-A, Villa P. 2006. Amphibians and squamate reptiles from the early Upper Pleistocene of Bois Roche Cave (Charente, southwestern France). Acta zoologica cracoviensia 49A (1-2):1-32.

Böhme G. 1977. Zur Bestimmung quartärer Anuren Europas an Hand von Skelettelementen. Wissenschaftliche Zeitschrift der Humboldt-Universität zu Berlin, MathematischNaturwissenschaftliche Reihe 26 (3):283-299.

Böhme M. 1998. Archeotriton basalticus (v. Mayer, 1859) (Urodela, Salamandridae) aus dem Unteroligozän von Hammerunterwiesenthal (Freistaat Sachsen). Abhandlungen des staatlichen Museums für Mineralogie und Geologie zu Dresden 43/44:265-280.

Böhme M. 2001. The oldest representative of a brown frog (Ranidae) from the Early Miocene of Germany. Acta Palaeontologica Polonica 46 (1):119-124.

Böhme M. 2003. The Miocene Climatic Optimum: evidence from ectothermic vertebrates of Central Europe. Palaeogeography, Palaeoclimatology, Palaeoecology 195 (3-4):389-401.

Böhme M. 2008. Ectothermic vertebrates (Teleostei, Allocaudata, Urodela, Anura, Testudines, Choristodera, Crocodylia, Squamata) from the Upper Oligocene of Oberleichtersbach (Northern Bavaria, Germany). Courier Forschungsinstitut Senckenberg 260:161-183.

Böhme M. 2010. Ectothermic vertebrates (Actinopterygii, Allocaudata, Urodela, Anura, Crocodylia, Squamata) from the Miocene of Sandelzhausen (Germany, Bavaria) and their implications for environment reconstruction and palaeoclimate. Paläontologische Zeitschrift 84 (1):3-41. 
1780 Böhme M, Ilg A. 2003. fosFARbase. Available at www.wahre-staerke.com (accessed 1 December

1781

1782

1783

1784

1785

1786

1787

1788

1789

1790

1791

1792

1793

1794

1795

1796

1797

1798

1799

1800

1801

1802

1803

1804

1805

1806

1807

1808

1809

1810

1811

1812

1813

1814

1815

1816

1817

1818

1819

1820

1821 2015).

Böhme M, Ilg A, Ossig A, Küchenhoff H. 2006. New method to estimate paleoprecipitation using fossil amphibians and reptiles and the middle and late Miocene precipitation gradients in Europe. Geology 34 (6):425-428.

Böhme M, Vasilyan D. 2014. Ectothermic vertebrates from the late Middle Miocene of Gratkorn (Austria, Styria). Palaeobiodiversity and Palaeoenvironments 94 (1):21-40.

Böhme M, Vasilyan D, Winklhofer M. 2012. Habitat tracking, range dynamics and palaeoclimatic significance of Eurasian giant salamanders (Cryptobranchidae) - indications for elevated Central Asian humidity during Cenozoic global warm periods. Palaeogeography, Palaeoclimatology, Palaeoecology 342-343:64-72.

Bonaparte CL. 1850. Conspectus systematum. Mastozoölogiae. Ornithologiae. Herpetologiae et Amphibiologiae. Ichthyologiae. Lugduni Batavorum: E. J. Brill.

Borisov BA. 1963. Stratigraphy of upper Cretaceus and Paleogene-Neogene of Zaisan basin. Transactions of Pansoviet scientific-research geological institute New Series, 94:11-75.

Borkin LJ. 1999. Distribution of Amphibians in North Africa, Europe, Western Asia, and the Former Soviet Union. In: Duellman WE, ed. Patterns of Distribution of Amphibians. Baltimore and London: The Johns Hopkins University Press, 329-420.

Bruch AA, Zhilin SG. 2007. Early miocene climate of Central Eurasia - Evidence from Aquitanian floras of Kazakhstan. Palaeogeography, Palaeoclimatology, Palaeoecology 248 (1-2):32-48.

Chkhikvadze VM. 1980. Systematic position of the Neogene freshwater turtle of Moldavia, Ukraine and some Central European Countries. Bulletin of the Academy of Sciences of Georgian SSR 99 (3):721-724.

Chkhikvadze VM. 1983. The fossil turtles of Caucasus and Northern Black Sea region. Tbilisi: Metsniereba.

Chkhikvadze VM. 1984. Survey of the fossil urodelan and anuran amphibians from the USSR. Izvestia Akademii Nauk Gruzinska SSR, Seria Biologitcheskaya 10 (1):5-13.

Chkhikvadze VM. 1985. Preliminary results of studies on tertiary amphibians and squamate reptiles of the Zaisan Basin. In: Darevsky I, ed.: Nauka, 234-235.

Chkhikvadze VM. 1989. Neogene turtles of USSR. Tbilisi: Metsniereba.

Chkhikvadze VM. 1998. Eocene - Oligocene herpetofauna of USSR. In: Krasheninnikov VA, Akhmetiev MA, eds. Late Eocene - Early Oligocene geological and biotic events. On the territory of the former Soviet Union, II. Moscow: Geos, 61-66.

Chkhikvadze VM. 2003. Perspectives of paleontological studies of Late Neogene vertebrate localities in the valley of River Iori, Eastern Georgia and Western Azerbaijan. In: Abdaladze 0, ed. Transactions of scientific works: Conservation arid and semiarid ecosystems in Transcaucasia. Tbilisi: NAGRES, 63-67.

Claessens, Leon P. A. M. 1997. On the herpteofauna of some Neogene Eastern Mediterranean localities and the occurence of Palaeobatrachus and Bufo (Amphibia, Anura) in the Lower Miocene of Turkey. Journal of Vertebrate Paleontology 17 (Suppl. 3):39.

Cope ED. 1859. On the primary division of the Salamandirdae, with description of two new species. Proceedings of the Academy of Natural Sciences of Philadelphia 11:122-128. 
1822 Cope ED. 1865. Sketch of the primary groups of Batrachia Salientia. Natural history review 5:971823120.

1824 Cope ED. 1868. On the origin of genera. Proceedings of the Academy of Natural Sciences of 1825 Philadelphia 20:242-300.

Cuvier G. 1817. Le Règne Animal distribué d'après son organisation pour servir de base à l'histoire naturelle des animaux et d'introduction à l'anatomie comparée. Les reptiles, les poissons, les mollusques et les annélides 2:1-532.

Danilov IG, Cherepanov G0, Vitek NS. 2013. Chelonological studies of l. I. Khosatzky with his annotated bibliography on turtles. Proceedings of the Zoological Institute RAS 317 (4):382-425.

1832

Daxner-Höck G, Badamgarav D, Erbaeva MA, Göhlich UB. 2013. Miocene Mammal

1833 Biostratigraphiy of Central Mongolia (Valley of Lakes): New Results. In: Wang X, J FL, Fortelius

1834 M, eds. Fossil mammals of Asia: Neogene biostratigraphy and chronology. New York: Columbia University Press, 477-507.

1835

Daza JD, Alifanov VR, Bauer AM. 2012. A redescription and phylogenetic reinterpretation of the

1836

1837

1838

1839 fossil lizard Hoburogekko suchanovi Alifanov, 1989 (Squamata, Gekkota), from the Early Cretaceous of Mongolia. Journal of Vertebrate Paleontology 32 (6):1303-1312.

Daza JD, Aurich J, Bauer AM. 2011. Anatomy of an enigma: an osteological investigation of the Namibian festive gecko (Narudasia festiva: Gekkonidae: Gekkota). Acta Zoologica 93 (4):465$1840 \quad 486$.

1841

1842

1843

Daza JD, Bauer AM. 2010. The Circumorbital Bones of the Gekkota (Reptilia: Squamata). The Anatomical Record: Advances in Integrative Anatomy and Evolutionary Biology 293 (3):402-413.

Delfino M, Bailon S, Pitruzzella G. 2011. The Late Pliocene amphibians and reptiles from "Capo Mannu D1 Local Fauna" (Mandriola, Sardinia, Italy). Geodiversitas 33 (2):357-382.

1845

1846

1847

1848

1849

Dybowski B. 1870. Beitrag zur Kenntniss der Wassermolche Sibiriens. Verhandlungen des Zoologisch-Botanischen Vereins in Wien 20:237-242.

Edwards JL. 1976. Spinal nerves and their bearing on salamander phylogeny. Journal of Morphology 148 (3):305-327.

1850

1851

1852

1853

1854

1855

1856

1857

Estes R. 1969. Die Fauna der miozänen Spaltenfüllung von Neudorf an der March (ČSSR) Reptilia (Lacertilia). Österreichische Akademie der Wissenschaften, Mathematisch-Naturwissenschaftliche Klasse Abteilung I, Sitzungsberichte 178:77-82.

Estes R, Darevsky I. 1977. Fossil amphibians from the Miocene of North Caucasus, USSR. Journal of Palaeontological Society of India 20:164-169.

Estes R, Queiroz K de, Gauthier J. 1988. Phylogenetic relationships within Squamata. In: Estes R, Pregill G, eds. Phylogenetic relationships of the lizard families. Stanford, California: Stanford University Press, 119-281.

1858

1859

Evans SE. 2008. The skull of lizards and tuatara. In: Gans C, ed. The skull of Lepidosauria, Volume 20, Morphology H. Ithaca: Society for the Study of Amphibians and Reptiles, 1-347.

1860

Fejfar O, Heinrich W-D, Pevzner MA, Vangengeim EA. 1997. Late Cenozoic sequences of mammalian sites in Eurasia: an updated correlation. Palaeogeography, Palaeoclimatology, Palaeoecology 133 (3-4):259-288.

1861

1862

1863

Fischer von Waldheim G. 1813. Zoognosia. Tabulis Synopticis Illustrata, in Usum Prælectionum Academiæ Imperialis Medico-Chirurgicæ Mosquensis Edita. Moscow: Typis Nicolai Sergeidis

$1864 \quad$ Vsevolozsky. 
1865 Fitzinger L. 1826. Neue Classification der Reptilien nach ihrer natürlichen Verwandtschaft. Wien: J. 1866 G. Heubner.

1867 Fitzinger L. 1843. Systema Reptilium. Fasciculus Primus. Wien: Braumüller et Seidel.

1868 Folie A, Rana RS, Rose KD, Sahni A, Kumar K, Singh L, Smith T. 2013. Early Eocene frogs from Vastan Lignite Mine, Gujarat, India. Acta Palaeontologica Polonica 58 (3):511-524.

1871

1872

Fritz U, Schmidt C, Ernst CH. 2011. Competing generic concepts for Blanding's, Pacific and European pond turtles (Emydoidea, Actinemys and Emys)—Which is best. Zootaxa 2971:41-53.

Gaiduchenko LL. 1984. On stratigraphy of Neogene sediments of the southmost Westsiberian Plain. In: Volkova VS, Kul'kova LA, eds. Environment and ligfe at the boundaries of Cenozoic epochs in SIberia and Far East. Novosibirsk: Nauka, 172-184.

1875

1876

Gaiduchenko LL, Chkhikvadze VM. 1985. First record of chelydrid turtle from the Neogene

1877 sediments of Pavlodarian Priirtyshya. Geologiya i geofizika (1):116-118.

1878

1879

Garcia-Porta J, Litvinchuk SN, Crochet PA, Romano A, Geniez PH, Lo-Valvo M, Lymberakis P, Carranza S. 2012. Molecular phylogenetics and historical biogeography of the west-palearctic common toads (Bufo bufo species complex). Molecular Phylogenetics and Evolution 63 (1):113130.

1881

1882

Gnibidenko ZN, Volkova VS, Kuz'mina OB, Dolya ZA, Khazina IV, Levicheva AV. 2011. Stratigraphic, paleomagnetic, and palynological data on the Paleogene-Neogene continental sediments of southwestern West Siberia. Russian Geology and Geophysics 52 (4):466-473.

Gnibitenko ZN. 2006. Cenozoic paleomagnetism of the West Siberian Plate. Novosibirsk: Geo.

1885

1886

1887

1888

1889

1890

1891

1892

Goldfuss GA. 1820. Handbuch der Zoologie. Nürnberg: J. L. Schrag.

Gray JE. 1825. A synopsis of the genera of reptiles and Amphibia, with a description of some new species. Annals of Philosophy, London 10:193-217.

Gray JE. 1870. Supplement to the Catalogue of shield reptiles in the collection of the British Museum. Part 1. Testudinata (Tortoises). London: Taylor \& Francis.

Gubin YM. 1995. The First Find of Pelobatids (Anura) in the Paleogene of Mongolia. Paleontologicheskiy zhurnal (4):73-76.

1893

1894

1895

1896

1897

1898

1899

1900

1901

1902

1903

1904

1905

1906

1907

Gvoždík V, Moravec J, Klütsch C, Kotlík P. 2010. Phylogeography of the Middle Eastern tree frogs (Hyla, Hylidae, Amphibia) as inferred from nuclear and mitochondrial DNA variation, with a description of a new species. Molecular Phylogenetics and Evolution 55 (3):1146-1166.

Heizmann EPJ, Bloos G, Böttcher R, Werner J, Ziegler R. 1989. Ulm-Westtangente und UlmUniklinik: Zwei neue Wirbeltier-Faunen aus der Unteren Süßwasser-Molasse (Untermiozän) von Ulm (Baden-Württemberg). Stuttgarter Beiträge Naturkunde Serie B 153:1-14.

Hodrova M. 1980. A toad from the Middle Miocene at Devínska Nová Ves near Bratislava. Věstník Ústředního ústavu geologichého 55 (5):311-316.

Hodrová M. 1987. Amphibians from the Miocene sediments of the Bohemian Karst. Časopis pro mineralogii a geologii 32 (4):345-356.

Hodrová M. 1988. Miocene frog fauna from the locality Devínska Nová Ves - Bonanza. Věstník Ústředního ústavu geologichého 63 (5):305-310.

Hoffstetter R, Gasc J-P. 1969. Vertebrae and rips of modern reptiles. In: Gans C, ed. Morphology A, Biology of the Reptilia. London, New York: Academic Press, 201-310.

Holman AJ. 1995. A New Species of Emydoidea (Reptilia: Testudines) from the Late Barstovian (Medial Miocene) of Cherry County, Nebraska. Journal of Herpetology 29 (4):548-553. 
1908 Iskakova K. 1969. Fossil amphibians from Priirtyshie. Proceedings of Academy of Sciences of

1909

1910

1911

1912

1913

1914

1915

1916

1917

1918

1919

1920

1921

1922

1923

1924

1925

1926

1927

1928

1929

1930

1931

1932

1933

1934

1935

1936

1937

1938

1939

1940

1941

1942

1943

1944

1945

1946

1947

1948

1949

1950 Kazakhian SSR, Series Biological (1):48-53.

Ivanov M. 2008. Early Miocene Amphibians (Caudata, Salientia) from the Mokrá-Western Quarry (Czech Republic) with comments on the evolution of Early Miocene amphibian assemblages in Central Europe. Geobios 41 (4):465-492.

Kirscher U, Prieto J, Bachtadse V, Abdul Aziz H, Doppler G, Hagmaier M, Böhme M. 2016. A biochronologic tie-point for the base of the Tortonian stage in European terrestrial settings: Magnetostratigraphy of the topmost Upper Freshwater Molasse sediments of the North Alpine Foreland Basin in Bavaria (Germany). Newsletters on Stratigraphy 49 (3):445-467.

Kordikova EG. 1994. Review of fossil Trionychid localities in the Soviet Union. Courier Forschungsinstitut Senckenberg 173:341-358.

Kuzmin SL. 1995. Die Amphibien Russlands und angrenzender Gebiete. Magdeburg: Westarp Wissenschaften.

Laurenti JN. 1768. Specimen medicum, exhibens synopsin reptilium emendatum cum experimentis circa venena et antidota Reptilium Austriacorum. Viennae: Typ. Joan. Thom. nob. de Trattnern.

Li J-T, Wang J-S, Nian H-H, Litvinchuk SN, Wang J, Li Y, Rao D-Q, Klaus S. 2015. Amphibians crossing the Bering Land Bridge: Evidence from holarctic treefrogs (Hyla, Hylidae, Anura). Molecular Phylogenetics and Evolution 87:80-90.

Linnaeus C. 1758. Systema naturae per regna tria naturae, secundum classes, ordines, genera, species, cum characteribus, differentiis, synonymis, locis. L. Salvi: Stockholm.

Linnaeus C. 1761. Fauna Svecica sisten Animalia Sveciae Regni Mammalia, Aves, Amphibia, Pisces, Insecta, Vermes. Distributa per Classes \& Ordines, Genera \& Species, cum Differentiis Specierum, Synonymis Auctorum, Nominibus Incolarum, Locis Natalium Descriptionibus Insectorum. Editio altera. Stockholm: Laurentius Salvus.

Lucas SG, Bray ES, Emry RJ, Hirsch KF. 2012. Dinour eggshell and the Cretaceous-Paleogene boundary in the Zaysan Basin, Eastern Kazakstan. Journal of Stratigraphy 36 (2):417-435.

Lychev GF. 1990. Use of relative higth of the tooth crown of castorids as a indicator of geological time. In: Tleuberdina PA, Kojamkulova BS, Rajushkina GS, eds. Vertebrate fauna and flora of the Mesozoic and Cenozoic of Kazakhstan, vol. 11. Alma-Ata: Nauka, 54-60.

Lymberakis P, Poulakakis N, Manthalou G, Tsigenopoulos CS, Magoulas A, Mylonas M. 2007. Mitochondrial phylogeography of Rana (Pelophylax) populations in the Eastern Mediterranean region. Molecular Phylogenetics and Evolution 44 (1):115-125.

Malakhov DV. 2003. The earliest known record of Mioproteus (Caudata; Proteidae) from the Middle Miocene of Central Kazakhstan. Biota 4 (1-2):67-72.

Malakhov DV. 2004. Toads (Anura, Bufonidae) from the Middle Miocene in the Turgay Depression (Central Kazakhstan). Biota 5 (1-2):41-46.

Malakhov DV. 2005. The early Miocene herpetofauna of Ayakoz (Eastern Kazakhstan). Biota 6 (12):29-35.

Malakhov DV. 2009. Fossil amphibians and reptiles from Cenozoic of Kazakhstan: state of art and new materials. Transactions of the Institute of Zoology MES RK 50:25-34.

Miklas PM. 2002. Die Amphibienfauna (Amphibia: Caudata, Anura) der obermiozänen Fundstelle Götzendorf an der Leitha (südliches Wiener Becken, Niederösterreich). Annalen des Naturhistorischen Museums in Wien 103A:161-211. 
1951

1952

1953

1954

1955

1956

1957

1958

1959

1960

1961

1962

1963

1964

1965

1966

1967

1968

1969

1970

1971

1972

1973

1974

1975

1976

1977

1978

1979

1980

1981

1982

1983

1984

1985

1986

1987

1988

1989

1990

1991

1992

1993

Młynarski M, Szyndlar Z, Estes R, Sanchíz B. 1982. Lower vertebrate fauna from the Miocene of Opole (Poland). Estudios geológicos 38:103-119.

Müller MJ, Hennings D. 2000. The Global Climate Data Atlas on CD-Rom. Flensburg and Köln.

Nikitina N, Ananjeva NB. 2009. Characteristics of dentition in gekkonid lizards of the genus Teratoscincus and other Gekkota (Sauria, Reptilia). Biology Bulletin 36 (2):193-198.

Nikitina NG. 2009. Pecularities of skull morphology and skin of geckos (Reptilia: Sauria: Gekkota) and their phylogenetic relevance, Zoological Institute of RAS.

Nilsson S. 1842. Skandinavisk herpetologi eller beskrifning öfver de sköldpaddor, ödlor, ormar och grodor, som förekomma i Sverige och Norrige, jemte deras lefnadssätt, födoämnen, nytta och skada m.m. Lund: Tryckt uti Borlingska Boktryckeriet.

Nokariya H. 1983. Comparative osteology of Japanese frogs and toads for paleontological studies (I): Bufo, Hyla, Microhyla and Bombina. Bulletin of Natural Science Museum, Series C 9 (1):23-40.

Oken L. 1816. Lehrbuch der Naturgeschichte. Leipzig, Jena: Reclam.

Oppel M. 1811. Die Ordnungen, Familien und Gattungen der Reptilien als Prodrom einer Naturgeschichte derselben. München: Joseph Lindauer.

Pabijan M, Wandycz A, Hofman S, Węcek K, Piwczyński M, Szymura JM. 2013. Complete mitochondrial genomes resolve phylogenetic relationships within Bombina (Anura: Bombinatoridae). Molecular Phylogenetics and Evolution 69 (1):63-74.

Pomel A. 1853. Catalogue méthodique et descriptif des vertébrés fossiles découverts dans le bassin hydrographique supérieur de la Loire. Paris: J. B. Baillières.

Rafinesque CS. 1815. Analyse de Nature, ou Tableau de l'Universe et des Corps Organisés. Palermo: Jean Barravecchia.

Rage J-C. 1976. Les Squamates du Miocène de Béni Mellal, Maroc. Géologie méditerranéenne 3 (2):57-70.

Rage J-C. 2003. Oldest Bufonidae (Amphibia, Anura) from the Old World: a bufonid from the Paleocene of France. Journal of Vertebrate Paleontology 23 (2):462-463.

Rage J-C, Hossini S. 2000. Les Amphibiens du Miocène moyen de Sansan. Mémoires du Muséum national d'histoire naturelle 183:177-217.

Ratnikov VY. 1997. Tailless amphibians and lanscape settings of the Late Cenozoic in Western Transbaikalia. Geologiya i geofizika 39 (9):1458-1464.

Ratnikov VY. 2001. Pliocene anurans of East-European platform. Russian Journal of Herpetology 8 (3):171-178.

Ratnikov VY. 2002. New find of amphibians and reptiles in type localities of Muchkapian, upper Don Basin. Bulletin of Voronezh State University: Geology (1):73-79.

Ratnikov VY. 2010. A review of tailed Amphibian remains from Late Cenozoic sediments of the East European plain. Russian Journal of Herpetology 17 (1):59-66.

Ratnikov VY, Litvinchuk SN. 2009. Atlant vertebrae of tailed amphibians of Russia and adjacent countries. Russian Journal of Herpetology 19 (1):57-68.

Ravkin YS, Bogomolova IN, Chesnokova SV. 2010. Amphibian and reptile biogeographic regions of Northern Eurasia, mapped separately. Contemporary Problems of Ecology 3 (5):562-571.

Ravkin YS, Yudkin VA, Tsybulin SM, Kuranova VN, Borisovich OB, Bulakhova NA, Patrakov SV, Shamgunova RR. 2008. Spatial-typological structure and mapping of reptile population of West Siberia. Contemporary Problems of Ecology 1 (2):214-220. 
1994 Recuero E, Canestrelli D, Vörös J, Szabó K, Poyarkov NA, Arntzen JW, Crnobrnja-Isailovic J,

1995

1996

1997

1998

1999

2000

2001

2002

2003

2004

2005

2006

2007

2008

2009

2010

2011

2012

2013

2014

2015

2016

2017

2018

2019

2020

2021

2022

2023

2024

2025

2026

2027

2028

2029

2030

2031

2032

2033

2034

2035

2036 Kidov AA, Cogălniceanu D, Caputo FP, Nascetti G, Martínez-Solano I. 2012. Multilocus species tree analyses resolve the radiation of the widespread Bufo bufo species group (Anura, Bufonidae). Molecular Phylogenetics and Evolution 62 (1):71-86.

Reichenbacher B, Böhme M, Heissig K, Prieto J, Kossler A. 2004. New approach to assess biostratigraphy, palaeoecology and past climate in the South German Molasse Basin during the Early Miocene (Ottnangian, Karpatian). Courier Forschungsinstitut Senckenberg 249:71-89.

Reichenbacher B, Krijgsman W, Lataster Y, Pippèrr M, Baak CC, Chang L, Kälin D, Jost J, Doppler G, Jung D, Prieto J, Abdul Aziz H, Böhme M, Garnish J, Kirscher U, Bachtadse V. 2013. A new magnetostratigraphic framework for the Lower Miocene (Burdigalian/Ottnangian, Karpatian) in the North Alpine Foreland Basin. Swiss Journal of Geosciences 106 (2):309-334.

Roček Z. 1984. Lizards (Reptili: Sauria) from the Lower Miocene locality Dolnice (Bohemia, Czechoslovakia). Řada matematických a přirodních vĕd 94 (1):4-69.

Roček Z. 2005. Late Miocene Amphibia from Rudabánya. Palaeontographia Italica 90:11-29.

Roček Z, Wuttke M, Gardner J, Singh Bhullar B-A. 2014. The Euro-American genus Eopelobates, and a re-definition of the family Pelobatidae (Amphibia, Anura). Palaeobiodiversity and Palaeoenvironments 94 (4):529-567.

Sanchiz B, Schleich H. 1986. Erstnachweis der Gattung Bombina (Amphibia: Anura) im Untermiozän Deutschlands. Mitteilungen der Bayerischen Staatssammlung für Paläontologie und historische Geologie 26:41-44.

Sanchíz B. 1998a. Salientia. München: Verlag Dr. Friedrich Pfeil.

Sanchíz B. 1998b. Vertebrates from the Early Miocene lignite deposits of the opencast mine Oberdorf (Western Styrian Basin, Austria). Annalen des Naturhistorischen Museums in Wien 99A:13-29.

Sanchíz B, Młynarski M. 1979. Remarks on the Fossil Anurans from the Polish Neogene. Acta zoologica cracoviensia 24 (3):153-174.

Sanchíz B, Schleich H-H. 1986. Erstnachweis der Gattung Bombina (Amphibia: Anura) im Untermiozän Deutschlands. Mitteilungen der Bayerischen Staatssammlung für Paläontologie und historische Geologie 26:41-44.

Sanchíz B, Schleich H-H, Esteban M. 1993. Water frogs (Ranidae) from the Oligocene of Germany. Journal of Herpetology 27 (4):486-489.

Savage JM. The geographic dstribution of frogs: patterns and predictions. In: Val (Ed.) 1973 Evolutionary biology of the anurans, 351-445.

Scopoli GA. 1777. Introductio ad historiam naturalem, sistens genera lapidum, plantarum et animalium hactenus detecta, caracteribus essentialibus donata, in tribus divisa, subinde ad leges naturae. Prague: Apud Wolfgangum Gerle.

Shpanskiy AV. 2008. Pecularities of the development of the hipparion fauna of the Pavlodar Priirtyshe. In: Tleuberdina PA, Erzhanov NT, Zykin VS, eds.: Pavlodarian State University, 92-96.

Stöck M, Dubey S, Klütsch C, Litvinchuk SN, Scheidt U, Perrin N. 2008a. Mitochondrial and nuclear phylogeny of circum-Mediterranean tree frogs from the Hyla arborea group. Molecular Phylogenetics and Evolution 49 (3):1019-1024.

Stöck M, Moritz C, Hickerson M, Frynta D, Dujsebayeva T, Eremchenko V, Macey JR, Papenfuss TJ, Wake DB. 2006. Evolution of mitochondrial relationships and biogeography of 
2037

2038

2039

2040

2041

2042

2043

2044

2045

2046

2047

2048

2049

2050

2051

2052

2053

2054

2055

2056

2057

2058

2059

2060

2061

2062

2063

2064

2065

2066

2067

2068

2069

2070

2071

2072

2073

2074

2075

2076

2077

2078

Palearctic green toads (Bufo viridis subgroup) with insights in their genomic plasticity. Molecular Phylogenetics and Evolution 41 (3):663-689.

Stöck M, Sicilia A, Belfiore N, Buckley D, Lo Brutto S, Lo Valvo M, Arculeo M. 2008b. PostMessinian evolutionary relationships across the Sicilian channel: Mitochondrial and nuclear markers link a new green toad from Sicily to African relatives. BMC Evolutionary Biology 8 (1).

Syromyatnikova EV. 2014. The first record of Salamandrella (Caudata: Hynobiidae) from the Neogene of Russia. Russian Journal of Herpteology 21 (3):217-220.

Tempfer PM. 2005. The herpetofauna (Amphibia: Caudata, Anura; Reptilia: Scleroglossa) of the Upper Miocene locality Kohfidisch, Burgenland, Austria, Wien, Universität.

Tleuberdina PA, ed. 1993. Faunistic and floristic complexes of Mesozoic and Cenozoic of Kazakhstan. Almaty: Baspager.

Tleuberdina PA, Kozhamkulova GS, Kondratenko BS. 1989. Catalogue of the Cenozoic mammals from Kazakhstan. Alma-Ata: Nauka Kazakhian SSR.

Tleuberdina PA, Volkova VS, Lushczaeva TT, Lychev GF, Pita OM, Tjutkova LA, Chkhikvadze VM. 1993. Vertebrate fauna of Kalkaman (Pavlodar Priirtyshe). In: Tleuberdina PA, ed. Faunistic and floristic complexes of Mesozoic and Cenozoic of Kazakhstan, vol. 12. Almaty: Baspager, 132157.

Tschudi JJv. 1838. Classification der Batrachier, Mit Berucksichtigung der fossilen Thiere dieser Abtheilung der Reptilien. Neuchâtel: Petitpierre.

Vangengeim EA, Pevzner MA, Tesakov AS. 2005. Ruscinian and Lower Villafranchian: age of boundaries and position in magnetochronological scale. Stratigraphy and Geological Correlation 13 (5):530-546.

Vasilyan D, Böhme M, Chkhikvadze VM, Semenov YA, Joyce WG. 2013. A new giant salamander (Urodela, Pancryptobrancha) from the Miocene of Eastern Europe (Grytsiv, Ukraine). Journal of Vertebrate Paleontology 33 (2):301-318.

Vasilyan D, Böhme M, Klembara J. 2016. First record of fossil Ophisaurus (Anguimorpha, Anguidae, Anguinae) in Asia (Russia and Kazakhstan). Journal of Vertebrate Paleontology:1-6.

Veith M, Kosuch J, Vences M. 2003. Climatic oscillations triggered post-Messinian speciation of Western Palearctic brown frogs (Amphibia, Ranidae). Molecular Phylogenetics and Evolution 26 (2):310-327.

Venczel M. 1999a. Fossil land salamanders (Caudata, Hynobiidae) from the Carpathian basin: relation between extinct and extant genera. Acta Palaeontologica Romaniae 2:489-492.

Venczel M. 1999b. Land salamanders of the family Hynobiidae from the Neogene and Quaternary of Europe. Amphibia-Reptilia 20:401-412.

Venczel M. 2000. Amphibians from the Lower Pleistocene Betfia 9 locality (Bihor country, Romania). Satu Mare - Studii şi comunicări, seria stiintele naturale 1:28-37.

Venczel M. 2001. Anurans and squamates from the Lower Pliocene (MN 14) Osztramos 1 locality (Northern Hungary). Palaeontologica Hungarica 19:79-90.

Venczel M. 2004. Middle Miocene anurans from the Carpathian Basin. Palaeontographica Abt. A 271:151-174.

Venczel M. 2008. A new salamandrid amphibian from the Middle Miocene of Hungary and its phylogenetic relationships. Journal of Systematic Palaeontology 6 (1):41-59. 
2079

2080

2081

2082

2083

2084

2085

2086

2087

2088

2089

2090

2091

2092

2093

2094

2095

2096

2097

2098

2099

2100

2101

2102

2103

2104

2105

2106

2107

2108

2109

2110

2111

2112

2113

2114

Venczel M, Codrea V, Fărcaş C. 2012. A new palaeobatrachid frog from the early Oligocene of Suceag, Romania. Journal of Systematic Palaeontology 11 (2):179-189.

Venczel M, Gardner JD, Codrea VA, Csiki-Sava Z, Vasile Ş, Solomon AA. 2016. New insights into Europe's most diverse Late Cretaceous anuran assemblage from the Maastrichtian of western Romania. Palaeobiodiversity and Palaeoenvironments 96 (1):61-95.

Venczel M, Hír J. 2013. Amphibians and Squamates from the Miocene of Felsötárkány Basin, NHungary. Palaeontographica Abteilung A 300 (1-6):117-147.

Vergnaud-Grazzini C, Młynarski M. 1969. Position systématic du genre Pliobatrachus Fejérváry 1917. Comptes Rendus hebdomadaires des Séances de l'Académie des Sciences, Série D: Sciences naturelles 268:2399-2402.

Villa A, Roček Z, Tschopp E, Van den Hoek Ostende, Lars W., Delfino M. 2016. Palaeobatrachus eurydices, sp. nov. (Amphibia, Anura), the last western European palaeobatrachid. Journal of Vertebrate Paleontology:e1211664.

Volkova VS. 1984. Changes in the palinofloras of Siberia in the late Cenozoic. In: Volkova VS, Kul'kova LA, eds. Environment and ligfe at the boundaries of Cenozoic epochs in SIberia and Far East. Novosibirsk: Nauka, 54-69.

Wagler JG. 1830. Natürliches System der Amphibien, mit vorangehender Classification der Säugethiere und Vögel . Ein Beitrag zur vergleichenden Zoologie. München, Stuttgart, Tübingen: J.G. Cotta.

Wuttke M, Přikryl T, Ratnikov VY, Dvořák Z, Roček Z. 2012. Generic diversity and distributional dynamics of the Palaeobatrachidae (Amphibia: Anura). Palaeobiodiversity and Palaeoenvironments 92 (3):367-395.

Zykin VS. 1979. Stratigraphy and unionids of the Pliocene of southern part of Western Siberian plain. Novosibirsk: Nauka.

Zykin VS. 2012. Stratigraphy and evolution of environments and climate during Late Cenozoic in the Southern West Siberia. Novosibirsk: Geo.

Zykin VS, Zazhigin VS. 2004. A new biostratigraphic level of the Pliocene in Western Siberia and the age of the Lower-Middle Miocene stratotype of the Beshcheul Horizon. Doklady Earth Sciences 398 (7):904-907.

Zykin VS, Zazhigin VS. 2008. On the Neogene stratigraphy of Pavlodarian Priirtyshya. In: Tleuberdina PA, Erzhanov NT, Zykin VS, eds.: Pavlodarian State University, 15-21.

Zykin VS, Zykina VS, Zazhigin VS. 2007. Issues in separating and correlating Pliocene and Quaternary sediments of Southerwestern Siberia. Archeology, Ethnology \& Anthropology of Eurasia 30 (2):24-40. 


\section{Figure $\mathbf{1}$ (on next page)}

Map of Eurasia (A) showing location of the Western Siberian studied fossil sites (B) (138, 58; black-thin outlined circles) as well as localities known from the literature (39-57; white - thick outlined circles).

1, Baikadam; 2, Malyi Kalkaman 2; 3, Malyi Kalkaman 1; 4, Shet-Irgyz 1; 5, Petropavlovsk 1; 6, Znamenka; 7, Pavlodar 1A; 8, Selety 1A; 9, Kedey; 10, Novaya Stanitsa 1A; 11, Borki 1A; 12, Lezhanka 2A; 13, Cherlak; 14, Pavlodar 1B; 15, Lezhanka 2B; 16, Olkhovka 1A; 17, Olkhovka 1B; 18, Olkhovka 1C; 19, Iskakovka 2A; 20, Isakovka 1A; 21, Peshniovo 3; 22, Isakovka 1B; 23, Kamyshlovo; 24, Beteke 1B; 25, Pavlodar 2B; 26, Pavlodar 3A; 27, Lezhanka 1; 28, Andreievka-Speransko; 29, Andreievka 1; 30, Livenka; 31, Beteke 1C; 32, Lebiazhie 1A; 33, Lebiazhie 1B; 34, Podpusk 1; 35, Beteke 2; 36, Beteke 4; 37, Kamen-na-Obi; 38, Razdole; 39, Akespe; 40, Ayakoz; 41, Golubye Peski; 42, Zmei Gorynych; 43, Vympel; 44, Poltinik; 45, Zaezd; 46, Tri Bogatyrja; 47, Kaymanovaja cherepakha; 48, Ryzhaya II; 49, Kentyubek; 50, Ashut; 51, Point "Y"; 52, Sarybulak Svita; 53, Kalmakpai Svita; 54, Karabastuz; 55, Kalmakpai; 56, Petropavlovsk 1/2; 57, Detskaya zheleznaja doroga; 58, Shet-Irgyz 2. Map data (c) 2016 Google and Map data @ OpenStreetMap contributors, CC BY-SA. 


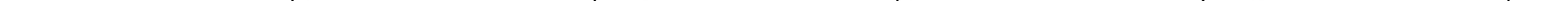




\section{Figure 2 (on next page)}

Compiled stratigraphy of the Middle Miocene - Early Pleistocene studied localities in Western Siberia grouped in the svitas and relative to their geographic positions.

The localities without assignment into a certain svita are given in coloured frames according to age. In the right column the small mammalian biochronologic data (species or lineages) used for age estimations are given, the numbers accompanying the species refer the locality numbers. The arrows left from the small mammal taxa indicates its/their first appearance. Abbreviations: klm - Kalkaman, ish - Ishim, pv - Pavlodar, kd - Kedey, nst - Novaya Stanitsa, rt - Rytov, is - Isakov, psh - Peshnev, krt - Krutogor, bt - Betekey, liv - Levetin, irt - Irtysh, kar - Karagash. 


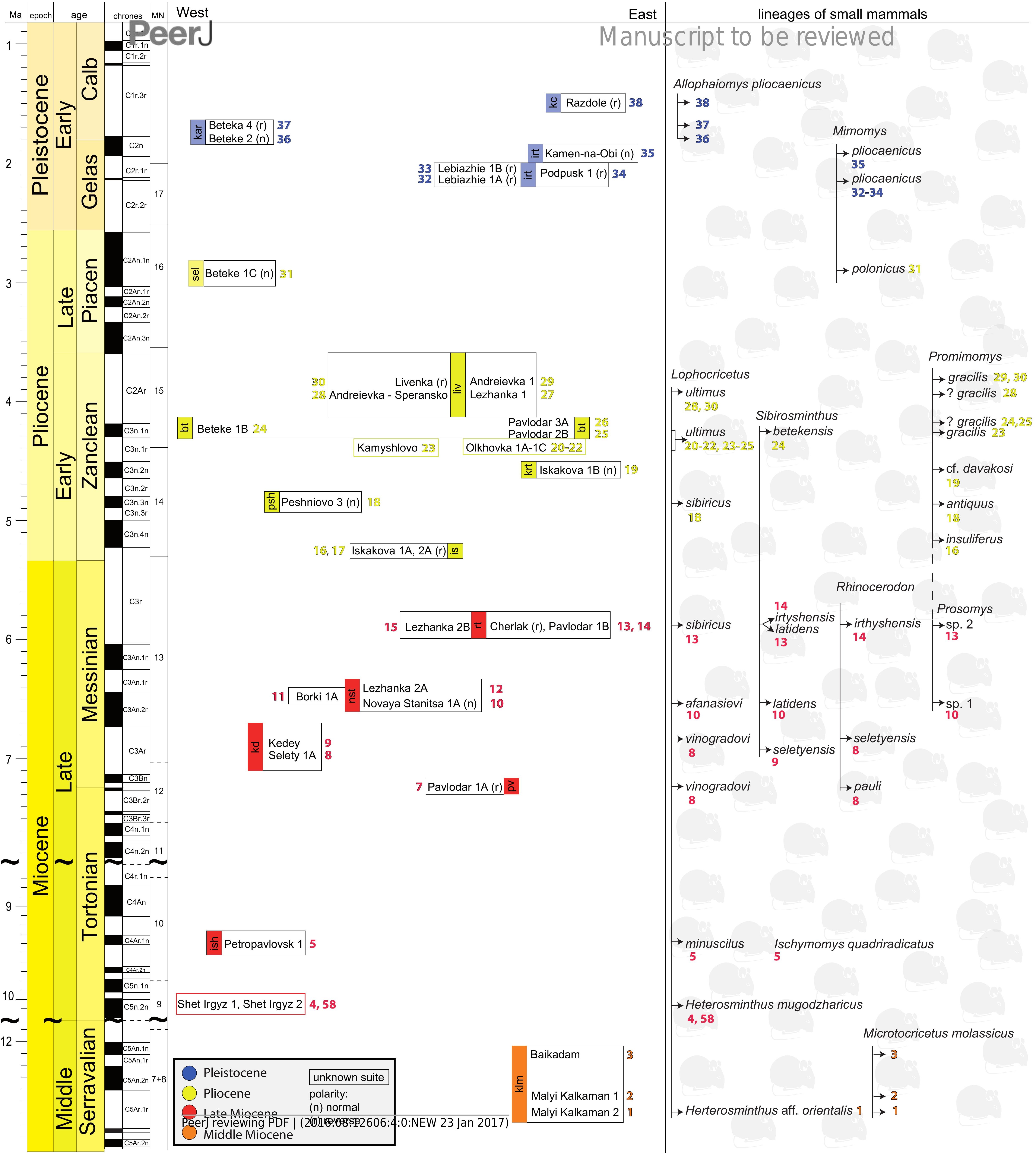




\section{Figure 3}

Salamander remains from Western Siberian localities.

A-C, Cryptobranchidae indet. from the loc. ? Gusiny Perelet, unnr. PIN specimens; A, fragmentary right dentary, natural cross-section; B, the same dentary, in lingual view; C, a jaw fragment, lingual view; D-G, Salamandrella sp., Lezhanka 2A, GIN 1130/1001-AM01, trunk vertebra; H-S, Mioproteus sp.; H-L, loc. Ayakoz, trunk vertebra, GNM unnr. specimen; M-O, trunk vertebra, Borki 1A, GIN 1115/1001-AM01; P-Q, right premaxilla, Malyi Kalkaman 2, GIN 1107/2001-AM01; R-S, left premaxilla loc. Grytsiv (Ukraine), unnr. MNMHK specimen; T-X, trunk vertebrae of aff. Chelotriton sp., loc. Ayakoz, GNM unnr. specimen; Y, Chelotriton sp. from Malyi Kalkaman 2, GNM unnr. specimen; D, H, M, P, R, T, Y, dorsal view; E, I, N, $\mathbf{Q}, \mathbf{S}, \mathbf{U}$, ventral view; $\mathbf{F}, \mathbf{J}, \mathbf{O}, \mathbf{V}$, lateral view; $\mathbf{G}, \mathbf{K}, \mathbf{W}$, anterior view; $\mathbf{L}, \mathbf{X}$, posterior view. Scale bars: $A-C=5 \mathrm{~mm} ; \mathrm{D}-\mathrm{G}=0.5 \mathrm{~mm} ; \mathrm{H}-\mathrm{Y}=1 \mathrm{~mm}$. 


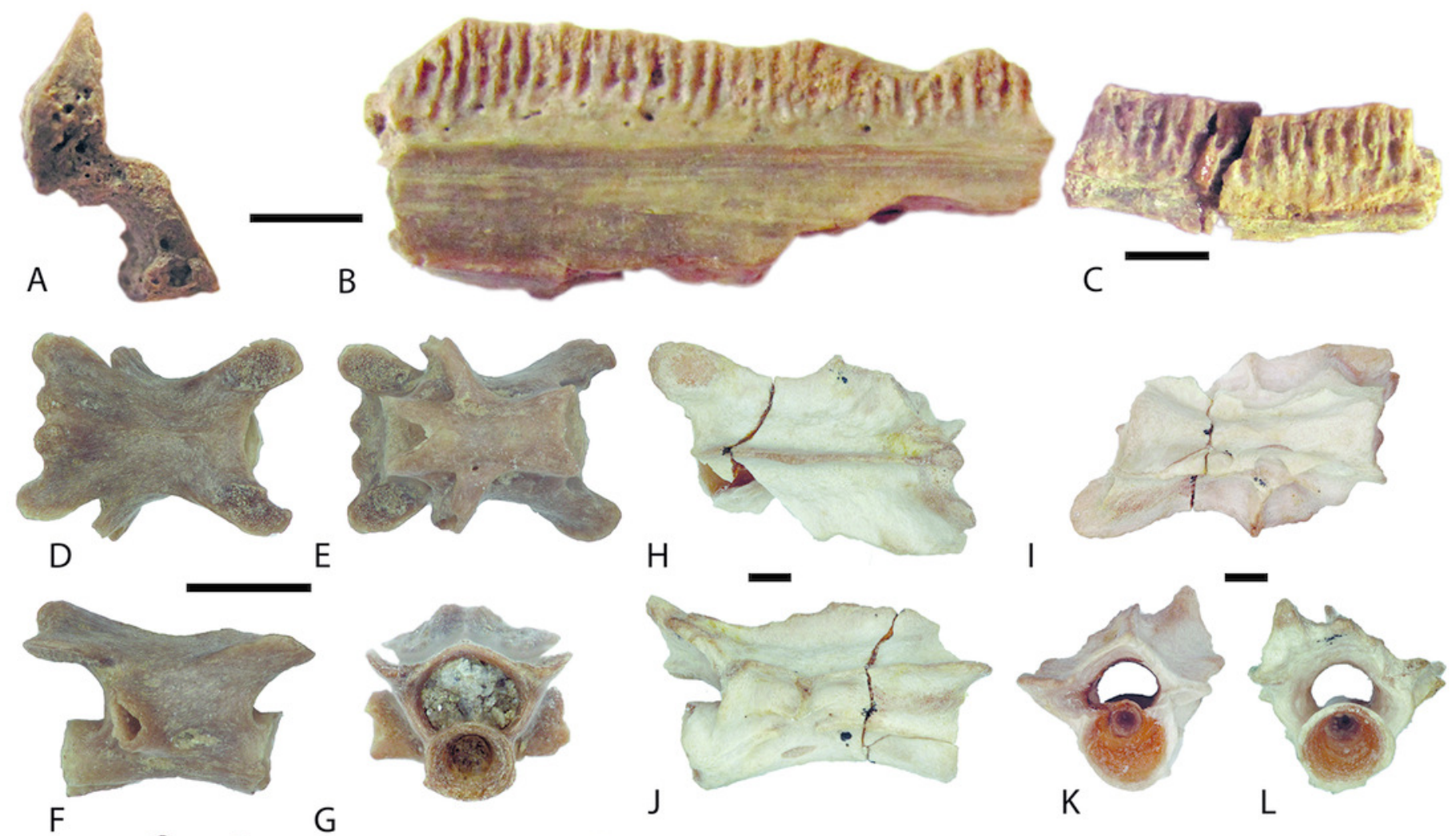

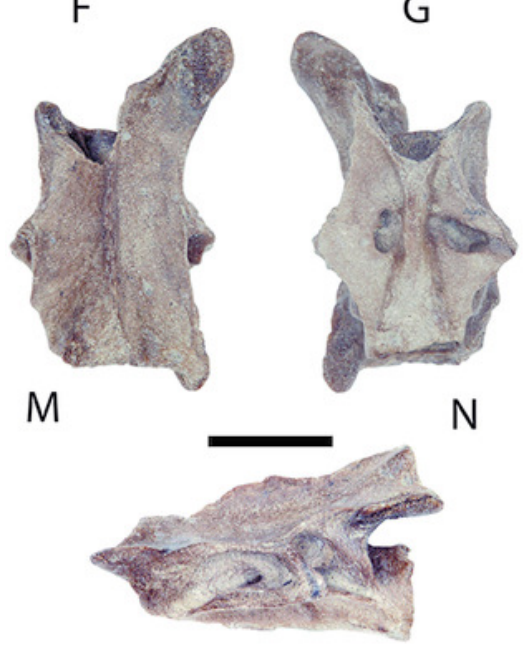
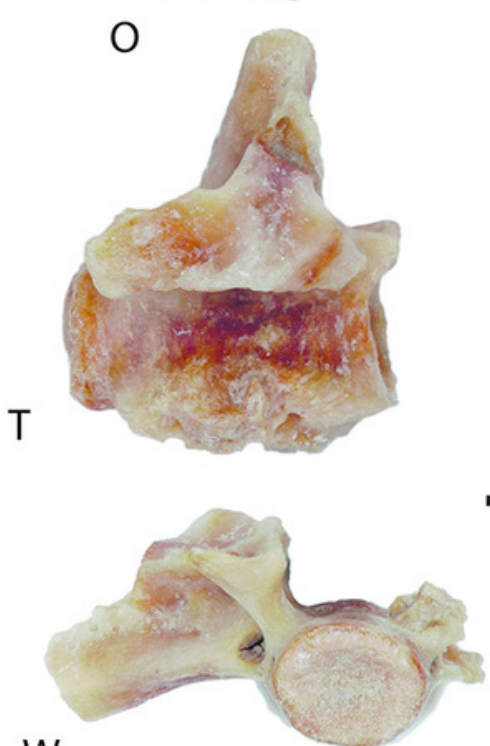

Peér) reviewing PDF | (2016:08:12606:4:0:NEW 23 Jan 2017)

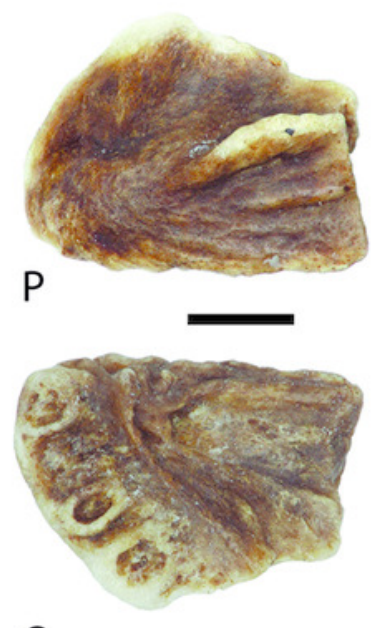

Q
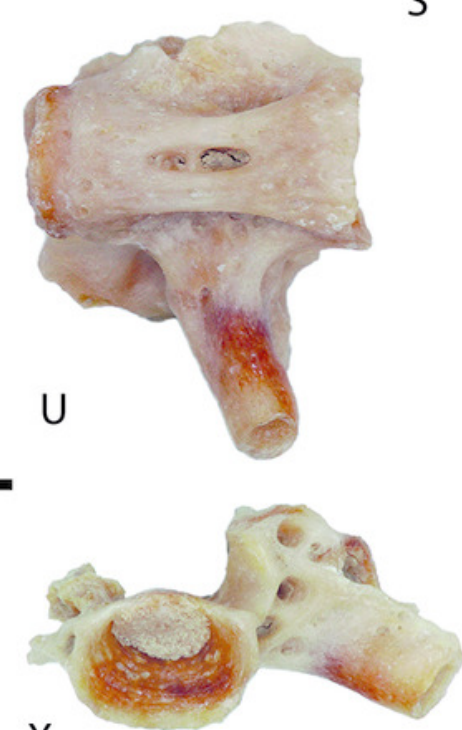

S
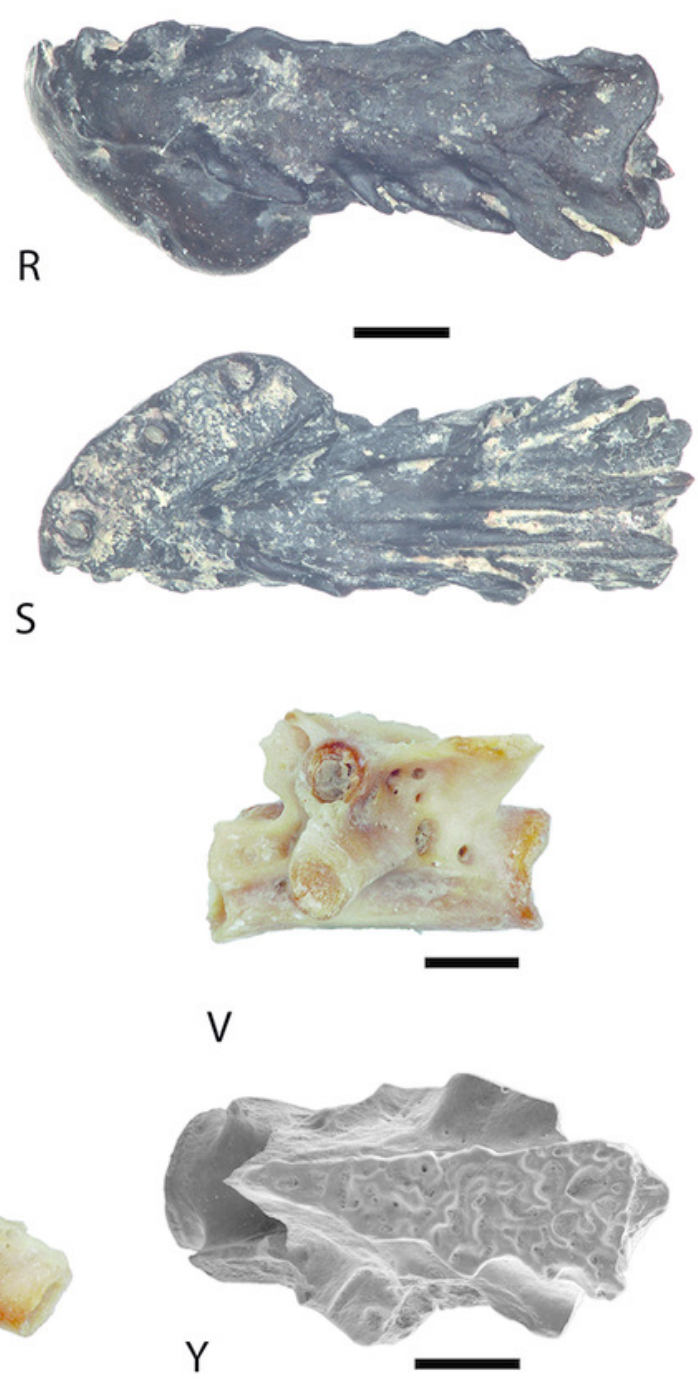
Figure 4

Trunk vertebrae of fossil aff. Tylototriton (A-K), and recent Tylototriton, Echinotriton and Cynops (L-AE).

A-E, aff. Tylototriton sp., locality Ayakoz, GNM unnr. specimen; F-K, GIN 950/2001-AM14 and GIN 950/2001-AM01, loc. Baikadam; L-P, Tylototriton verrucosus, GPIT unnr. specimen; Q-U, Tylototriton shanjing, GPIT unnr. specimens; V-Z, Echinotriton andersoni, GPIT unnr.

specimen; AA-AE, Cynops pyrrhogaster, GPIT unnr. specimen; A, F, G, L, Q, V, AA, lateral view; B, H, M, R, W, AB, dorsal view; C, I, N, S, X, AC, ventral view; D, J, O, T, Y, AD, anterior view; E, $\mathbf{K}, \mathbf{P}, \mathbf{U}, \mathbf{Z}, \mathbf{A E}$, posterior view. Scale bars $=2 \mathrm{~mm}$. 


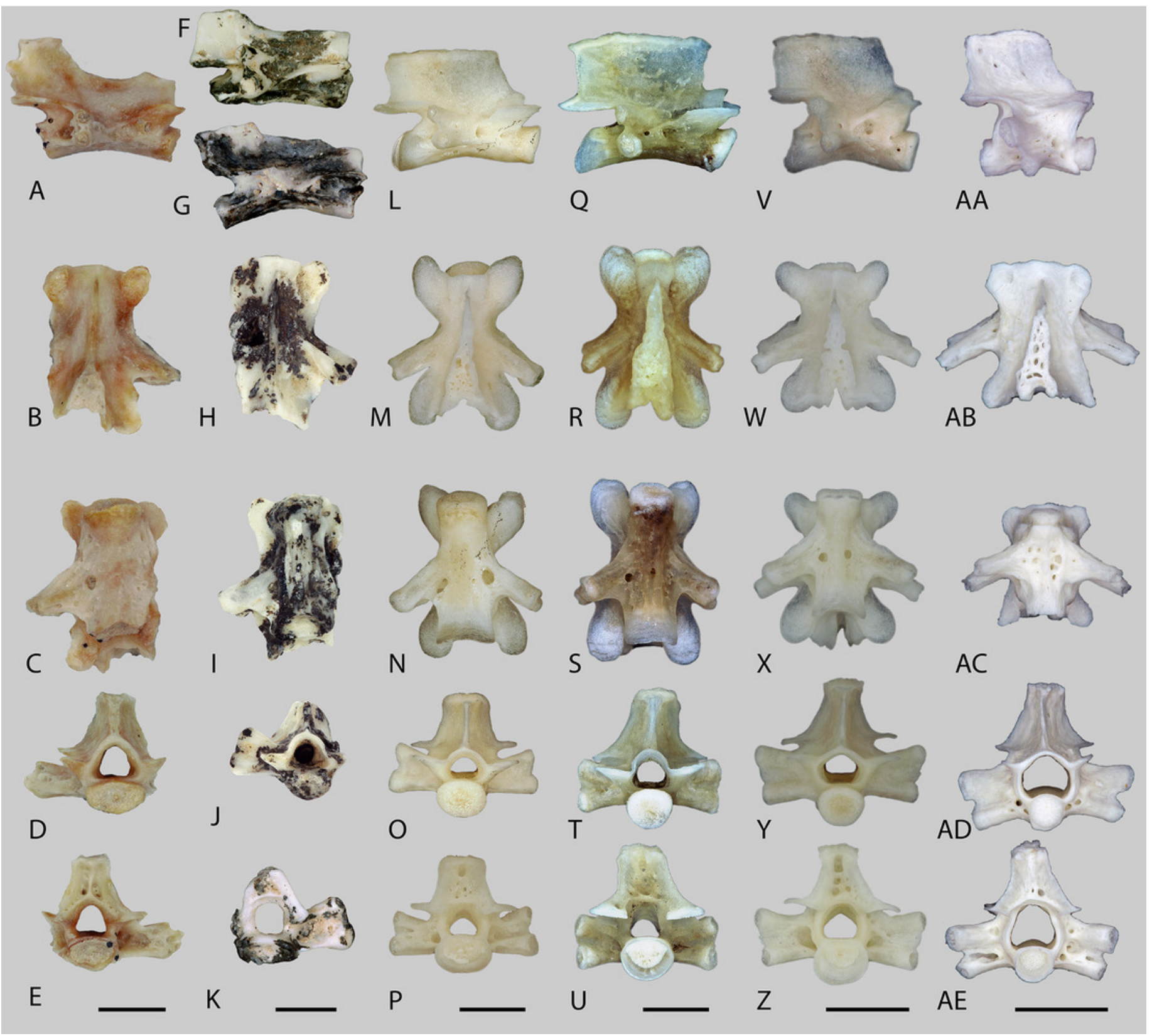




\section{Figure 5}

Palaeobatrichid sphenethmoids.

A-D, Palaeobatrachidae indet., Novaya Stanitsa 1A, GIN 948/2001-AM12; E-H, Palaeobatrachus sp. from Grytsiv (Ukraine), unnr. NMNHK specimen; A, E, ventral view; B, F,, dorsal view; C, G, anterior view; D, H, lateral view. Abbreviations: ao, antrum olfactorium; alo, antrum pro lobo olfactorio; is, incisura semielliptical; ff, frontoparietal facet; Ip, lateral processes; Is, lamina supraorbitalis; nf, nasal facet; onf, orbitonasal foramina; olf, olfactory foramina; pf, parasphenoid facet. Scale equals $1 \mathrm{~mm}$ 

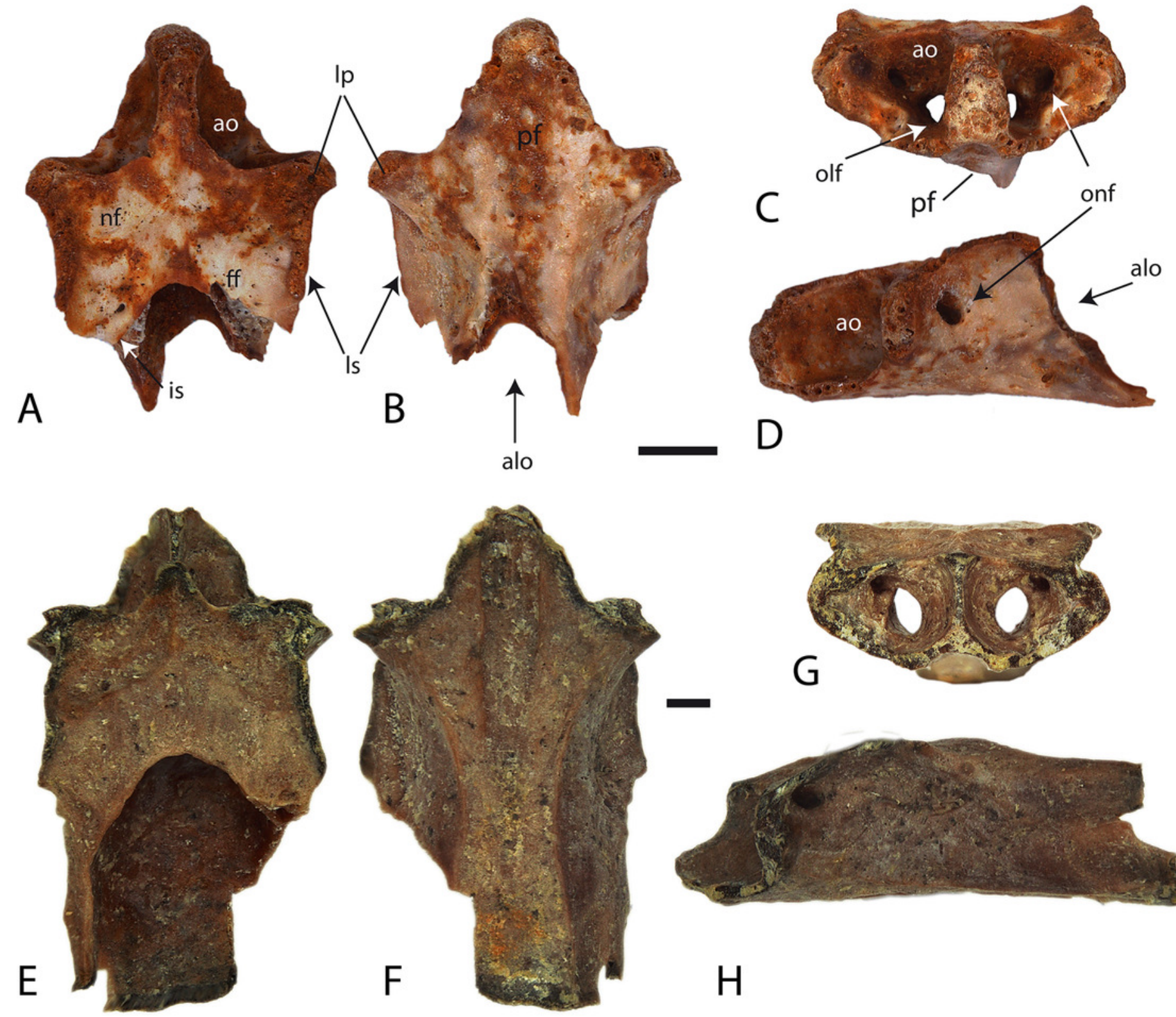

$\mathrm{H}$ 


\section{Figure 6}

Fossil frogs from Western Siberia.

A-L, P-Q, X, AA, AB, A, AF, Ilia; A-C Bombina cf. bombina, Selety 1A, GIN 951/1001-AM06;

D-E, Bombina sp., Cherlak, GIN 1110/2001-AM13; G-I, Pelobates sp., Selety 1A, GIN

951/1001-AM07; J-L, Hyla gr. H. savignyi, Lezhanka 2A, GIN 1130/1001-AM29; P, Q, Bufo

bufo, Olkhovka 1B, GIN 11 11/2001-AM03; X, Bufotes cf. viridis, Pavlodar 1A, GIN 640/5001AM01; AA, AB, Pelophylax sp., Lezhanka 1, GIN 1129/1001-AM05; AE-AF, Rana arvalis, Malyi Kalkaman 1, GIN 1107/1001-AM10; A, D, G, J, P, U, AA, AE, in lateral view; B, E, H, K, Q, $\mathbf{A B}$, in proximal view; C, F, I, L, in medial view; M-O, R-T, Y, Z, AC, AD, AG, AH, Scapulae of frogs; M-O, Hyla gr. H. savignyi from Lezhanka 2A, GIN 1130/1001-AM33; R-T, Bufo bufo, Olkhovka 1C, GIN 1111/3001-AM01; Y-Z, Bufotes cf. viridis, Pavlodar 1A, GIN 640/5001AM63; AC-AD, Pelophylax sp., Lezhanka 1, GIN 1129/1001-AM07; AG-AH, Rana temporaria, Malyi Kalkaman 1, GIN 1107/1001-AM01; M, R, Y, AC, AG, dorsal view; N, S, Z, AD, AH, ventral view; $\mathbf{0}, \mathbf{T}$, posterior view; $\mathbf{U}, \mathbf{V}$, trunk vertebra of Bufo bufo, Olkhovka 1C, GIN 1111/3001-AM02; U, anterior view; V, lateral view; W, urostyle of Bufo bufo, Olkhovka 1C, GIN 1111/3001-AM03, dorsal view. The arrows show the position of the angular fossa. Scale bars: $A-Q, A A-A D, A G, A H=1 \mathrm{~mm}, R-Z, A E, A F=2 \mathrm{~mm}$. 


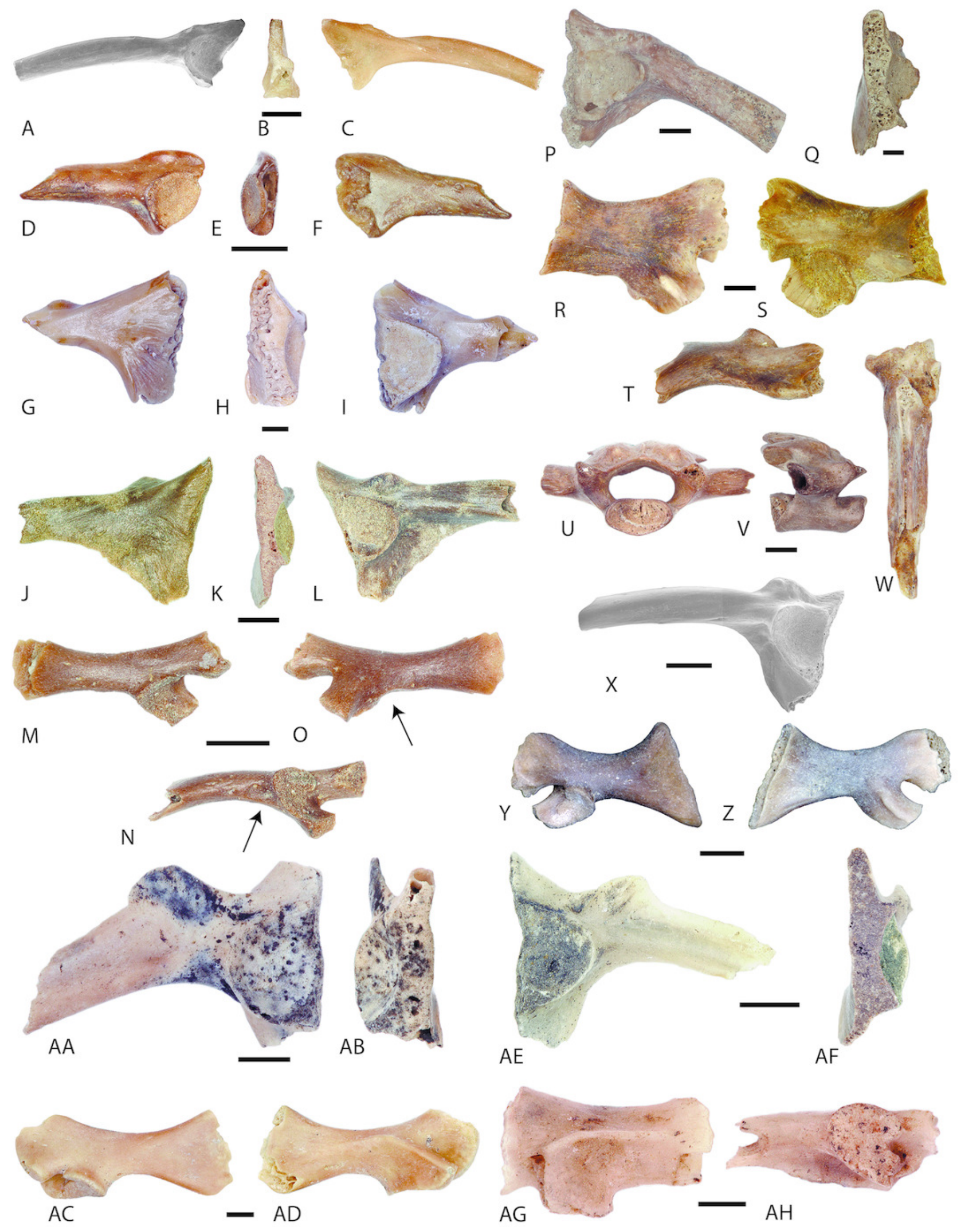




\section{Figure 7}

Alsophylax sp. from the localities Cherlak (A-P) and Mynsualmas-MSA 3 (Q).

A-E, two left dentaries; A-D, left dentary, GIN 1110/2001-RE11; A, mirrored labial view; B-D, mirrored lingual view; $\mathbf{C}$, symphyseal region in lingual view; $\mathbf{D}$, the same region in ventral view, both display the symphyseal groove; E, posterior fragment of left dentary, GIN 1110/2001-RE12, lingual view; F-M, five maxillae; F-G, left maxilla, GIN 1110/2001-RE26, lingual view; H, right maxilla, GIN 1110/2001-RE39, lingual view; I-J, right, GIN 1110/2001RE40 and K-L, left maxillae GIN 1110/2001-RE27; I, K, lingual view; J, L, labial view; M, left maxilla, GIN 1110/2001-RE28, labial view; N-P, cervical vertebra, GIN 1110/2001-RE44; N, anterior view; O, left lateral view; $\mathbf{P}$, posterior view; $\mathbf{Q}$, right dentary, unnr. GPIT specimen, lingual view. Abbreviations: dl, dental lamina; ds, dental shelf; fcpr, facial process of maxilla; $\mathrm{fMx5}$, foramina for mandibular division of the fifth cranial (trigeminal) nerve; hfr, haemal foramen; hl, horizontal lamella; If, lacrimal facet; Ig, longitudinal groove; Ih, lamina horzontalis; mc, Meckelian canal; na, neural arch; nc, neural canal; nf, nasal facet; pfc, palatine facet; ph, paries horizontalis; prz, prezygapophysis; psz, postzygapophysis; pv, paries verticalis; pxp, premaxillary process; pyp, pterygapophysis; sac, opening of superior alveolar canal; sg, symphyseal groove; sf, splenial facet; tpr, transverse process. 

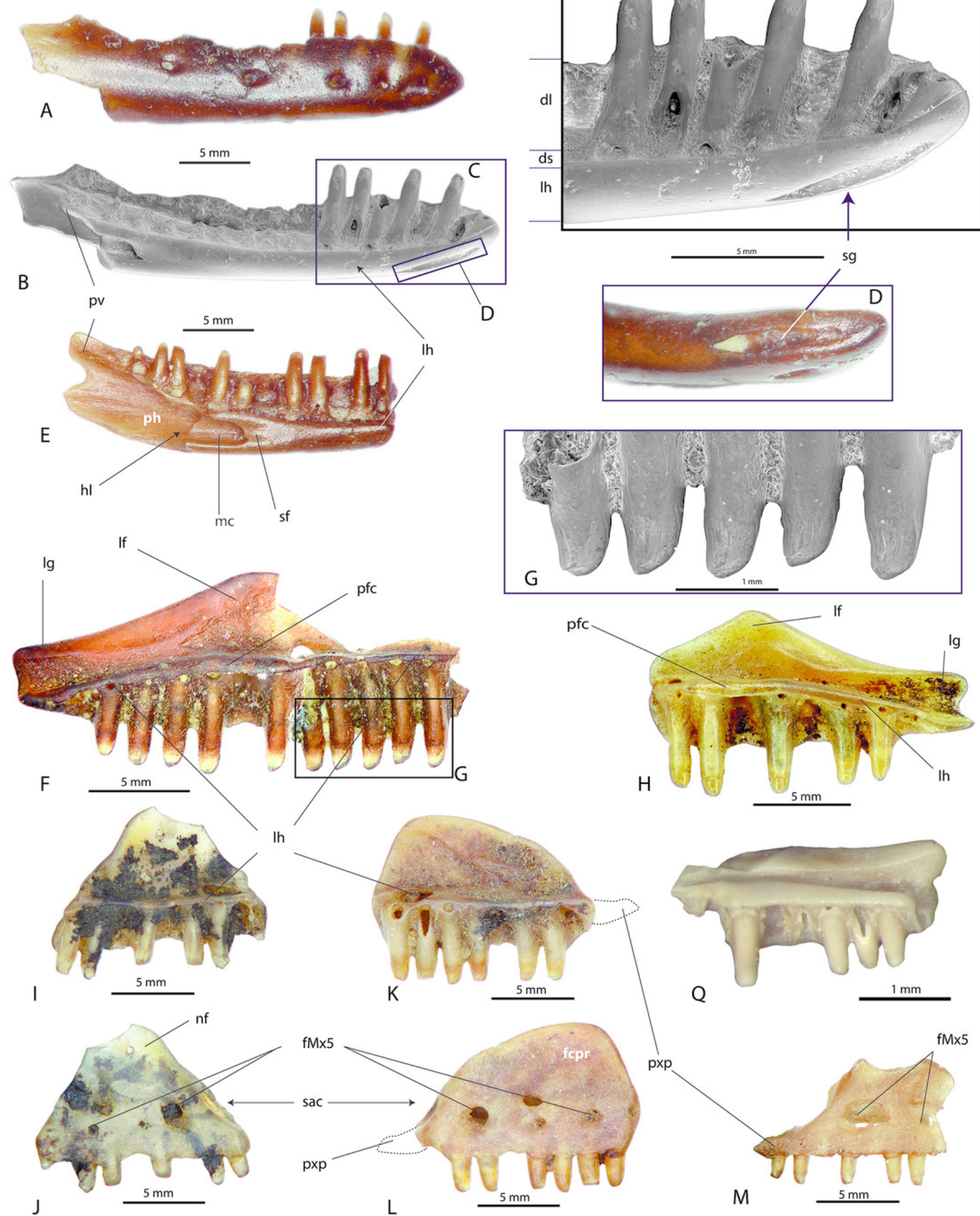

$\mathrm{L}$

$5 \mathrm{~mm}$
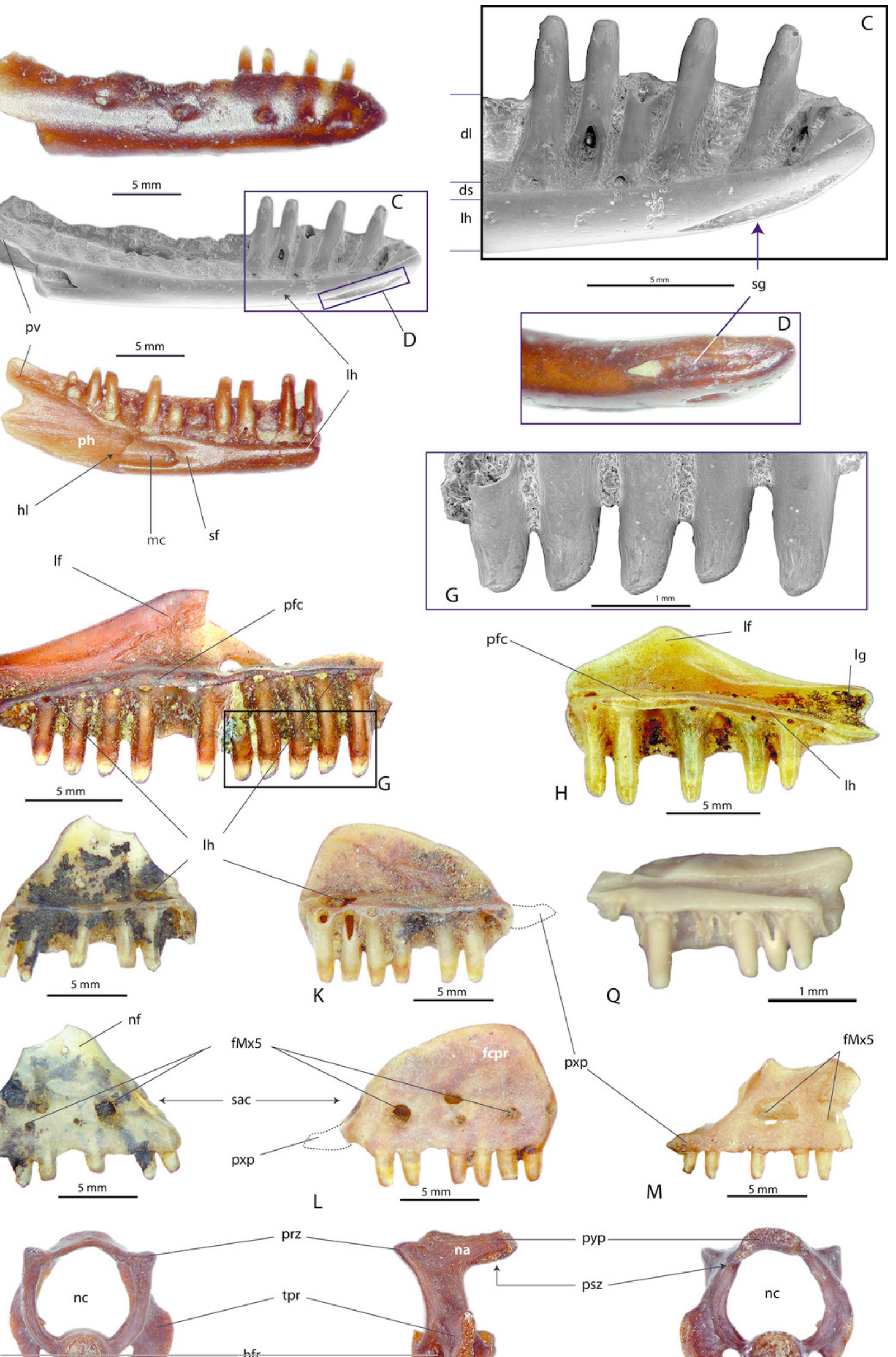

Peer) reviewing PDF | (2016:08:126fo6:4:0:NEW 23 Jan 2017) IN1

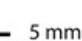

$\mathrm{O}$
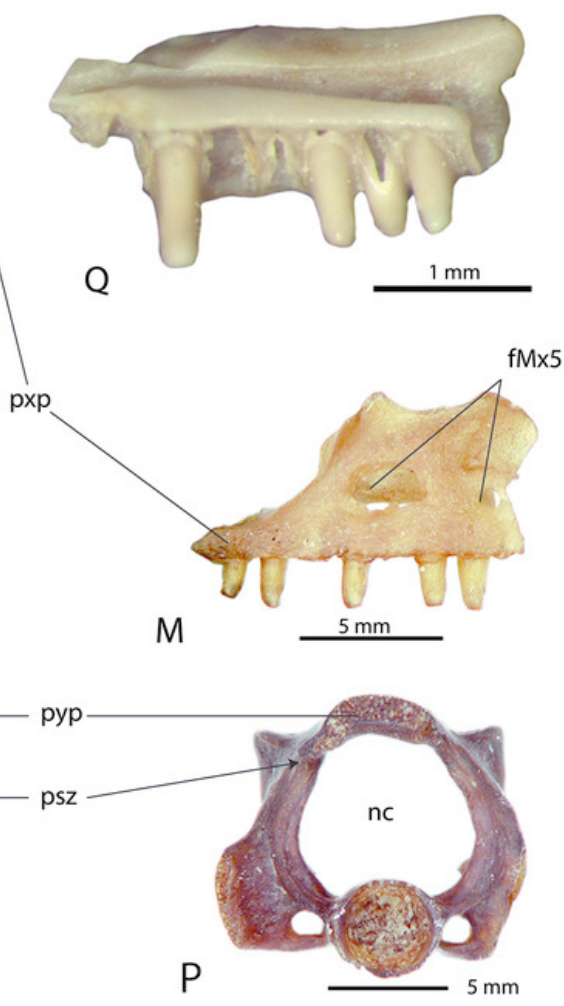


\section{Figure 8}

Lizard and turtle remains from the Western Siberian localities.

A, Lacerta s.I. sp. 1, left dentary, Pavlodar 1A, GIN 640/5001-RE01, lingual view; B, Lacerta s.l. sp. 2, right dentary, Pavlodar 1A, GIN 640/5001-RE34, lingual view; C-D, Eremias sp., frontal, Pavlodar 2B, GIN 1108/2001-RE01; C, dorsal view; D, ventral views; E, Emydoidea sp., fragment of right hypoplastron, GIN 948/2001-RE01, ventral view; F-G, Emydoidea sp., left femur, GIN 948/2001-RE02; F cranial view; G, ventral view. Scale bars: A, C, D = 2 mm; B $=1 \mathrm{~mm} ; \mathrm{E}-\mathrm{G}=1 \mathrm{~cm}$.
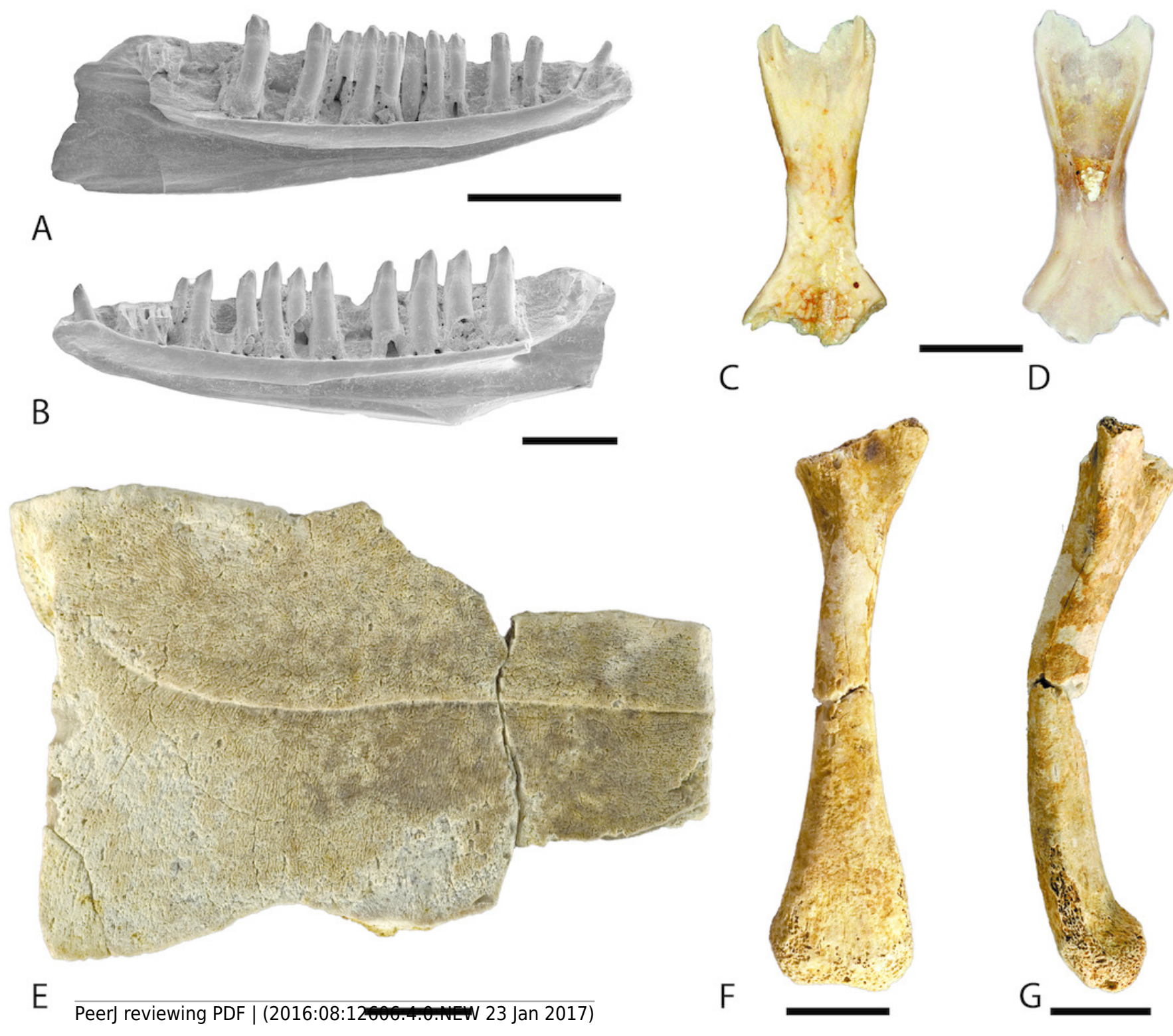


\section{Figure 9 (on next page)}

The European (Suppl. 3) and Western Siberian (present study) Neogene fossil record of the studied amphibian groups.

Detailed list of the localities see the Additional file 3 and for the family Cryptobranchidae Böhme et al. (2012; table 1). The occurrences of each group in Europe and Western Siberia are given in the same colour. The Paleogene records of the groups are indicated by arrows. Abbreviations: Hyn, Hynobiidae; Cry, Cryptobranchidae; Prot, Proteidae; Chel, Chelotriton; Tylt, Tylototriton; Bomb, Bombina; red balk, Bombina (cf.) variegata; black balk, Bombina (cf.) bombina; Palbr, Palaeobatrachidae; Pelb, Pelobatidae; Hyla, Hyla; white balk, Hyla (cf.) arborea; Bbuf, Bufo bufo (group); Bvir, Bufotes (cf.) viridis / group of Bufotes viridis; Rana, Rana (cf.) temporaria; Pelx, Pelophylax. 


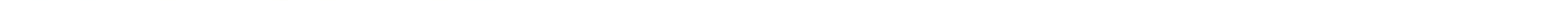


Figure 10 (on next page)

Palaeoprecipiation development of Western Siberia including the Zaisan Basin.

$A$, curve displaying the development of the absolute values of mean annual precipitation (MAP); $B$, the ratio of MAP to recent precipitation value (MAP/ MAP $\left._{\text {recent }} \mathbf{1 0 0 \%}\right)$, dashed black line (100\%) indicates the recent precipitation values. Localities: 1, Ayakoz; 2, Vympel; 3, Poltinik; 4, Tri Bogatyrja; 5, Kentyubek; 6, Malyi Kalkaman 2; 7, Malyi Kalkaman 1; 8, Baikadam; 9, Novaya Stanitsa 1A; 10, Cherlak; 11, Detskaya zheleznaya doroga; 12, Olkhovka 1B. 


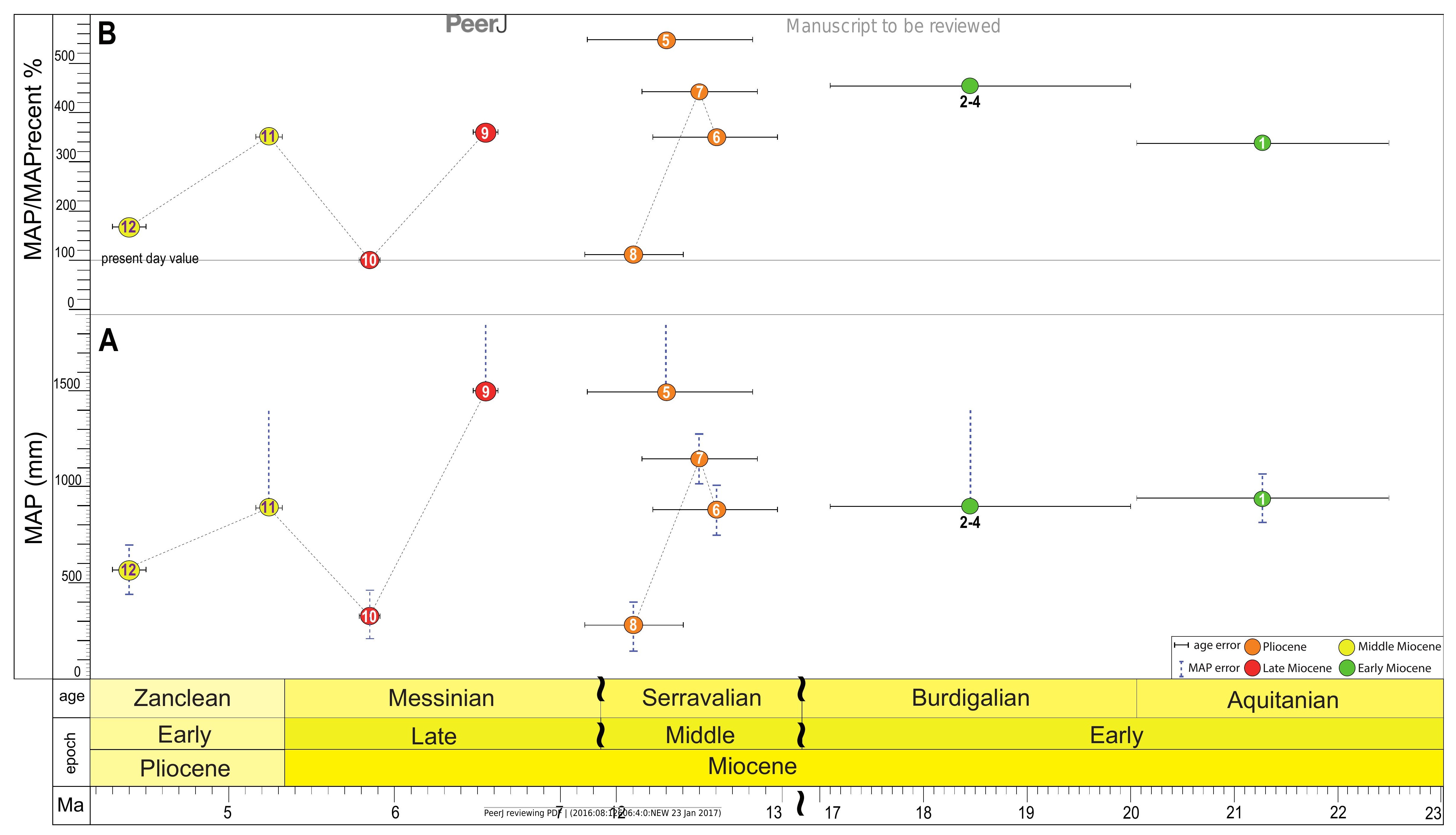




\section{Table $\mathbf{1}$ (on next page)}

Recent herpetofauna of south-western part of Siberia (Ob and Irtysh River drainages) according to different authors.

Recent herpetofauna of south-western part of Siberia (Ob and Irtysh River drainages)

according to different authors. References: 1 - Kuzmin (1995) ; 2 - Borkin (1999) ; 3 - Ravkin, Bogomolova \& Chesnokova (2010) ; 4 - Amphibiaweb (2016) ; 5 - Ananjeva et al. (2006). Abbreviation: is - insular occurrence. 


\begin{tabular}{|c|c|c|c|c|c|c|}
\hline & \multirow{2}{*}{ Taxa } & \multicolumn{5}{|c|}{ References } \\
\hline & & 1 & 2 & 3 & 4 & 5 \\
\hline \multirow{2}{*}{ Caudata } & Salamandrella keyserlingii & + & + & + & + & \\
\hline & Lissotriton vulgaris & is & + & - & + & \\
\hline \multirow{8}{*}{ Anura } & Rana arvalis & + & + & + & + & \\
\hline & Rana amurensis & + & + & + & + & \\
\hline & Rana temporaria & + & - & + & + & \\
\hline & Pelophylax ridibundus & is & - & + & is & \\
\hline & Bufotes viridis & is & + & + & is & \\
\hline & Bufotes variabilis & - & - & - & + & \\
\hline & Bufo bufo & + & + & + & + & \\
\hline & Bufo gargarizans & - & $?$ & - & is & \\
\hline \multirow{2}{*}{ Lacertoidea } & Lacerta agilis & & & & & + \\
\hline & Zootoca vivipara & & & & & + \\
\hline \multirow{5}{*}{ Serpentes } & Elaphe dione & & & & & + \\
\hline & Natrix natrix & & & & & + \\
\hline & Vipera berus & & & & & + \\
\hline & Vipera renardi & & & & & + \\
\hline & Gloydius halys & & & & & + \\
\hline
\end{tabular}

2 


\section{Table 2 (on next page)}

Neogene testudinoid fauna of Western Siberia and the Zaisan and Turgay Basins.

According to Chkhikvadze (1989), as well as the superscriptions before the taxa indicate the references: * Kordikova (1994); ** Danilov, Cherepanov \& Vitek (2013) , *** Kentyubek fauna (Suppl. 3), *- Chkhikvadze (1989) and *+ Tleuberdina et al. (1993) , ${ }^{K}$ Kuznetsov (1982), ${ }^{\circ}$ our results. The aquatic families are indicated with blue and terrestrial families with dark yellow colour. Abbreviations: Ty - Trionychidae, Cy - Chelydridae, Pl - Platysternidae, Ts Testudinidae, Ey - Emydidae, Gey - Geoemydidae. 


\begin{tabular}{|c|c|c|c|c|c|c|}
\hline \multirow{2}{*}{\multicolumn{2}{|c|}{ Stage }} & \multicolumn{3}{|r|}{ Zaisan Basin } & Turgay Basin & Western Siberia \\
\hline & & Suite & $\begin{array}{l}\text { Turtle } \\
\text { "Stage"*- }\end{array}$ & taxa & taxa & taxa \\
\hline \multicolumn{2}{|c|}{ Pliocene } & & & & & $\begin{array}{l}\text { Chelydropsis kuznetsovi(Cy), } \\
\text { ?Sakya sp. (Ey) }\end{array}$ \\
\hline \multirow{14}{*}{ Miocene } & \multirow{2}{*}{ Late } & Karabulak & & *Protestudo illiberalis (Ts) & & ${ }^{O}$ Emydoidea sp. (Ey) \\
\hline & & Kalmakpai & & Protestudo kegenica (Ts) & & KProtestudo karabastusica (Ts) \\
\hline & \multirow{4}{*}{ Middle } & \multirow{2}{*}{ Sarybulak } & up. & *Protestudo darewskii (Ts) & \multirow{4}{*}{$\begin{array}{l}\text { ***Chrysemys sp. (Ey), } \\
\text { ?Ocadia sp. (Gey), } \\
\text { Emydoidea tasbaka (Ey), } \\
\text { Kazakhemys zaisanensis } \\
\text { (PI), ?Chelydropsis sp. (Cy) }\end{array}$} & ${ }^{*+}$ Chrysemy sp. (Ey), Ocadia sp. \\
\hline & & & low. & *Pelodiscus jakhimovitchae (Ty) & & (Gey) \\
\hline & & \multirow{2}{*}{ Zaisan } & up. & ${ }^{* *}$ Baicalemys moschifera (Ey) & & \\
\hline & & & low. & $\left({ }^{* *}\right)$ Baicalemys sp. (Ey) & & \\
\hline & \multirow{8}{*}{ Early } & \multirow{8}{*}{ Akzhar } & up. & Protestudo sp. (Ts) & & \\
\hline & & & \multirow{5}{*}{ midd. } & *-Chelydropsis poena (Cy) & & \\
\hline & & & & *Pelodiscus sp. (Ty) & & \\
\hline & & & & *-Kazakhemys zaisanensis (PI) & & \\
\hline & & & & **Baicalemys jegalloi (Ey) & & \\
\hline & & & & **Ocadia iliensis (Gey) & & \\
\hline & & & \multirow{2}{*}{ low. } & *-Protestudo alba (Ts) & & \\
\hline & & & & Emydidae gen. indet. (Ey) & & \\
\hline
\end{tabular}

